\title{
Developing a model to facilitate the improvement of the quality of crash data collection in West Virginia
}

\author{
David Scott Bucy \\ West Virginia University
}

Follow this and additional works at: https://researchrepository.wvu.edu/etd

\section{Recommended Citation}

Bucy, David Scott, "Developing a model to facilitate the improvement of the quality of crash data collection in West Virginia" (2002). Graduate Theses, Dissertations, and Problem Reports. 2409. https://researchrepository.wvu.edu/etd/2409

This Dissertation is protected by copyright and/or related rights. It has been brought to you by the The Research Repository @ WVU with permission from the rights-holder(s). You are free to use this Dissertation in any way that is permitted by the copyright and related rights legislation that applies to your use. For other uses you must obtain permission from the rights-holder(s) directly, unless additional rights are indicated by a Creative Commons license in the record and/ or on the work itself. This Dissertation has been accepted for inclusion in WVU Graduate Theses, Dissertations, and Problem Reports collection by an authorized administrator of The Research Repository @ WVU. For more information, please contact researchrepository@mail.wvu.edu. 


\title{
Developing a Model To Facilitate the Improvement Of the Quality of Crash Data Collection in West Virginia
}

David S. Bucy

\author{
Dissertation submitted to the \\ College of Human Resources and Education \\ at West Virginia University \\ in Partial Fulfillment of the Requirements \\ for the degree of
}

Doctor of Education

in

Technology Education

David G. McCrory, Ph.D. Chair

Gary L. Winn, Ph.D.

John G. Wells, Ph.D.

Larry Stead, Ph.D.

Daniel Della-Giustina, Ph.D.

Advanced Educational Studies

Morgantown, West Virginia

2002

Keywords: Crash Data Collection, Crash Data Model, Crash Data Quality, Technology

Copyright 2002 David S. Bucy 


\section{ABSTRACT \\ Developing a Model To Facilitate the Improvement \\ Of the Quality of Crash Data Collection in \\ West Virginia}

David S. Bucy

Most federal, state, and local agencies use information derived from traffic crash reports for decision - making purposes. The accuracy and timeliness of this data is vital to safety program managers and traffic engineers. The purpose of this study was to assess improvements in the crash data process and examine the impact of the research assessment model developed by the West Virginia University Project Research Team on the West Virginia Uniform Traffic Crash Report.

A three - year research study funded by the West Virginia Division of Highways was conducted statewide with law enforcement agencies at all levels. Four hundred fifty three officers participated in the study. Data were collected from law enforcement agencies through the use of focus groups, a telephone survey, a mock crash demonstration, pilot testing and follow-up surveys. The study presented two study questions.

A telephone survey was developed by the WVU Department of Safety and Environmental Management (SEM) and an administered by the WVU Survey Research Center to assess problem areas with the current crash form and suggest areas for improvement. Data were also collected sixty days after full implementation of the crash form in three sites around the state. Finally a quality control survey was initiated to ensure that no remaining deficiencies existed.

Results suggested that the improvements by enforcement personnel and implemented by the study group at WVU would yield improvements in data quality, namely accuracy, and timeliness of data submission. 


\section{DEDICATION}

This work is dedicated to my mother Louise Bucy.

Thank you for the love, support and sacrifices you made for me throughout the years Thank you, for the lessons of life you taught me along the way.

I could not have accomplished this without you.

I love you and miss you. 


\section{ACKNOWLEDGEMENTS}

A number of people have helped make this work a reality. I am extremely grateful for your contributions and want to take this opportunity to recognize each of you.

My family has made tremendous sacrifices to allow me to spend the time necessary to complete this work. Without the unwavering support of my wife, Vicki Bucy, I could not have devoted the time and effort necessary to complete this task. My children, Lindsay, Dana, and Drew, may not have totally understood that my long hours of work away from home would mean doing things without Dad. I hope you know this hard work was for you. I love you all so very much.

My parents, James and Louise Bucy, who instilled in me the value of hard work, I wish you could be here to share this success with me. I love you and miss you.

My associates at Dick Corporation, you have encouraged and supported me, my thanks to you. I owe a special thanks to Jim Owen and Jean Bickerton.

The Chairperson of my committee, Dr. David L. McCrory, without your leadership and guidance this work would never have been completed. Thank you for being there for me.

Dr. Gary L. Winn, my mentor, my sounding board, and my friend, your encouragement allowed me to achieve things that I never believed I could. I will always be grateful.

The remaining members of my committee, Dr. Dan Della-Giustina, Dr. John Wells and Dr. Larry Stead have been valuable resources and guides though my learning process. We have traveled this road together for quite some time, and I am grateful for your time and effort on my behalf. 


\section{PROJECT SUPPORT}

This project was supported by a three-year cooperative agreement between West Virginia

University's Department of Safety and Environmental Management and the West Virginia Division of Highways - Traffic Engineering Division.

A special thanks goes to Fred VanKirk, Commission of the Department of Motor Vehicles;

Cindy Cramer, Technical Contract Officer for the Division of Highways;

Ray Lewis, Advisor; and Carlin Kendrick, Advisor.

I would also like to express my appreciation to Richard Shiflett, Graduate Research Assistant;

Eilene McDaniel, Administrative Secretary; and Marilyn Noah, Graphics Arts Designer, for their efforts in this research. 


\section{TABLE OF CONTENTS}

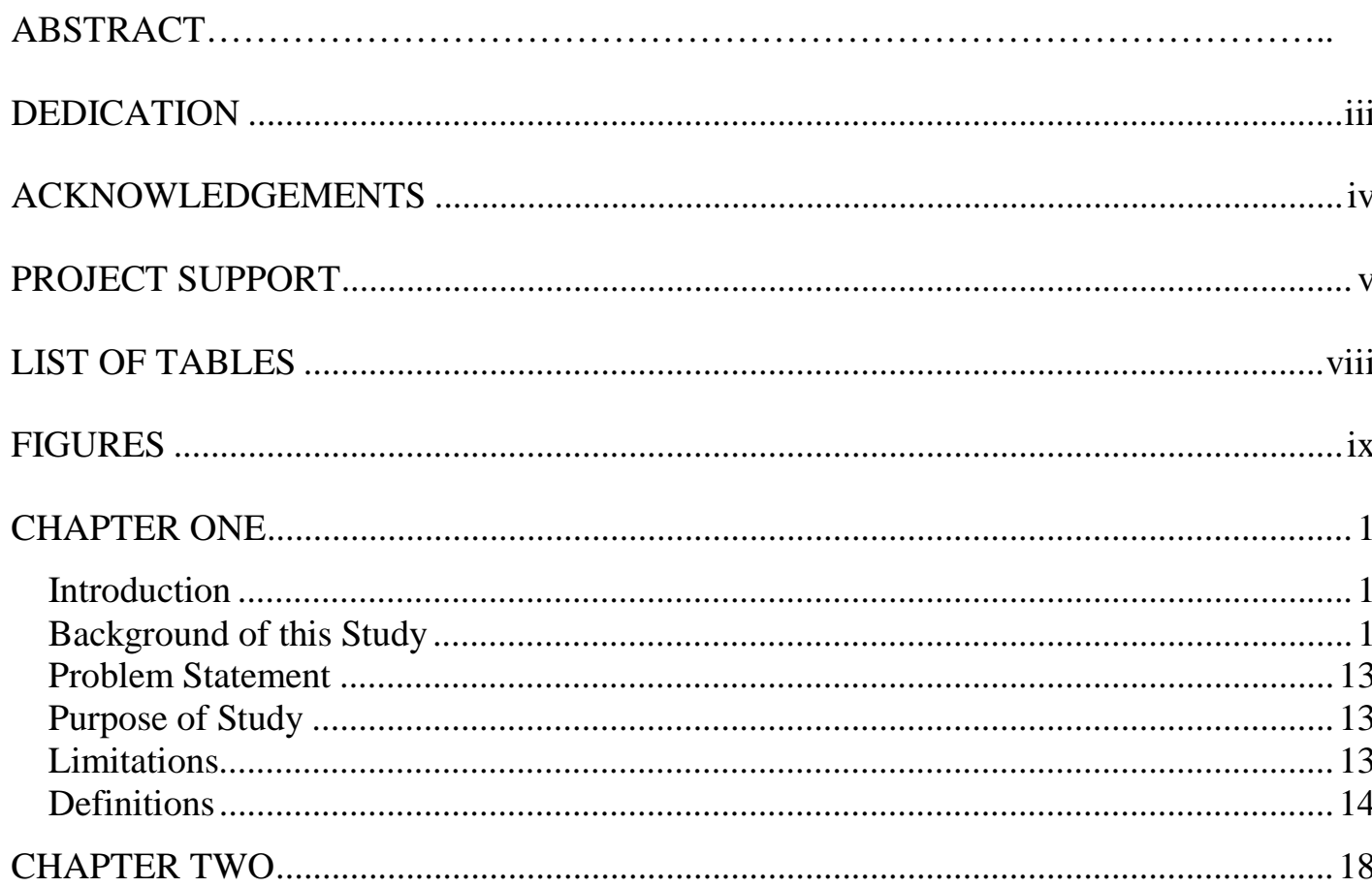

Review of the Literature

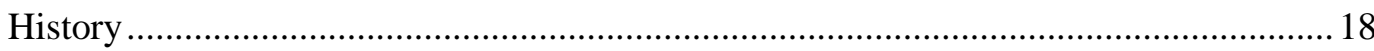

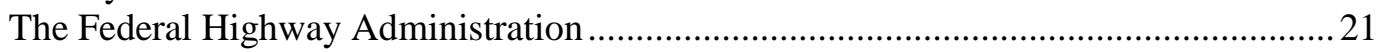

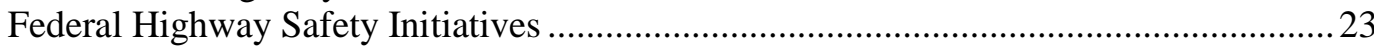

Federal Motor Carrier Safety Administration (FMCSA) ...........................................2 23

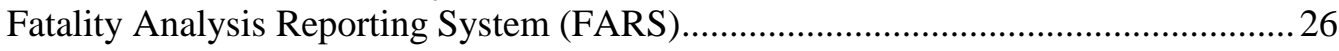

Crash Outcome Data Evaluation Systems (CODES) ….............................................. 28

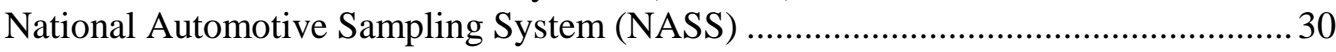

Intermodal Surface Transportation Efficiency Act of 1991 (ISTEA) ........................... 31

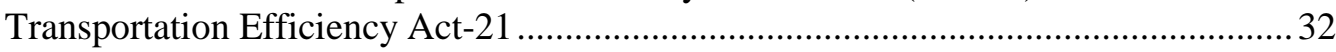

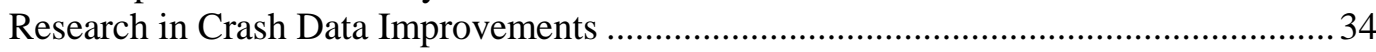

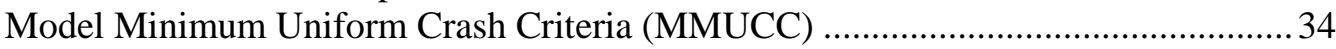

The National Model For Traffic Data Collection .......................................................... 40

State Initiatives in Crash Data Collection and Record Integration................................... 41

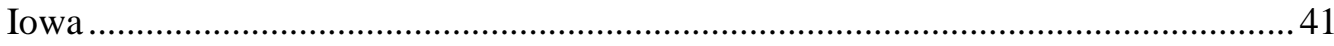

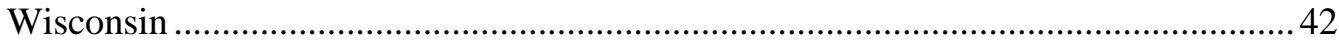

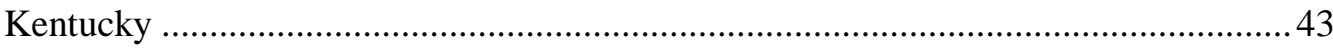

West Virginia Initiatives to Enhance the Crash Data Process......................................... 45

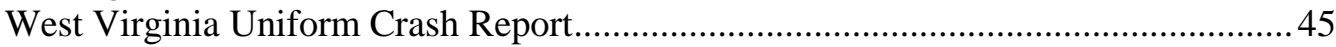

West Virginia Research in Crash Data Linking Capability ..........................................4

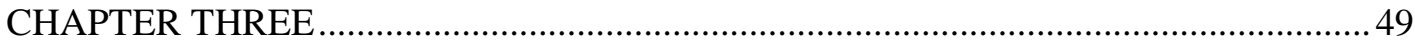

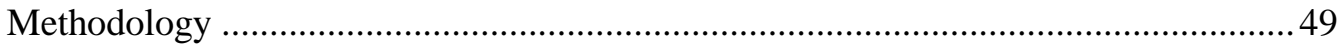

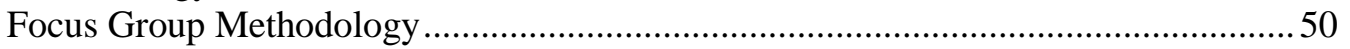

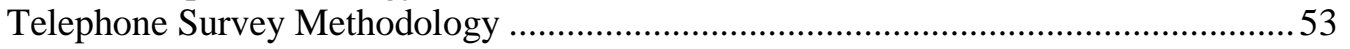

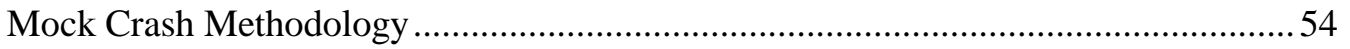

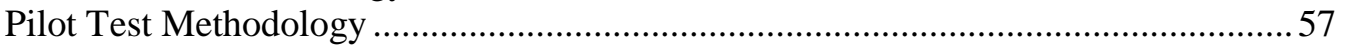

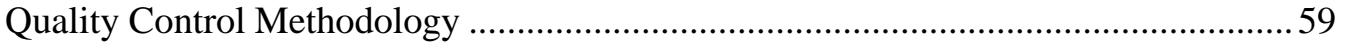




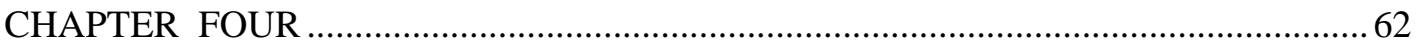

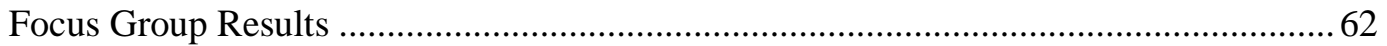

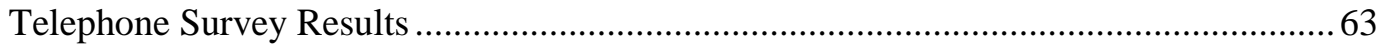

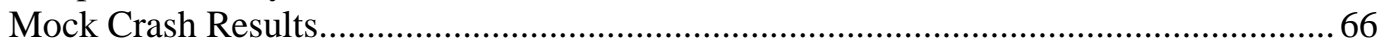

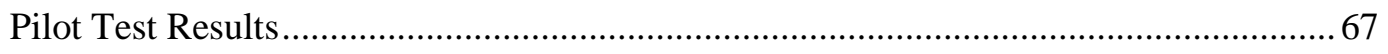

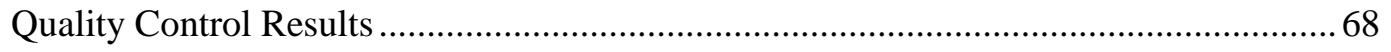

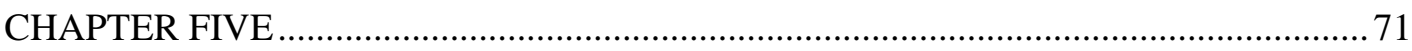

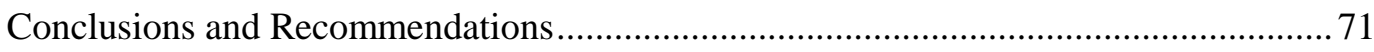

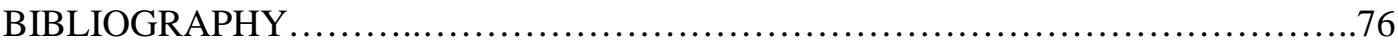

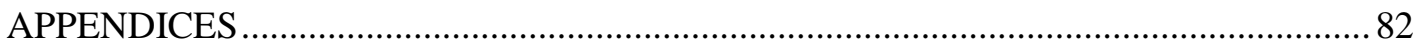

APPENDIX A: West Virginia Uniform Traffic Crash Report Days and Locations

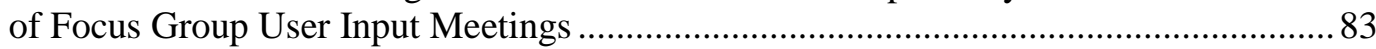

APPENDIX B: West Virginia Uniform Traffic Crash Report Focus Group Protocol..... 85 APPENDIX C: West Virginia Uniform Traffic Crash Report Telephone Survey ............88 88 APPENDIX D: Morning Mock Crash Session Crash Scenario and Survey .....................95 APPENDIX E: Afternoon Mock Crash Session Crash Scenario and Survey ….............. 103 APPENDIX F: West Virginia Uniform Traffic Crash Report Training Materials.......... 112 APPENDIX G: West Virginia Uniform Traffic Crash Report Pilot Instrument ............. 120 APPENDIX H: West Virginia Uniform Traffic Crash Report Pilot Test Post Survey .. 125 APPENDIX I: West Virginia Uniform Traffic Crash Report Quality Control Survey .. 130 APPENDIX J: West Virginia Uniform Traffic Crash Report Focus Group Summary

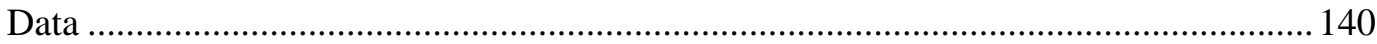
APPENDIX K West Virginia Uniform Traffic Crash Report Focus Group Results...... 142 APPENDIX L: West Virginia Uniform Traffic Crash Report Mock Crash Summary

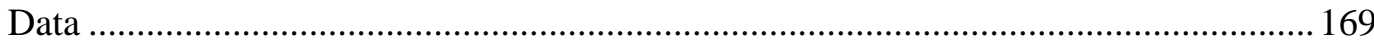
APPENDIX M: West Virginia Uniform Traffic Crash Report Pilot Test Summary Data 


\section{LIST OF TABLES}

Table. Page

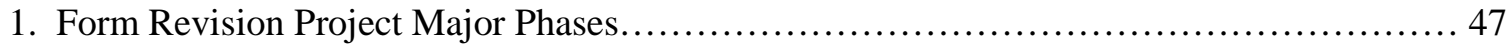

2. West Virginia Uniform Traffic Crash Report Mock Crash Session Survey Summary Key... 56

3. Quality Control Group Regional Session: Date and Attendance ....................... 61

4. Telephone Survey Agency/Officer Demographic................................... 64

5. Quality Control Meetings Dates and Locations...................................... 69 


\section{FIGURES}

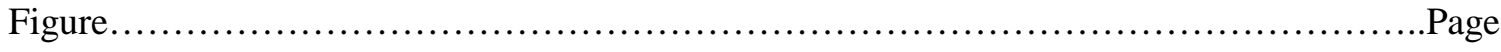

1. A Typical Traffic Crash Data File Has Many Users.....................................12

2. Motor Vehicle Related Death Rates.............................................. 19

3. West Virginia Uniform Crash Report Needs Assessment Model.......................50 


\section{CHAPTER ONE}

\section{Introduction}

Motor vehicle crash reports are the primary source of statistics that are used by safety program managers and traffic safety engineers. These data included specific data collected at the scene of a motor vehicle crash. Crash data described characteristics of the crash, the vehicles, and the people (drivers, injured and uninjured occupants, and injured non-occupants) involved. The crash report also represents the archival product of a police officer's investigation of the crash.

Crash data lacked uniformity between the states and, often, within a state. Data elements may have had different meanings at different locales around the state. Data elements that were infrequently used or for which a standard definition are not available were often left out of reports. Consequently, crash data suffered at the output point.

Lack of uniform reporting made the use and comparison of state crash data tenuous or difficult. The use of different elements or definitions within a state can result in inconsistent data and, potentially, incorrect interpretations of data. When computer operators must interpret what the reporting officer meant on a given report, or must locate and query the officer, delays are inevitable. In the end, safety program or traffic engineering decisions are made on the basis of incomplete, inaccurate, delayed data, or simply good intentions alone.

\section{Background of this Study}

Highway and police departments are the most visible state government users of automobile crash reports and related data. Analyses are distributed privately within the 
appropriate departments, and are seldom part of the referenced journal literature. These documents, however, lead to many operational decisions within a state. Many state departments and construction activities rely on accurate and timely data generated on-site by the investigating officer at a traffic crash.

In each state, the highway agency used these data to identify locations needing safety improvement or other funding decisions (Heath, 1991). When changes are introduced to improve highways, the effects of such changes are measured by a change in crash frequency and severity. District engineers have direct access to crash computer files, while in other states the data were analyzed in a state office and distributed to the districts. State highway agencies conduct research activities that include analysis of a crash as a function of roadway characteristics. State police agencies analyzed crash data to develop operation plans, or support budget requests. In addition, highway departments work closely with academics and students at state universities in researching crash related problems.

\section{State Agencies}

Driver licensing agencies routinely associated crash data with their driver record file, and most maintain a point system to identify problem drivers. In some states the data about crashes was put into the driver files as a part of the crash processing, in other states it was done after the fact. In either case, it was an important part of the driver control process. Many drivers licensing agencies conduct research about driver improvement methods, and the crash data were a major input to that research. 
Health departments had developed trauma registers to link the police crash information with their data. State education departments used crash data to study the incidence of school bus crashes. State legislators requested data about the type and number of crashes in their district. Finally, highway safety-planning agencies needed access to crash data to plan and justify safety programs proposed for the upcoming year.

\section{United States Government Agencies}

The Federal Highway Administration (FHWA) needed crash data for research for its programs, but had limited capabilities of data collection. The FHWA uses information obtained from states to develop travel and crash trends to identify safety problems and to evaluate programs by assessing the effectiveness of safety resource investments. The FHWA had developed a Highway Safety Information System (HSIS) (Council, 1988). In this program, crash related data files had been acquired from five states that had a combination of useful crash data and computerized files of complimentary roadway information (Federal Highway Administration, 1990).

In addition, the FHWA annually acquired and compiled data on crashes and mileage by road class from all states. The crash counts come from various state crash files. The Highway Performance Monitoring System (HPMS) permitted estimates of vehicle miles of travel, as well as crash, fatality, and injury data tabulated by road, class, and state (Hughes, 1992). This data were summarized and published annually.

The National Highway Traffic Administration (NHTSA) had several programs of its own for crash data acquisition, the National Automotive Sampling System (NASS), and the Fatal Crash Reporting System (FARS) (Hughes, 1992). NASS depended directly 
on the police reported crashes in each of the states in which it collected data. There are two parts of the NASS program: one of which uses the police reported information directly and another that is augmented by reports of specialist investigators. FARS reports are extracts generated by a specialist in fatal crashes, but these reports ultimately are dependent on the police officers original on-site investigation and report.

NHTSA also acquired and maintained crash data files from states to have a source for queries of importance to that agency. Analyses of these data contributed to the development and evaluation of vehicle standards, the identification of problem vehicles, the evaluation of restraint systems, and the evaluation of social programs (e.g., anti-drunk driving or restraint usage campaigns).

As of 1991, there were 28 states for which working Statistical Analysis System (SAS) files of crash data were available to the NHTSA staff. Codebooks have been prepared for each state and an instructional manual guides the users in SAS operations (U.S. Department of Transportation, National Highway Traffic Safety Administration, 1991).

NHTSA provided a grant to the National Association of Governor's Highway Safety Representatives (NAGHSR) to demonstrate the acquisition of data and the computations involved in developing a Sensitivity Index (Johnson, 1991). This index is intended to serve as a measure of the responsiveness of emergency medical services (EMS), to the medical care needs of highway crash victims statewide. In the pilot program, data were acquired so that this index could be computed for several states, linking computerized crash injury data to EMS, hospital, and census data. The pilot 
program assessed the quality of data and pointed out some of the problems of linking such data. The intent is to extend this program to other states, and all states are being encouraged to provide linkages between crash data files and medical files so that this index may be computed.

Many other U.S. government agencies were considered occasional users of this information. These included the Department of Energy studying the incidence of traffic crashes involving hazardous materials and the Department of Health and Human Services' National Center for Environmental Health and Injury Control in Atlanta, that conducted a research program in conjunction with NHTSA. With 40 percent of workplace facilities the result of traffic crashes, the Occupational Health and Safety Administration acquired an interest in crash data as well (CDC/National Highway Traffic Safety Administration, 1992).

The Department of Transportation established the Federal Motor Carrier Safety Administration on January 1, 2000. Formerly a part of the Federal Highway Administration, the Federal Motor Carrier Safety Administration's primary mission was to prevent commercial motor vehicle related fatalities and injuries. Administration activities contribute to ensuring safety in motor carrier operations through the enforcement of safety regulations; targeted high-risk carriers and commercial motor vehicle drivers; improved safety information systems and commercial motor vehicle technologies; strengthened commercial motor vehicle equipment and operating standards; and increased safety awareness. To accomplish these activities, the Administration worked with Federal, state, and local enforcement agencies; the motor 
carrier industry; labor safety interest groups; and others.

Among its many programs the Administration collected and disseminated safety data concerning motor carriers. Data collected by Federal safety investigators and state partners from roadside inspections, crashes, compliance reviews, and enforcement activities were indexed by carrier. This information provided a national perspective on carrier performance and assists in determining Administration and state enforcement activities and priorities. Combined with data from other sources (including the National Highway Traffic Safety Administration), extensive analysis was performed to determine trends in performance by carrier and other factors such as cargo, driver demographics, location, time, and type of incident. Based on identified trends, the Administration directs resources in the most efficient and effective manner to improve motor carrier safety.

Industry and Trade Users of Police Crash Reports

Industrial users include domestic and foreign automobile manufacturers, the insurance industry, vehicle component manufacturers, and highway equipment manufacturers. Auto manufacturers conduct researches to prevent crashes or reduce injury severity. Insurers used crash data in developing rate structures. Automotive component manufacturers believe that their products improved safety on the highway, and they analyzed the data to support their claims. In the highway supplier field, components such as guardrails, anti-skid treatment for pavements, signing, and signaling are typical elements evaluated by analysis of crash data.

Associations Using Police Crash Reports 
Many associations in the transportation field were major users of crash data. Local automobile clubs frequently used tabulated crash data obtained from the state in their periodicals. Frequently, associations used data in support of legislative action, and it was important that the data be factual. Mothers Against Drunk Driving (MADD) state chapters were active users of the available crash data. User groups such as the League of American Wheelmen representing bicyclists, the American Motorcyclist Association representing motorcycle users, and even the American Automobile Association for car operators, all rely on national statistical summaries that begin at the originating enforcement officer.

\section{Local Agencies}

Traffic engineers and police at the city and county level often maintain their own crash records. There were some economies of scale in computerizing the data at the state level. In addition, the statewide-standardized data format made it possible to compare distributions with other jurisdictions. Many state crash data processing groups tailored reports for local agencies, and some had experimented with computer connections or downloading of subsets of the state data. One such group in West Virginia, The Technology Transfer Center located at WVU, used, in part, engineering data generated by enforcement officers to improve local roadway maintenance and repair projects.

\section{Other Users of Police Crash Reports}

News media used crash data in a variety of ways. Most usage was of published tabulated data, but for in-depth treatments, reporters seek the results of special analyses. 
Newspaper reporters have learned to access crash data files by computer, and argued successfully that these files are public under the freedom of information laws.

Academic researchers - specialists in psychology, engineering, medicine, public health, sociology, and economics - all made use of crash data in their studies. Journal editors typically reference published results of academic research, and this added some credence to their reports. The analysis of less-than-perfect data in the usual crash collection sometimes lead to academic disputes in controversial areas such as seat belt laws, blood alcohol level legislation, and helmet-use laws. Lawyers made use of crash data to support an argument, but many courts viewed crash data as hearsay testimony, giving it much less weight than the testimony of actual witnesses. Quality of data would be questioned in litigation, and such users would find the more defensible data important to the success of their arguments.

The media, the academics, and the lawyers often used data in ways that may have lead to large expenditures or to major policy changes. In such applications, it certainly behooved the producers of the data to strive to make the files truthful and complete.

\section{Deficiencies with the Current Crash Data Collection Process}

There were numerous deficiencies and problems associated with the current crash data collection process. These include the following problems noted nationally (Hughes, 1992) and locally by Winn, Carr and Bucy (1997): (1) Administrative/staffing problems -- inadequate funding and/or personnel are a frequently repeated problem. The contention is that the designated state agency does not have the resources to adequately 
process the extremely large numbers of report forms. In some states, there were additional demands on the state data center personnel imposed by additional report forms (i.e., forms required to be completed by drivers) or nonstandard forms used by selected cities or agencies. In addition, many police officers had a less than optimum attitude towards crash data collection. (2) Timeliness problems -- there is often a delay between when the crash occurs and when the report was received by the central agency. There was also a considerable time lag between when the crash report form arrived at the state data center and when it was key-entered into the database. The total time lag could exceed several months. (3) Legibility problems -- completing a handwritten form in a hurried manner under less than ideal conditions contributes to the poor legibility of many crash reports. Illegible reports posed substantial obstacles to data coders and keypunchers and almost always caused delays in report processing. (4) Ascertainment -(incomplete reports) and under ascertainment (missing data problems). The amount of missing data varied considerably among variables as well as across states. Missing data ranged from 0 to 10 percent for any other variable within a given state (O'Day, 1991). In addition, reports are often submitted with no collision diagram and/or narrative (O'Day, 1991). (5) Errors, inconsistencies and data problems -- the magnitude of erroneous data in the crash record database varied, depending on the practices, procedures, and policies of the state. Many data elements were questionable because they required the reporting officer to make judgements (e.g., restraint use, injury severity, alcohol and drug involvement, contributing factors/causes, etc.). Factual data related to the driver, vehicle, and the location were often erroneously recorded or entered in the database. In 
addition, narratives and sketches were often inadequate for highway safety analysis or otherwise inadmissible in court because of past data quality problems. (6) Consistency of Coverage -- the degree of ascertainment varies by jurisdiction, time, personal characteristics, weather, size of staff, or other factors. (7) Consistency of Interpretation -- the report elements (injury level, degree of damage, fault, crash type) are not consistently reported in the same manner in different states or local jurisdictions, or by different officers.

The West Virginia Crash Data Collection Culture In March 1993, a technical paper by the U.S. Department of Transportation (DOT), "New and Emerging Technologies for Improved Data Collection," reported that law enforcement was failing to include vehicle identification numbers (VIN) on between 40 and 50 percent of completed motor vehicle accident reports, some involving criminal activity (Winn, Bucy, and Klishis 1997). The DOT report inspired a highly coordinated partnership between West Virginia officials, law enforcement, and the state university. The research team was determined to improve the data collection process for motor vehicle crashes.

Improved technology, particularly computers and specially designed software, could help with traffic crash data collection. Computers and modems could significantly improve the speed of data transmission. Furthermore, recent technical improvements and optical disks improved the basic crash data collection system by quickly capturing events or information in digital formats. Improved data collection made it a simple 
matter to enter, locate, and share the photos of events, people or entire data files by standard data link (e.g., modem or fax) (Winn, Bucy, and Klishis, 1997).

While speed of basic data was vastly improved via technical improvements, several other necessary improvements in the current data collection methods must be addressed. Improving accuracy in recording basic details that the data ultimately represented, standardizing both the written and unwritten definitions of events or people, and improving the sequence of data flow on a collection form, improved crash data collection. How a data collection form is coded, or not coded, could help officers intuitively understand what information is needed without reference to a lengthy, complicated codebook. The cost of all the technology improvements, such as computers, is also a factor in technical improvements. Less expensive alternatives would be necessary.

In a three and one-half year research project, the research team found that basing the entire collection form on consensus of the actual data collection form user was as valuable in any technology and was less expensive. In fact, the research team surmised that when subtle form-procedures are left undefined, or the logic of data-flow was not intuitive, many times the officer would find a reason to avoid using the data form in the first place. In actual fact, this was already taking place in West Virginia when in 1993 the state government recognized that changes had to be made.

Crash data was the tools of the trade for data customers such as law enforcement, highway safety programmers, local police departments, and traffic engineers who were all interested in reliable and valid crash data. They all know that safety or engineering 
countermeasures should not be built on good intentions alone. Improving the quality, (that is, the precision, timeliness, accuracy and completeness of traffic crash data) contributed immensely to the ability of these data customers to make correct historical interpretations of events, predict the future, and measure the effectiveness of past programs. Yet consider that the four attributes of data quality were driven in the first instance by people (culture). Figure 1 shows how basic highway crash data forms had many data customers (data users). These are people and institutions that used the data in summary, or report form, to investigate all sorts of questions.

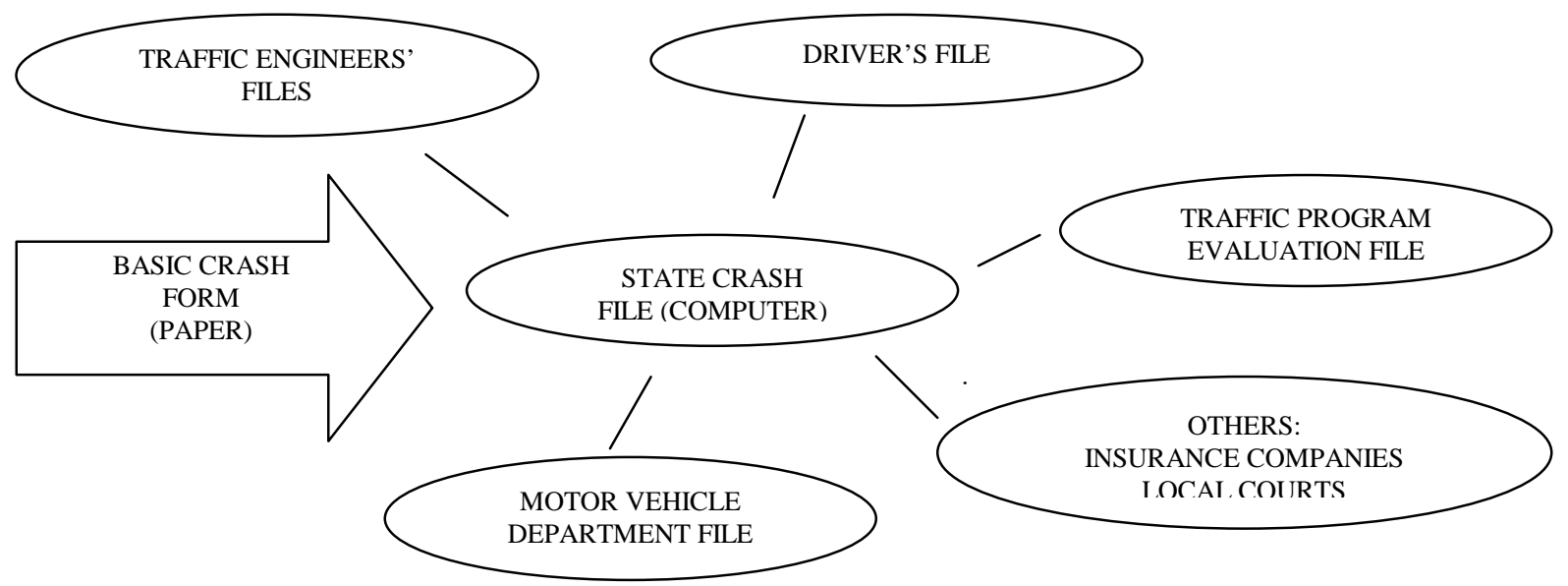

Figure 1: A Typical Traffic Crash Data File Has Many Users

Technology to Improve the Data Collection Process 
At least some of the crash data problems described could be eliminated through the use of new and emerging technologies for the collection and processing of motor vehicle crashes. The application of new and emerging technologies had the potential to yield improvements to the data collection process. Technology could be applied to reduce the time it took for a police officer to complete a crash report, improve the timeliness of crash data, reduce the demand and costs associated with data processing personnel, and improve the quality of crash data. The application of technology can reduce the magnitude of one particular problem, but it can create other issues and problems.

\section{Problem Statement}

The problem of this research was to describe a model that can be used to develop a traffic crash form.

\section{Purpose of Study}

The purpose of this study was to assess a model that can be used for perfecting the instrument used to collect traffic crash data.

\section{Study Questions}

The following research questions were answered through this research:

Q1. What processes were used by the West Virginia University Research Team to develop the new West Virginia Uniform Crash Report?

Q2. What were the results?

\section{Limitations}

The primary limitations of this study were: 
1. West Virginia University Form Revision Research Team Project Reports, Surveys and Findings.

2. Conversations with West Virginia University Form Research Team Members.

3. Conversations with West Virginia Law Enforcement Officers who participated in the research study.

4. My personal notes.

\section{Definitions}

The following terms and appropriate definitions are used in this study:

Alert Vehicle -- a second-generation law enforcement vehicle that will test and demonstrate emerging technologies.

Critical Crash Data Reporting Elements (CADRE) - A program to establish minimum report criteria to ensure national uniform data on deaths and injuries.

Commercial Motor Vehicle -- Any self-propelled or towed vehicle used on highways in interstate or intrastate commerce to transport passengers or property.

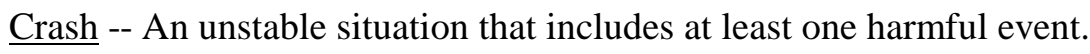

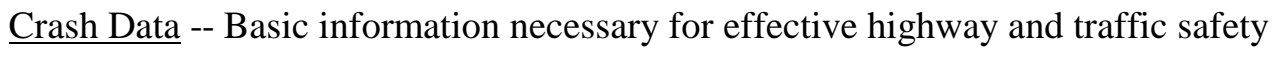
decision - making.

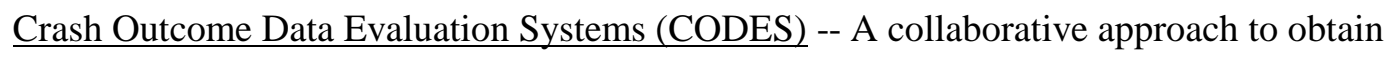
medical and financial information related to motor vehicle crashes for highway safety and injury control decision-making.

$\underline{\text { Culture }}$ - People, conditions and the environment in which they work. 
Data -- Factual information used as a basis for reasoning, discussion, and calculation. Normally gathered post-crash.

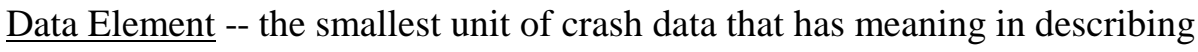
information.

Data Linking -- Statewide computerized crash and medical records collected at a crash scene, enroute, at the emergency department, in the hospital, and after discharge for occupants involved in a motor vehicle crash.

Data Quality -- The methods of reporting, data collection procedures, the analysis and quality control measures employed, and the communications systems used.

Discrete Unit of Data -- The smallest unit of data that has meaning in describing information.

Department of Transportation (DOT) -- The primary agency in the federal government with the responsibility for shaping and administering policies and programs to protect and enhance the safety, adequacy, and the efficiency of the transportation system and services.

Event -- The occurrence relevant to the vehicle/crash.

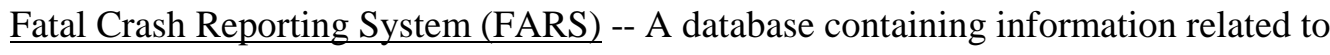
fatal collisions.

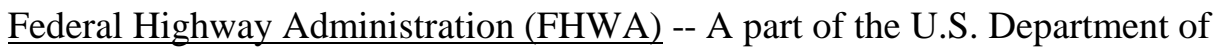
Transportation. Providing federal financing assistance to the states to improve the National Highway System. Providing funds for general improvement and development of safe highways and roads. 
Global Information Systems (GIS) -- a computerized data management system designed to capture, store, retrieve, analyze and report geographic and demographic information. Global Positioning Systems (GPS) -- A government owned system of 24 orbiting satellites that transmit data to ground based receivers. GPS provides extremely accurate latitude and longitude ground positions in WGS 84 co-ordinates. Inter-modal Surface Transportation Efficiency Act 1991 (ISTEA) -- Provides for federal funding for highway safety programs in the U.S.

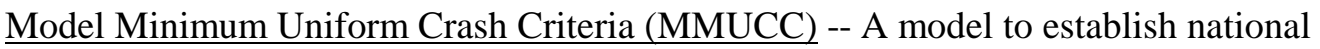
uniform data and to establish minimum criteria for reporting highway injuries and deaths.

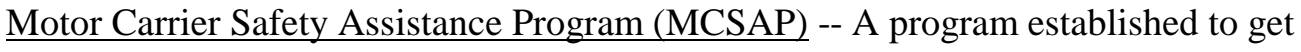
potentially unsafe drivers and imminently hazardous vehicles off the highway by increasing the level of safety enforcement activity. National Highway Traffic Safety Administration (NHTSA) -- A branch of the U.S. Department of Transportation responsible for overseeing and improving safety and standards in the United States.

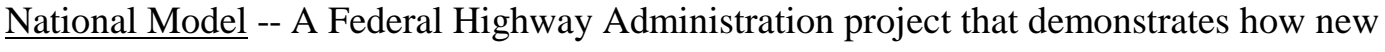
technologies and techniques be used cost effectively in a statewide environment to improve highway safety data collection and management processes.

National Association of Governors Highway Safety Representatives (NAGHSR) -- The voice of highway safety. Represents the highway safety programs of the states and 
human behavioral aspects of highway safety.

National Governors' Association (NGA) -- An organization whose members are the governors of each state in the United States of America. It serves as a vehicle through which governors influence the development and implementation of national transportation policy.

National Automotive Sampling System (NASS) -- The mechanism the National Highway Traffic Safety Administration collects nationally representative data on motor vehicle traffic crashes to aid in the development, implementation, and evaluation of motor vehicle and highway safety countermeasures.

Quality (Data Quality)-- Refers to aspects of timeliness of data submission, degree of match between data element, and definition.

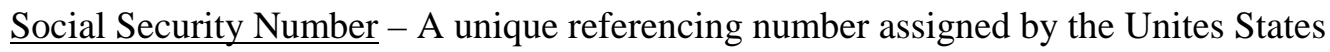
Government to everyone within the Social Security System.

$\underline{\text { Vehicle Identification Number }-A ~ u n i q u e ~ s e r i e s ~ o f ~ n u m b e r s ~ t h a t ~ i s ~ u s e d ~ t o ~ i d e n t i f y ~ a ~}$ vehicle. This number can normally be found on a plate located on the dashboard or on the frame of a vehicle.

West Virginia Division of Highways (WV DoH) -- A unit of the West Virginia Department of Transportation that is responsible for planning, engineering, construction, maintenance and highway research. 


\section{CHAPTER TWO}

Review of the Literature

This chapter is divided into five major sections, each presenting a review of relevant literature. The literature review presented in this chapter relates specifically to (a) History, (b) Federal Initiatives, (c) Research, (d) State Initiatives, and (e) West Virginia Initiatives.

\section{History}

While certain improvements were in evidence under the Hoover Administration, systematic motor-vehicle safety efforts began in the United States during the 1960's. In 1960, unintentional injuries caused 93,803 deaths (Center for Disease Control, 1999); $41 \%$ of which were associated with motor-vehicle crashes. In 1966, the passage of the Highway Safety Act and the National Traffic and Motor Vehicle Safety Act authorized the federal government to set and regulate standards for motor vehicles and highways, a mechanism necessary for effective prevention (Committee on Injury Prevention and Control, Institute of Medicine, 1999 and Transportation Research Board, 1990).

Initiation of programs by federal and state governments, academic institutions, community based organizations, and industry have caused the population death rate and vehicle mile rates to drop during the ensuing three decades (See Figure 1). The National Highway Traffic Safety Administration (NHTSA) and the Federal Highway Administration (FHWA), within the U.S. Department of Transportation, have provided national leadership for traffic and highway safety efforts since the 1960's (Institute of Medicine, 1999). State and local governments have enacted and enforced laws that 
affect motor vehicle and highway safety, driver licensing and testing, vehicle inspections, and traffic regulations (Committee on Injury Prevention and Control, Institute of Medicine, 1999). Citizen and community based advocacy groups have played important prevention roles in areas such as drinking and driving and child occupant protection (Graham, 1993).

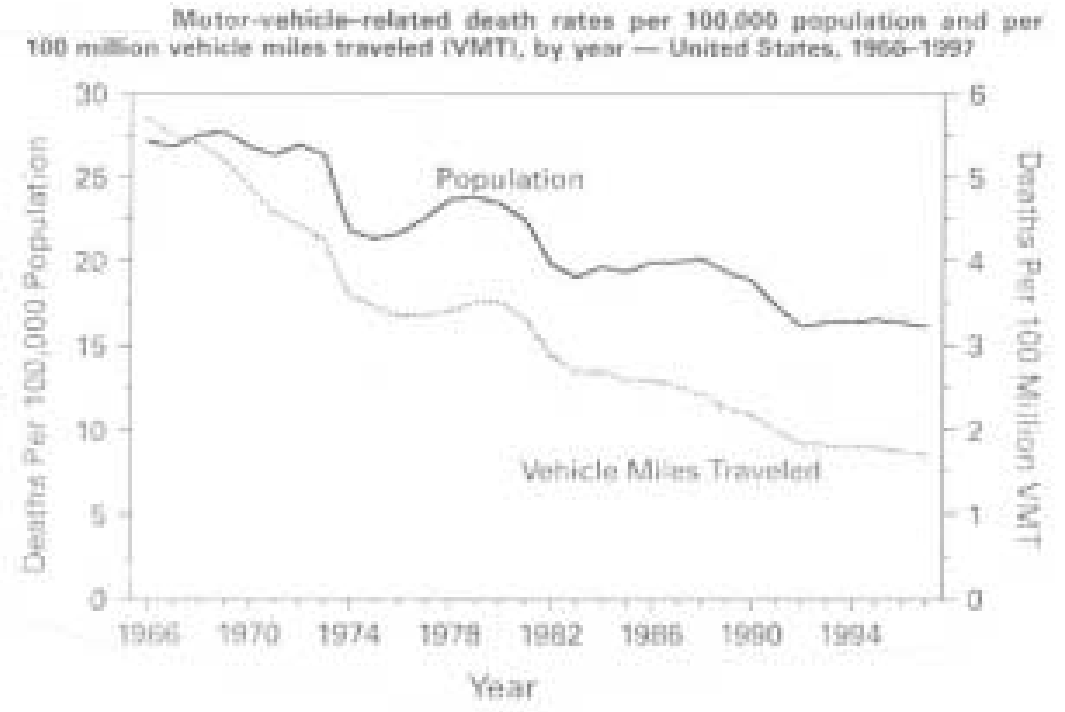

Figure 2: Motor Vehicle Related Death Rates

The U.S. Department of Transportation Act of 1966 created the US Department of Transportation to develop and coordinate national transportation policies and programs that is consistent with other national objectives. The Highway Safety Act of 1966 provided a coordinated national safety program by requiring each state to have a highway program designed to reduce traffic crashes and created the National Highway Safety Agency. The National Traffic and Motor Vehicle Safety Act of 1966 establishes 
safety standards for motor vehicles involved in interstate commerce, expands the national driver registry, and establishes both the National Motor Safety Advisory Council and the National Traffic Safety Agency (National Traffic and Motor Vehicle Act, 1966).

\section{Department of Transportation}

The Department of Transportation (DOT) was established by Act of Congress and signed into law by President Lyndon B. Johnson on October 15, 1966. The mission of the DOT is to develop and coordinate policies that will provide an efficient and economical national transportation system (United States Department of Transportation, 2001). It is the primary agency in the federal government with the responsibility for shaping and administering policies and programs to protect and enhance the safety, adequacy, and efficiency of the transportation system and services (United States Department of Transportation, 2001).

The Department of Transportation contains the Office of the Secretary and twelve individual operating administrations. Among them are the Federal Highway Administration, the Federal Motor Carrier Safety Administration, and the National Highway Traffic Safety Administration.

National Highway Traffic Safety Administration

In 1970, the Highway Safety Act authorized the establishment of the National Highway Traffic Safety Administration. The Highway Safety Act separated highway administration into two parts: design, construction, and maintenance on the one hand which fell to the FHWA, and highway and automobile safety on the other which are still 
the general charge of the NHTSA.

Functioning under the U.S. Department of Transportation, NHTSA was established as the successor to the National Highway Safety Bureau, to carry out safety programs under the National Traffic and Motor Vehicle Safety Act of 1966 and the Highway Safety Act of 1966. NHTSA is responsible for reducing deaths, injuries and economic losses resulting from motor vehicle crashes (National Highway Traffic Safety Administration, 2001). NHTSA's goal is accomplished by setting and enforcing safety performance standards for motor vehicles and motor vehicle equipment, and through grants to state and local governments to enable them to conduct effective local highway safety programs.

NHTSA investigates safety defects in motor vehicles, sets and enforces fuel economy standards, helps states and local communities reduce the threat of drunk drivers, promotes the use of safety belts, child safety seats and air bags, investigates odometer fraud, establishes and enforces vehicle anti-theft regulations, and provides consumer information on motor vehicle safety topics (National Highway Traffic Safety Administration, 2001).

NHTSA also conducts research on driver behavior and traffic safety, to develop the most efficient and effective means of bringing about safety improvements. NHTSA also provides, with consensus and advice from Congress, state-level grants that address local problems such as alcohol, seat belts, and coordination of safety data systems.

The Federal Highway Administration

The goal of the Federal Highway Administration (FHWA) is to create the best 
transportation system in the world for the American people through proactive leadership, innovation, and excellence in service (U.S. Department of Transportation, Federal Highway Administration, 2001). The FHWA provides expertise, resources, and information to continually improve the quality of our nation's highway system and its intermodal connections. Undertaking this mission, in cooperation with all of its partners, enhances the country's economic vitality, quality of life, and the environment (U.S. Department of Transportation, Federal Highway Administration, 2001).

The FHWA is a part of the Department of Transportation and is headquartered in Washington, D.C., with field offices across the United States. The FHWA performs its mission through these main programs:

The Federal Aid Highway Program provides federal financial assistance to the states to construct and improve the National Highway System, urban and rural roads, and bridges. The program provides funds for general improvements and development of safe highways and roads (U.S. Department of Transportation, Federal Highway Administration, 2001).

The Federal Lands Highway Program provides access to and within national forests, national parks, Indian reservations and other public lands by preparing plans, letting contracts, supervising construction facilities, and conducting bridge inspections and surveys (U.S. Department of Transportation, Federal Highway Administration, 2001).

To support all of these program areas, the FHWA conducts and manages a comprehensive research, development, and technology program, and like NHTSA, 
delivers state-level programs through local grants to improve local highway maintenance and road construction through education and technology transfer.

Federal Highway Safety Initiatives

Federal Motor Carrier Safety Administration (FMCSA)

The Federal Motor Carrier Safety Administration was established within the Department of Transportation on January 1, 2000, pursuant to the Motor Carrier Safety Improvement Act of 1999 (Public Law No. 106-159, 113 Stat. 1748 (December 9, 1999)) (U.S. Department of Transportation, Federal Motor Carrier Safety Administration, 2001). Formerly a part of the Federal Highway Administration, the Federal Motor Carrier Safety Administration's primary mission is to prevent commercial motor vehiclerelated fatalities and injuries. Administrative activities contribute to ensuring safety in motor carrier operations through strong enforcement of safety regulations, targeting high-risk carriers and commercial motor vehicle drivers; improving safety information systems and commercial motor vehicle technologies; strengthening commercial motor vehicle equipment and operating standards; and increasing safety awareness (U.S. Department of Transportation, Federal Motor Carrier Safety Administration, 2001). The Administration works with federal, state and local enforcement agencies, the motor carrier industry, labor safety interest groups, and others to accomplish these activities.

The Administration operates several programs. Two programs associated with crash data collection are the Motor Carrier Safety Assistance Program and the Research and Technology Program.

Motor Carrier Safety Assistance Program 
The Motor Carrier Safety Assistance Program (MCSAP) is a Federal grant program that provides states with financial assistance for roadside inspections and other commercial motor vehicle safety programs (U.S. Department of Transportation, Motor Carrier Safety Act Assistance Program, 2001). It promotes detection and correction of commercial motor vehicle safety defects, commercial motor vehicle driver deficiencies, and unsafe motor carrier practices before they become contributing factors to crashes and hazardous materials incidents. The program also promotes the adoption and uniform enforcement by the states of safety rules, regulations, and standards compatible with the Federal Motor Carrier Safety Regulations and Federal Hazardous Materials Regulations.

Data and Analysis

The Administration collects and disseminates safety data concerning motor carriers. Data are collected by Federal safety investigators and state partners from roadside inspections, crashes, compliance reviews, and enforcement activities. This information provides a national perspective on carrier performance and assists in determining Administration and state enforcement activities and priorities. Combined with data from other sources, including the NHTSA, extensive analysis is performed to determine trends in performance by carrier and other factors such as cargo, driver demographics, location, time, and type of incident (U.S. Department of Transportation, Motor Carrier Safety Act Assistance Program, 2001). Based on identified trends, the Administration can direct resources in the most efficient and effective manner to improve motor carrier safety.

Research and Technology Program 
The Administration identifies, coordinates, and administers research and development to enhance the safety of motor carrier operations, commercial motor vehicles, and commercial motor vehicle drivers. The Administration promotes the use of information systems and advanced technologies to improve commercial vehicle safety, simplify government administrative systems, and provide savings to states and the motor carrier industry (U.S. Department of Transportation, Motor Carrier Safety Act Assistance Program, 2001).

The Motor Carrier Safety Assistance Program (MCSAP) is a Federal grant program that provides financial assistance to States to reduce the number and severity of crashes and hazardous materials incidents involving commercial motor vehicles (CMV). The goal of the MCSAP is to reduce CMV-involved crashes, fatalities, and injuries through consistent, uniform, and effective CMV safety programs. Investing grant monies in appropriate safety programs will increase the likelihood that safety defects, driver deficiencies, and unsafe motor carrier practices will be detected and corrected before they become contributing factors to crashes (U.S. Department of Transportation, Motor Carrier Safety Act Assistance Program, 2001).

The MCSAP also sets forth the conditions for participation by States and local jurisdictions and promotes the adoption and uniform enforcement of safety rules, regulations, and standards compatible with the Federal Motor Carrier Safety Regulations (FMCSR's) and Federal Hazardous Material Regulations (HMR's) for both interstate and intrastate motor carriers and drivers (U.S. Department of Transportation, Motor Carrier Safety Act Assistance Program, 2001). 
Fatality Analysis Reporting System (FARS)

FARS is a large data file containing data on all fatal traffic crashes within the 50 states, the District of Columbia, and Puerto Rico. The data system was conceived, designed, and developed by the National Center for Statistics and Analysis (NCSA), a branch of NHTSA, to assist the traffic safety community in identifying traffic safety problems, developing and implementing vehicle and driver countermeasures, and evaluating motor vehicle safety standards and highway safety initiatives (National Highway Traffic Safety Administration, 2001).

FARS data are used extensively within NHTSA, and requests are received from sources such as state and local governments, research organizations, private citizens, the auto and insurance industries, Congress, and the media.

Many questions on the safety of vehicles, drivers, traffic situations, and roadways can be answered through the use of FARS data. FARS data can also be accessed at the state level by the FARS analyst to respond to state safety issues. To protect individual privacy, no personal information, such as names, addresses, or specific crash locations, is coded.

Data are available for every year since FARS was established in 1975. Users can obtain FARS data in several ways. NHTSA has a contract with an agency in each state to provide information on fatal crashes. FARS analysts are state employees who tabulate the information and put it in a standard useable format. Data on fatal motor vehicle traffic crashes are gathered from the states own source documents, and are coded on standard FARS forms. The analysts obtain the documents needed to complete the 
FARS forms, which generally include some or all of the following (National Highway Traffic Safety Administration, 2001): (1) Police Accident Reports (PARS), (2) State vehicle registration files, (3) State driver-licensing files, (4) State Highway Department data, (5) Vital Statistics, (6) Death certificates, (7) Coroner/Medical examiner reports, (8) Hospital medial records, and (9) Emergency medical service reports.

To be included in FARS, a crash must involve a motor vehicle traveling on a traffic way customarily open to the public, and result in the death of a person (either an occupant of a vehicle or a non-motorist) within 30 days of the crash (National Highway Traffic Safety Administration, 2001). The FARS file contains descriptions of each fatal crash reported. The specific data elements may be modified slightly at times, in response to users' needs and highway safety emphasis areas. All data elements are reported on four forms: (1) The Crash Form asks for information such as the time and location of the crash, the first harmful event, whether it is a hit-and-run crash, whether a school bus was involved, and the number of vehicles and people involved (National Highway Traffic Safety Administration, 2001). (2) The Vehicle and Driver Forms call for data on each crash-involved vehicle and driver. Data include the vehicle type, initial and principal impact points, most harmful event, and driver's license status (National Highway Traffic Safety Administration, 2001). (3) The Person Form contains data on each person involved in the crash, including age, gender, and role in the crash (driver, passenger, non-motorist) injury severity, and restraint use (National Highway Traffic Safety Administration, 2001). (4) The FARS Alcohol forms contain driver and nonoccupant blood alcohol content estimates that supplement the data files when no alcohol 
information would otherwise be available.

Quality Control is a vital system feature. One important part of the quality control program is a series of consistency checks. Other quality checks are for timeliness, completeness, and accuracy. Statistical control charts are also employed to monitor the coding of key data elements over time.

\section{Crash Outcome Data Evaluation Systems (CODES)}

CODES is a cooperative approach to obtain medical and financial outcome information related to motor vehicle crashes for highway safety and injury control decision making. It evolved as the result of the Intermodal Surface Transportation Efficiency Act (ISTEA) of 1991 which provided funds to the National Highway Traffic Safety Administration (NHTSA) to report to Congress about the benefits of safety belts and motorcycle helmets for persons involved in motor vehicle crashes. To measure benefits in terms of reducing death, disability, and medical costs, NHTSA determined that statewide data were needed that included all persons involved in police reported crashes, those who were injured or who died, as well as those who were not injured. In this manner, comparisons between those using and not using safety belts or motorcycle helmets could be made by identifying and contrasting the characteristics of the injured and uninjured persons within each of the restraint use groups.

Since none of the state data files documenting the crash and injury events at the scene, en route, and at the hospital have sufficient information alone to document medical and financial outcome for specific factors related to motor vehicle crashes. NHTSA funded Hawaii, Maine, Missouri, New York, Pennsylvania, Utah, and 
Wisconsin to implement Crash Outcome Data Evaluation Systems to develop data linkage capabilities and highway safety and injury control applications for the linked data, and perform the required analysis (National Highway Traffic Safety Administration, 1996). The CODES sites successfully linked statewide police reported crash reports to emergency medical services, emergency department, hospital discharge, rehabilitation, long term care, death certificate and claims data. Each state's linked data base is person specific, population-based, statewide, includes at least 12 months of data, and permits tracking of all persons involved in motor vehicle crashes from the scene to final disposition (National Highway Traffic Safety Administration, 1996).

A model CODES consists of linked statewide crash and injury data that match vehicle, crash, and human behavior characteristics to their specific medical and financial outcomes. Data related to motor vehicle crashes are located in multiple sources: crash data collected by police at the scene; EMS data collected by EMTs who provide treatment at the scene and enroute; medical data collected by physicians, nurses and others who provide treatment at the emergency department, in the hospital, or outpatient setting (National Highway Traffic Safety Administration, 1996). Additional state data such as driver licensing, vehicle registration, citation/conviction records, insurance claims, HMO/managed care, outpatient record data are also useful for linkage to meet State objectives. Probabilistic heuristics (algorithms) allow certain data to be extracted and linked even though there is no perfect one-to-one relationship; in this way, the utility of CODES is expanded somewhat. 
The CODES states demonstrated that data linkage helped to fulfill their expanded data needs without the additional expense and delay of new data collection. The linked data were used to identify populations at risk for increased severity of high health care costs, the impact of different human behaviors on outcome, the safety needs at the community level, the allocation of resources for emergency medical services, the injury patterns by type of roadway and geographic location, the benefits of collaboration on data quality, and others (National Association of Governor's Highway Safety Representatives, 1995). Crash, vehicle, and behavior characteristics linked with outcome information enable decision-makers to identify those prevention programs that will have the most impact on preventing or reducing the medical and financial costs associated with motor vehicle crashes.

National Automotive Sampling System (NASS)

The National Automotive Sampling System (NASS) is under the auspices of the NHTSA's HTSA National Center for Statistics and Analysis. The NASS program, formerly know as the National Accident Sampling System, is the mechanism through which NHTSA collects nationally representative data on motor vehicle traffic crashes to aid in the development, implementation and evaluation of motor vehicle and highway safety countermeasures.

The NASS System was originally designed and implemented in 1979 to support highway and motor vehicle safety programs. The NASS program was reexamined in the mid-1980's. The evaluation committee concluded that the program should be redesigned to focus on enhanced in-depth analysis of passenger vehicle crash protection 
performance. This reexamination resulted in changes that NHTSA implemented in January 1988. To enhance its applicability in addressing crashworthiness issues, the NASS was divided into two components: (1) the General Estimates System (GES), which collects data from an annual sample of approximately 55,000 police reported motor vehicle traffic crash reports and (2) the Crashworthiness Data System (CDS), which collects additional detailed information on an annual sample of approximately 5,000 police-reported motor vehicle traffic crashes involving a towed passenger car, light truck or van that is less than or equal to 10,000 pounds gross vehicle weight rating (GVWR) (National Automotive Sampling System, 1999).

Intermodal Surface Transportation Efficiency Act of 1991 (ISTEA)

The 1991 Intermodal Surface Transportation Efficiency Act (ISTEA) requires each state to implement a Safety Management System (SMS) to ensure better coordination of state and local highway safety efforts and provide the information needed by officials to make informed decisions on utilizing resources. According to the legislation, an SMS will promote widespread collaboration around highway safety issues and broaden the range of organizations involved in such efforts by including public health, emergency medical services (EMS), and law enforcement agencies in the development and implementation of the systems (Intermodal Surface Transportation Efficiency Act, 1991). An SMS is defined as a systematic process that has the goal of reducing the number and severity of traffic crashes by ensuring that all opportunities to improve highway safety are identified, considered, implemented as appropriate, and evaluated in all phases of highway planning, design, construction, maintenance, and 
operation and by providing information for selecting and implementing effective highway safety strategies and projects. (Intermodal Surface Transportation Efficiency Act, 1991).

When it was originally enacted in 1966, the Highway Safety Act required the agencies to establish uniform standards for state highway safety programs to assist states and local communities in implementing their highway safety programs. Eighteen such standards were established and, until 1976, the Section 402 Program was directed principally toward achieving state and local compliance with these standards. Over time, state highway safety programs matured and, in 1976, the Highway Safety Act was amended to provide for more flexible implementation of the program. States were no longer required to comply with every uniform standard or with each element of every uniform standard. As a result, the standards became more like guidelines for use by the states and management of the program shifted from enforcing standards to using the standards as a framework for problem identification, countermeasure development, and program evaluation. In 1987, Section 402 of the Highway Safety Act was amended, formally changing the standards to guidelines. This is a fundamental shift in policy away from the mandates seen in the 1966 legislation and toward participation by empirical example in the late 1990's.

\section{Transportation Efficiency Act-21}

Section 2001 of TEA-21 reauthorizes the State and Community Highway Safety Formula Grant Program (Section 402 of Chapter 4 of Title 23) to support state highway safety programs designed to reduce traffic crashes and resulting deaths, injuries, and 
property damage (Intermodal Surface Transportation Efficiency Act, 1991 \& National Association of Governor's Highway Safety Representatives, 2001). A state may use these grant funds only for highway safety purposes and at least 40 percent of these funds are to be used to address local traffic safety problems.

For a highway safety program to be effective, it must include a process that identifies highway safety problems, develops measures to address the problems, implements the measures, and evaluates the results. Each stage of the process depends on the availability of highway safety data and traffic records. If these data and records are not accurate, comprehensive, and timely, the program will not be likely to achieve its goals. For this reason, highway safety program managers have always sought improved data and traffic records.

By including Section 411 in TEA-21, Congress has created a grant program to assist the states in developing more accurate, timely and complete highway safety data and traffic records systems. A state that satisfies each of Section 411's criteria will have increased its ability to ensure that its actions to reduce highway deaths and injuries will be effective (Highway Safety Act 1966, 1998).

\section{Highway Safety Data and Traffic Records Assessment}

The prerequisite for multiple-year grants under Section 411 is that the state must have conducted, within the preceding five years, an assessment of its highway safety data and traffic records. An assessment is an in-depth formal review of a state's highway safety data and traffic records system. The objective of an assessment is to provide the state with an impartial report of the status of the highway safety data and traffic records 
system in the state. For the purpose of this rule, an assessment includes an audit or strategic planning analysis.

Integrating the planning of highway safety programs and highway safety information systems provided managers and users with resources to select appropriate technologies to support information needs. Establishing a cadre of professionals in each state training users in analytic methods appropriate for evaluation of highway safety information, and establishing technical standards for characteristics of highway safety information systems (Highway Safety Act 1966, 1998).

\section{Research in Crash Data Improvements}

\section{Model Minimum Uniform Crash Criteria (MMUCC)}

Paragraph (a)(2) of Section 411 requires consultation with states and other appropriate parties, to determine the model data elements necessary to observe and analyze national trends in crash occurrences, rates, outcomes, and circumstances.

NHTSA has determined that the Model Minimum Uniform Crash Criteria (MMUCC) serve the purposes of the law and has defined "model data elements" to mean the elements specified in the MMUCC. The agency developed the MMUCC criteria in cooperation with the FHWA and the National Association of Governor's Highway Safety Representatives and presented them in final form at the National Safety Council's $24^{\text {th }}$ International Forum on Traffic Records and Highway Information Systems in July 1998 (National Association of Governor's Highway Safety Representatives, 1998). While conformity to the MMUCC is not required for grant eligibility under Section 411, NHTSA strongly encourages the States to employ the criteria in their highway safety 
data and traffic records systems, and to consider these criteria when conducting their assessments and developing their strategic plans.

Each state, in cooperation with its political subdivisions, should establish and implement a complete and comprehensive traffic records program. The statewide program should include, or provide for, data for the entire state. A complete and comprehensive traffic records program is essential for the development and operation of a viable Safety Management System and effective traffic related injury control efforts (National Association of Governor's Highway Safety Representatives, 1998). It is also essential for the performance of planning, problem identification, operational management and control, tracking of safety trends, and the implementation and evaluation of highway safety countermeasures and activities. It is the key ingredient to safety effectiveness and management.

\section{MMUCC's Traffic Records System}

To provide a complete and useful record system for safety program management at both the state and local level, the state should have a database consisting of the following: (1) A Crash File with data on the time, environment, and circumstances of a crash; identification of the vehicles, drivers, cyclists, occupants, and pedestrians involved; and documentation of crash consequences (fatalities, injuries, property damage and violations charged) with the data tied to a location reference system (National Association of Governor's Highway Safety Representatives, 1998). (2) A Driver File or driver history record of licensed drivers in the state, with data on personal identification and driver license number, type of license, license status (suspended or revoked), driver 
restrictions, driver convictions for traffic violations, crash history, driver control or improvement actions, and safety education data (National Association of Governor's Highway Safety Representatives, 1998). (3) A Vehicle File with information on identification, ownership and taxation, and vehicle inspection (where applicable) (National Association of Governor's Highway Safety Representatives, 1998). (4) A Roadway File with information about roadway location, identification, and classification as well as a description of a road's total physical characteristics, which are tied to a location reference system. This file should also contain data for normalizing purposes, such as miles of roadway and average daily traffic (National Association of Governor's Highway Safety Representatives, 1998). (5) A Commercial Motor Vehicle Crash File that uses uniform data definitions and collects information on the vehicle configuration, cargo body type, hazardous materials, information to identify the motor carrier, as well as information on the crash (National Association of Governor's Highway Safety Representatives, 1998). (6) A Citation/Conviction File which identifies the type of citation and the time, date and location of the violation; the violator, vehicle and the enforcement agency; and adjudication action and results, including court of jurisdiction (an Enforcement/Citation File could be maintained separate form a Judicial/Conviction File) and fines assessed and collected (National Association of Governor's Highway Safety Representatives, 1998). (7) An Emergency Medical Service (EMS) file with emergency care and victim outcome information about ambulance responses to crashes, e.g. emergency care unit, care given, injury data, times of EMS notification and arrival, information on emergency facility and hospital care including trauma registry data, and 
medical outcome data relative to crash victims receiving rehabilitation and for those who die as the result of the crash (National Association of Governor's Highway Safety Representatives, 1998). (8) Provision for file linkage through common data elements between the files or through other consistent means; performance level data as part of the traffic records system; demographic data to normalize or adjust for exposure when analyzing the various data in the files; and provision for the use of cost data relative to amounts spent on countermeasure program and the costs of fatalities, injuries and property damage (National Association of Governor's Highway Safety Representatives, 1998).

\section{Data Characteristics}

Traffic records programs should meet basic requirements for the most effective use of the data by program managers. Accordingly, each state should emphasize the following characteristics: (1) Timely, accurate, and complete data collection and input to all files, especially to the Crash and Driver Files, to assure maximum utilization and confidence in the traffic records system. Each state is encouraged to join and fully participate in the driver license compact to ensure that complete data are available from other states (National Association of Governor's Highway Safety Representatives, 1998). (2) Data uniformity, providing for uniform coding and definition of data elements to allow a state to compare its crash problems to other states, regions and the nation, and the use of uniform coding of violations and convictions for the efficient exchange of driver information between states. (3) Data consistency within a State over time to provide for multi-year analysis of data to detect trends and for identification of emerging 
problems, as well as to determine beneficial effects of highway safety programs, and timely, accurate, and complete data output to ensure that highway safety program managers will have records that are accessible, understandable, and effective (National Association of Governor's Highway Safety Representatives, 1998).

Using MMUCC Traffic Records

According to recommendations made in MMUCC, each state should establish a process for the effective use of traffic records by highway safety management and other injury control professionals both statewide and for political subdivisions, when conducting the following activities: (1) Performing planning, problem identification, program management or control, tracking, implementation and evaluation pursuant to a management process developed by the state that addresses the role or use of traffic records data (National Association of Governor's Highway Safety Representatives, 1998). (2) Developing a problem identification strategy that specifies the necessary data, assures that accurate and timely data area available, defines the analyses conducted (including the variables used, statistical tests applied, and trends examined), and describes how results are reported and used (National Association of Governor's Highway Safety Representatives, 1998).

Conducting analyses and presenting results so that they are clearly understood and usable by managers, including the use of problem reports that describe the magnitude of the problems, and appropriate graphs, tables and charts to support the conclusions reached, and performing program evaluation, beginning at the planning stage and carrying through implementation and final evaluation, essentially using the same 
types of data that were used in developing the programs implemented (National Association of Governor's Highway Safety Representatives, 1998).

\section{Managing MMUCC Traffic Records}

An organizational structure is in place for effective administration of its traffic records program, at a minimum consisting of the following components: A permanent Traffic Records Committee, representing the principal users and custodians of the data in the state that provides administrative and technical guidance. The Committee should be responsible for adopting requirements for file structure and linkage, assessing capabilities and resources, establishing goals for improving the traffic records program, evaluating the program, continuously developing cooperation and support from state and local agencies as well as the private sector, and ensuring that high quality and timely data are available to authorized persons or agencies for appropriate data analysis. (National Association of Governor's Highway Safety Representatives, 1998).

Statewide Application of Data Collection and Management Technology to Improve Highway Safety

Federal, state, and local agencies perform a wide range of functions to improve safety. These activities continue to grow in volume and complexity. Incident reporting is a vital component of closed loop management process for acquiring, disseminating, and analyzing information to improve short and long range response to safety trends (National Association of Governor's Highway Safety Representatives, 1998). Current incident reporting procedures are paper based, labor intensive, redundant, and 
unresponsive to customer and stakeholder needs. Additionally, they do not enable agencies to achieve new performance levels for safety improvement.

The lack of accurate and timely electronic information means government safety agencies lag behind their private sector counterparts in the use of state of the art risk management practices and tools, like data mining and decision analytics to improve performance.

The National Model For Traffic Data Collection

In 1994, FHWA let a large contract to the Iowa Department of Transportation to develop a nationally representative model for traffic crash data collection and record integration. The goal of the National Model is to demonstrate, in a statewide operational environment, how new technologies and techniques can be cost effectively used to improve highway safety data collection and management processes. The National Model partners believe that using these new approaches can shorten the data collection time, minimize disruption to traffic, increase officer safety and efficiency, and improve data quality. According to FHWA, this will not only contribute to better informed highway safety decisions and improved safety of the highway system, it will also leverage proven technology for law enforcement activities.

The National Model also supports a number of FHWA nationwide goals and objectives. These include: Bridging the gap between current practice (paper and pencil, tape measure) and best practice (tablet and palm-sized computers, Global Positioning Systems (GPS), laser measurement, Mobile Data Computes (MDC), the Advanced Law Enforcement Response Technology program (ALERT), bar codes, and/or digital cameras 
(The Iowa Department of Transportation, National Model, 1994).

Building upon and implementing existing research and technology development efforts (The Iowa Department of Transportation, National Model, 1994). Shortening the time and reducing the risks and costs for technology implementation (The Iowa Department of Transportation, National Model, 1994). Raising the awareness of these new technologies with other states (The Iowa Department of Transportation, National Model, 1994). Sharing lessons learned and maximizing resources by not repeating mistakes (The Iowa Department of Transportation, National Model, 1994).

State Initiatives in Crash Data Collection and Record Integration Iowa

The Iowa Department of Transportation along with the FHWA wanted to demonstrate how new technologies and techniques can be cost effectively used in a statewide operational environment to improve the highway safety data collection and management processes. Using these new approaches can shorten the data collection time, minimize disruption to traffic, increase officer efficiency, and improve data quality. All of which contribute to better-informed highway safety decision and improved safety of the highway system.

\section{Reengineer the Crash Data Collection Process in Iowa}

The entire onsite crash data collection process has the potential to be significantly improved through the use of a variety of existing and emerging technologies. These include bar code, laser measurement, digital cameras, voice recognition, etc. This task reviews the current data collection process and improves the 
process by reengineering it for cost effective use of technology. It also addresses the methods to effectively handle a wealth of electronic data supplied by such a system at all jurisdictional levels.

Specifically, the task includes new crash diagramming, police incident reporting, citation disposition form, contact management, time and activity reporting, and selective end shift options (Iowa Department of Transportation, 1994).

Wisconsin

The automated Wisconsin crash recordkeeping system was developed in the mid1980's, funded in large part through federal grants. A statewide task force comprised of law enforcement officials, safety specialists, and engineers was convened to develop an improved uniform police accident report form. The new system went on line in January 1987, providing Wisconsin with the nation's most highly automated accident recordkeeping system.

In 1992, another task force was formed to study and update the Wisconsin Crash Report. The task force introduced a four page report that incorporated optical mark recognition, all 18 Critical Automated Data Reporting Elements (CADRE), and the Wisconsin Crash Report Truck and Bus Crash Supplement, MV4000 (Wisconsin Department of Transportation, 2001). The new form went into use on January 1, 1994. The task force reconvened in 1995 to evaluate the effectiveness of the MV4000 and incorporate legislative changes and task force/law enforcement suggestions (Wisconsin Department of Transportation, 2001).

Traffic Crash Section provided outreach and training to law enforcement 
agencies as requested. The “Law Enforcement Officer's Instruction Manual For Completing the Wisconsin Motor Vehicle Accident Report Form (MV4000)" was updated and published biennially (Wisconsin Department of Transportation, 2001). Quarterly Law Enforcement Packages, a series of 10 reports dealing with accident data, are sent to each county sheriff, each State Patrol district, and 84 municipal agencies. Ad hoc reports are provided to any agency requesting information (Wisconsin Department of Transportation, 2001).

The crash database contains four years of reportable motor vehicle crashes. All information captured on the MV4000 crash report, with the exception of the diagram, narrative, skid marks, witness information and the truck and bus section, are included. The Truck and Bus information captured is used by State Patrol for their reporting purposes. CADRE elements are captured as of January 1, 1994.

A number of manual and automated edits are run to ensure the accuracy and integrity of the system. A series of edits, error reports and other performance measures are reported on a daily, weekly, and monthly basis (Wisconsin Department of Transportation, 2001). Missing Fields, Quarterly Law Enforcement, and ad hoc reports are provided to local agencies (Wisconsin Department of Transportation, 2001). Selective studies on different aspects of accident reporting/recordkeeping are done annually (Wisconsin Department of Transportation, 2001).

\section{Kentucky}

Kentucky State Police (KSP) is the custodian of the CRASH (Collision Report Analysis for Safe Highways) System (Kentucky State Police, 2001). The CRASH 
System is being developed to improve the analysis of traffic collision data and roadway data, not only by KSP but also by state, federal and local law enforcement agencies throughout the Commonwealth. This system is being developed to replace the old KARS (Kentucky Accident Reporting System).

CRASH consists of a relational database containing information that is on the traffic collision report (henceforth referred to as the CRASH statistical database) and a database containing images of the traffic collision reports (Kentucky State Police, 2001). CRASH is an open system, allowing data to be extracted easily for data analysis by any agency requesting this information. The CRASH system includes the following capabilities: (1) Imaging, (2) Scanning/OCR, (3) Electronic file transfer, (4) Internet capable, (5) Electronic version, (6) Remote scanning, and (7) Ad hoc queries.

The primary goal of CRASH was to design and implement a single, uniform cost effective system to accurately capture, analyze and report traffic collision data. The CRASH system was developed to improve the analysis of traffic collision data and roadway data, not only by the Kentucky State Police, but also by state, federal and local law enforcement agencies throughout the Commonwealth.

The project started in August 1993, after a review of the current accident system by the Region IV Office of the Federal Highway Administration. A traffic records committee was formed to replace the existing accident report and the accident system (KARS). The major agencies involved in this lengthy process include: Kentucky State Police, Kentucky Transportation Cabinet, Lexington-Fayette County Division of Police, Louisville Division of Police, Jefferson County Police Department, University of 
Kentucky (Transportation Center and Kentucky Injury Prevention and Research Center), the Federal Highway Administration, and the Governors Office for Technology (Kentucky State Police, 2001). Numerous other local law enforcement agencies also participated throughout the design of CRASH.

\section{West Virginia Initiatives to Enhance the Crash Data Process}

\section{West Virginia Uniform Crash Report}

In West Virginia in 1994, the traffic crash form was approaching twenty years old. A small research team was assembled for revision of the "Uniform Traffic Crash Report" (UTAR) from the West Virginia Division of Highway Engineers including computer consultants, state and federal agency members, but most significantly, about one hundred enforcement personnel at all levels, including sheriffs departments and the state police, plus small town West Virginia offices. Before custody of the data form was transferred to engineers and computer analysts, the West Virginia University Research Team spent two years with the law officers themselves.

The West Virginia Research Team recognized that unfortunately, the initial design of many crash forms takes place without input by the data creators (usually law enforcement officers) or data customers (usually engineers or safety programmers). Computer analysts or traffic engineers most times will design the actual data form itself, and determine the logical sequence of data element flow, establish definition on their own, plus box size, line spacing, even the fonts and so on, without consulting those who must interpret the same instrument with limited training, or who must fill out a vehicle identification number inside a very small box on the paper. After the design of the form 
is complete, law enforcement officers are often called upon to use the same form to collect data, or years later, to reconstruct a crash or to establish facts in a legal proceeding. Sometimes officers must fill out the original form under the pressure of injured victims or during inclement weather, which makes any basic problems with the form obvious. In the worst cases, law enforcement or security personnel stop using the form entirely.

Working from the basic assumption that data accuracy and representativeness are established by people and culture, and that these must come well before improvements are made in technologies or hardware, the West Virginia University Research Team assembled a highly coordinated partnership between enforcement officers, state officials, and the state university to completely revise the simple piece of paper which records basic crash data in West Virginia (Winn, Bucy, Klishis, 1997). After three-plus years, the research team estimated that more than 120 separate improvements have been made in this basic data collection document. Improvements in speed were made through this project, but, at this point in time, each major improvement is attributable with respect to the "culture of data collection", not to the technology of it. It is the purpose of this study to document the cultural changes, if any, upon West Virginia law enforcement, which came about as a result of the crash form revisions during this project.

The Form Revision Project was broken down into four distinct phases (See Table 1). In each phase the research team collected input and evaluated its progress carefully before going on to the next level.

Table 1. Form Revision Project Major Phases 


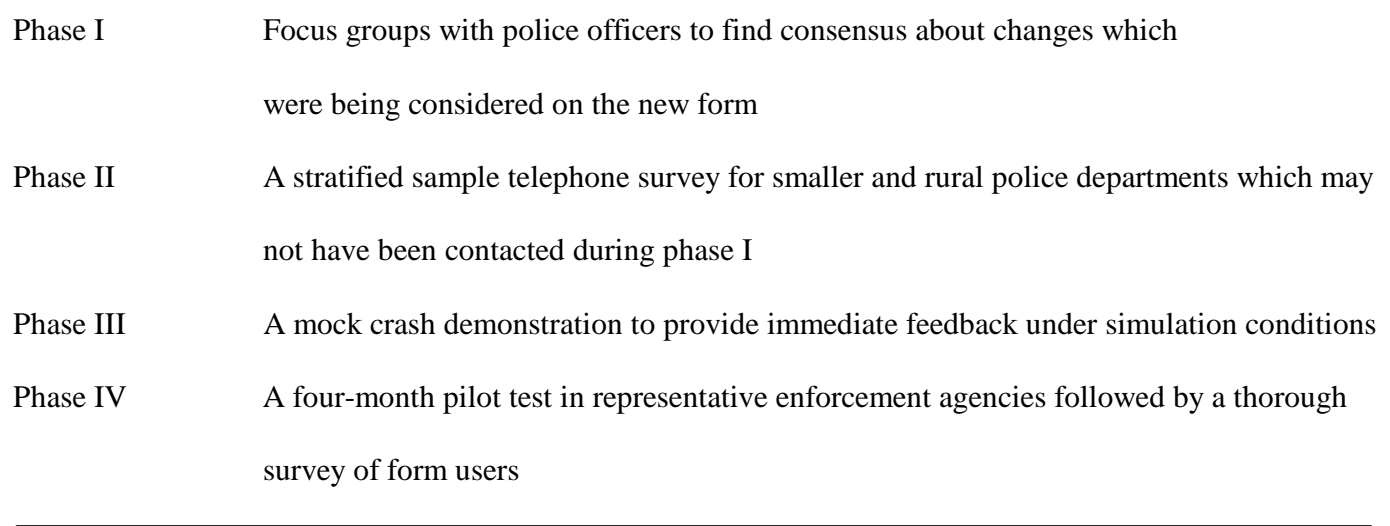

The West Virginia University Research Team decided early that any proposed changes with no champion(s) among law enforcement would be summarily disregarded. For example, when many state officials complained that vehicle identification numbers (VIN) were often left off the old form, enforcement officers replied that the VIN box was far to small to write in all seventeen digits, much less write them in legibly. Thus, just as the VIN box was enlarged substantially on the revised form, the culture of the West Virginia police officer community as a whole set the tone for each and every change in the form. Many of these were changes that would have gone unnoticed by engineers or programmers who did not have actual experience with the form in the field.

\section{West Virginia Research in Crash Data Linking Capability}

The first goal of this separate research purpose is to make an assessment. The second goal of this research is to identify areas that could improve or facilitate the linking of traffic crash data among the various groups of data owners.

A key to successful data linking is accurate and meaningful data obtained from the various agencies and organizations. Often this data may be stored differently on each system. Also, there may be policies and procedures about data confidentiality that may 
inhibit their use. These issues must be overcome in order for the linking of data to be successful.

The initial step taken in this research was to identify all of the possible sources of traffic crash related data throughout the state. Once identified, interviews with each entity were scheduled and performed. In all, 15 organizations were visited resulting in 21 separate interviews. These interviews were performed between May 12, 1995 and August 29, 1995. Follow-up of the interviews continued until February 12, 1996. When applicable, each organization supplied the West Virginia research team with various documentation e.g. system descriptions, data dictionaries, and a written questionnaire, at its request.

First and foremost, it was recommended that a person be chosen to lead a steering committee to deal with the following issues: data access, data quality, data processing, patient confidentiality, interpretation of linked data, standardized data definitions, and developing standardized codes for cities and counties, etc. The steering committee would need to consist of representatives of the involved agencies and organizations in order to facilitate the cross-communication that must occur.

The essence of the results of the West Virginia Crash Data Linking Project was that inconsistent data platforms (technologies) and lack of a champion and forum to routinely discuss linkage problems were very real impediments to enhance linkage capabilities in West Virginia. 


\section{CHAPTER THREE}

\section{Methodology}

Working from the basic assumption that data accuracy and representativeness are established and improved by people, and that these must come well before improvements are made in technologies or hardware, I reviewed the methods used by the West Virginia University Research Team. The West Virginia University Research Team assembled a coordinated partnership between enforcement officers, state officials, and the state university to completely revise the simple piece of paper that records basic crash data in West Virginia. To meet these objectives the research team developed a needs assessment model (See Figure 3). I reviewed the needs assessment model and found it provided a logical sequence and a sense of direction to the research team's activities. Each phase of the research served as a building block for the next phase or activity. The study was designed to address the following research questions:

Q1. What process was used by the West Virginia University Research Team to develop the new West Virginia Uniform Crash Report?

Q2. What were the results? 


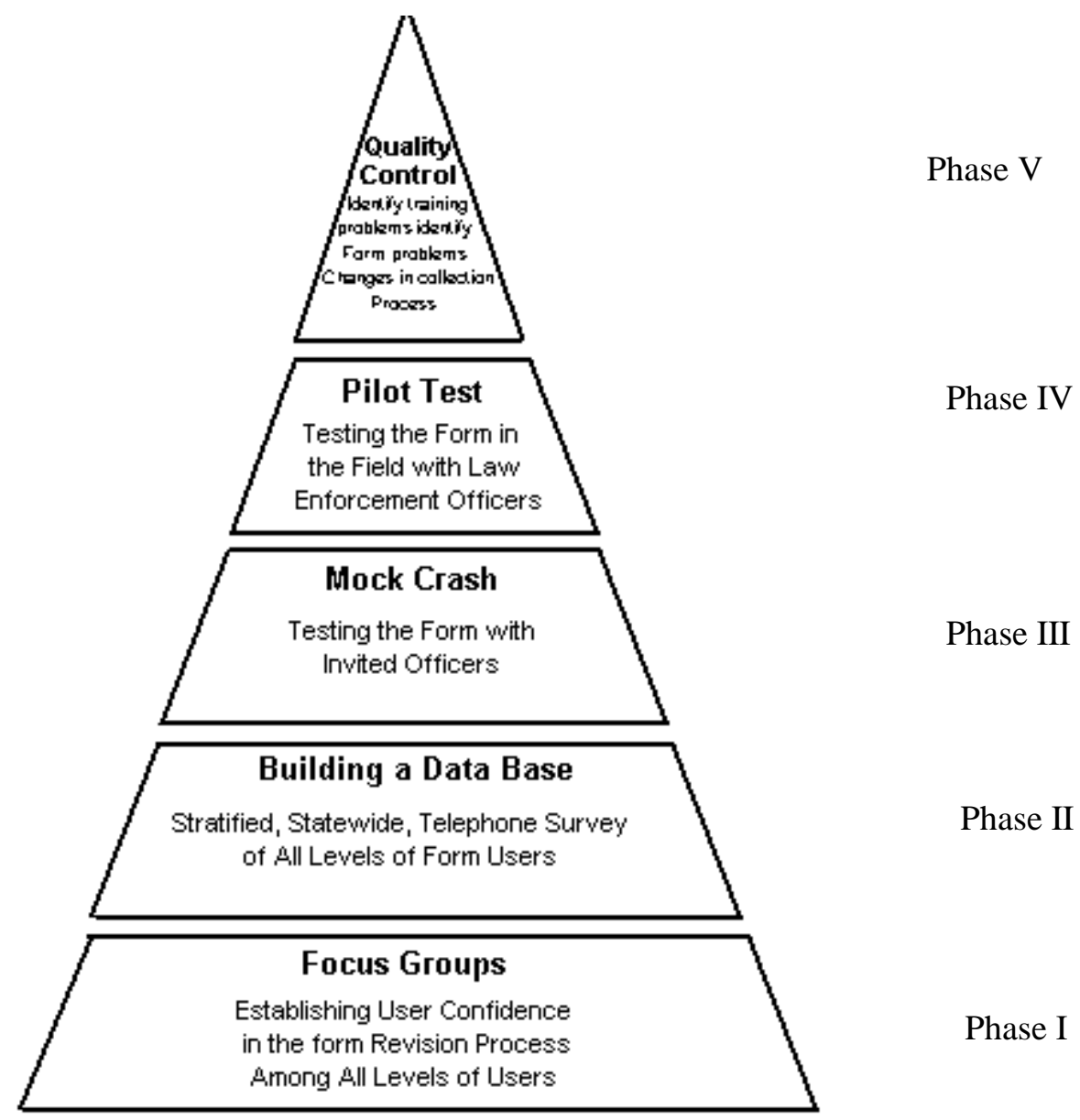

Figure 3: West Virginia Uniform Crash Report Needs Assessment Model

\section{Focus Group Methodology}

The first phase of the research was dedicated to collecting information from law enforcement officers about problem areas with the old crash form. Additionally, the research team asked law enforcement about areas of the form that could be improved as well as elements they wanted to maintain. The idea behind the focus groups was twofold. First, it was important that state law enforcement officers knew they were part of 
the team and that there was value and confidence placed on their experience. The research team and the DoH wanted to instill the idea that the development of this new form was a partnership between the research team and law enforcement, and that the gains, efficiency and accuracy, would benefit all users. Second, because law enforcement is the initial generator of crash data information objective and empirical feedback from law enforcement about real in-the-field strengths and weaknesses of the UTCR could serve as a measurement baseline.

\section{Subject Selection}

Beginning in August of 1995 and concluding in February of 1996, each law enforcement agency in the state was invited to a focus group meeting in their geographic region (See Appendix A). If an agency did not send a representative(s), that agency was later invited to another region's session. The geographic representation was validated, in writing, by the West Virginia DoH.

Each agency was asked to respond if it would be participating in its respective focus group meeting and how many officers would be attending. There was no limitation placed on the number of officers an agency could send. This information was helpful to the research team in preplanning each of the sessions.

Research Procedures

The focus group meetings were set up as brainstorming sessions. Each meeting followed a tightly controlled protocol (See Appendix B). Each meeting was divided into three sections and lasted approximately two and one half hours. The first section of the meeting consisted of an introduction and opening remarks by a member of the research 
team. The introduction, which lasted approximately thirty minutes, was designed not only to put the officers at ease but also to give them a history of how the current crash form was developed, why there was a need for change, and what changes were being considered. The introduction section concluded with an outline of the day's activities and what the research team hoped to accomplish.

Section two consisted of actual brainstorming activity. This section lasted approximately one hour. Before the actual brainstorming session began, a law enforcement officer from the group was selected to act as a moderator. His role was to oversee the meeting and list each response on a flip chart provided by the research team.

The goal of the meeting was to encourage all of the participants to make suggestions. It was important not to let a few individuals dominate the meeting. Also, the research team reinforced the idea that no responses would be rejected. No deep discussions on a suggestion were allowed. If a suggestion proved to be controversial, a three-minute discussion limitation was enforced. All suggestions were given equal consideration, thus none of the brainstorm responses were ranked or given priority over another. Finally, the research team played a very low-key role during the brain storming session because they felt it was important that law enforcement knew that their input was the central data necessary to develop a useful and functional form.

Section three was the evaluation portion of the meeting. During this phase, every idea that had been suggested was cardinally numbered and reviewed. Similar ideas were clustered together while impractical ideas were eliminated. The moderator would then rank order, and list the suggestions in order. 
At the conclusion of each session the officers voted on the suggestions that they believed would most improve the form. A "weighted vote" method was used. Each officer received five votes. An officer could split his or her vote between suggestions or, if an officer felt one suggestion was superior to the others, he or she could cast their vote for that suggestion. Once all of the votes were cast, the moderator would tabulate them and put them in rank order. The research team would record the responses for later tabulation. After a final debriefing period the meeting was adjourned.

The research team evaluated all of the responses that were generated after all of the focus group meetings had been completed. Similar responses were consolidated and a list of unique identifiable responses was sent to a panel for review. The panel included members of the research team and the West Virginia DoH Traffic Engineering Division, sponsors of the research project. The panel reviewed the list and selected the initial response changes that were eventually incorporated into the new form.

\section{Telephone Survey Methodology}

In this step, the comprehensive statewide telephone survey of law enforcement agencies, including large and small municipal police departments, county sheriffs' offices, and state police, was conducted. The research team felt it was important to contact agencies that had been unable to participate in focus groups, especially the smallest ones, so that a broader statistical baseline could be generated about uses of the UTCR. Since brainstorming was not feasible, a 23-question telephone survey instrument was developed in a cooperative effort between the research team and the West Virginia University Survey Research Center (See Appendix C). 


\section{Subject Selection}

A comprehensive list of all 272 local, county, and state agencies was compiled by the WVU Survey Research Center using information from the West Virginia Criminal Justice Director and the Marshall University Research \& Economic Development Center. A random number table was then used to select a sample of 150 law enforcement agencies that participated in the survey.

Research Procedures

The interviews were conducted by two trained telephone interviewers on an arranged schedule between 9:00 a.m. and 4:00 p.m. from January 20 to February 23, 1995. Interviews were monitored to ensure consistent interviewing techniques and interviewers were provided with scripted fallback statements, clarifications, and question for question $(\mathrm{Q} \& \mathrm{Q})$ objectives. Each agency was contacted up to four times, or more when appointments to call back were scheduled. Since the nature of the survey often required obtaining specific or detailed information about crash reporting in contrast to storage and transmission of information, more than one respondent was interviewed at an agency, and more than four attempts were often necessary.

The survey questions asked officers to describe the storage and transfer of UTCR information within and between agencies. Officers were also polled on content, format, organization, and computer resources within their agency. Officers were also given an opportunity to offer additional comments.

Mock Crash Methodology 
The third phase of the research dealt with an intensive one - day session to evaluate a prototype of the UTCR under mock crash conditions. The purpose of the oneday session was to preview the new form for comment and test the prototype form with law enforcement officers from across the state.

\section{Subject Selection}

An invitation was extended to every law enforcement agency across the state to attend a mock crash session held on October 20, 1995 at the West Virginia University Coliseum. No limitations were placed on the number of participants an agency could send. However, agencies were asked to respond if they would be attending so that the proper amount of training materials would be available.

Research Procedures

The research team briefed the officers on the events and activities that lead to this meeting. After the opening remarks were concluded, the participating officers were randomly divided into three groups, which would be put through different scenarios to test the usefulness of the new form versus the old form and the value of training officers to use the new form.

The meeting consisted of two sessions; the morning session was a "paper and pencil" session where the officers were given a fictitious crash scenario (See Appendix D) and were then asked to complete a crash report. The first group of the groups chosen in the morning session, which was called the red group, served as a control group and filled out the current or old form. The second group, which was called the white group, filled out the new form but received no training prior to filling out the form. While the 
third group, which was called the blue group, received 15 minutes of training prior to filling out the new form (See Table 2). Each of the groups was allowed 30 minutes to fill out the form that they had been given. Immediately after completing his/her form the participant was given a survey instrument with which he/she could evaluate the form the officer had just completed (See Appendix D).

Table 2. West Virginia Uniform Traffic Crash Report Mock Crash Session Survey Summary Key

\begin{tabular}{ll}
\multicolumn{1}{c}{ Summary Key } \\
\hline AM Session: $\quad$ Paper and Pencil Scenario \\
Red Group = Control Group (Old Form) \\
White Group = New Form with No Training \\
Blue Group = New Form with 15 Minute Training Period \\
All Groups Surveyed \\
Mock Crash Investigation \\
Red Group = New Form with No Training \\
White Group = New Form with 15 Minute Training Period \\
Blue Group = Control Group (Old Form) \\
All Groups Surveyed \\
All Participants Debriefed \\
Participants Dismissed
\end{tabular}

In the afternoon session, the three groups were asked to investigate one of the three comparable (simulated) crashes and fill out a crash report (See Appendix E). Each group had its own individual mock crash site to investigate and collected information from volunteer drivers as they would under actual crash conditions. As in the morning 
session, each group was allowed 30 minutes to complete the investigation. In the afternoon session the red group, which served as the control group in the morning session, filled out the new form without prior training. The white group, as they had done in the morning session, filled out the new form. However, in the afternoon session the white group received 15 minutes of training prior to filling out the new form. The blue group, acting as the control group, filled out the old form in the afternoon session. In the afternoon session there was no true control group because the blue group had been exposed to the new form in the morning session. The research team was aware this confound existed but felt that it was important that all of the participants fill out the new form. As in the morning session, each participant was given a survey instrument with which he/she could evaluate the form the officer had just completed (See Appendix E).

Once the surveys were completed the officers participated in a thorough debriefing session where they gave the project team feedback on the day's activities. This session lasted approximately 45 minutes. After the debriefing session was completed, the meeting was adjourned and the officers were free to leave.

\section{Pilot Test Methodology}

The fourth phase of the research was to conduct a 60-day pilot test. The new crash form was field-tested from December 1, 1995 to January 31, 1996 to allow law enforcement officers to fill out the new traffic crash form when investigating actual crash occurrences. Taking the input from the mock crash session, the research team developed a pilot test form.

Subject Selection 
Three agencies participated in the 60-day pilot test. The West Virginia DoH approved the particular agencies that were volunteers for the research project, the Bridgeport Detachment of the West Virginia State Police, Mineral County Sheriff's Department, and the Charleston Police Department. The agencies were carefully chosen so that various aspects of the agencies would be represented. First, each represented an agency from one of the three levels of the law enforcement hierarchy: state, county and local.

Second, the participating agencies were geographically dispersed throughout the state. The Bridgeport Detachment was located in north-central West Virginia, the Mineral County Sheriff's Department was located in the state's eastern panhandle, and the Charleston Police Department was located in southern West Virginia.

Third, each of the participating agencies varied in size. The Bridgeport Detachment was a mid-size detachment with ten to fifteen troopers working at that location. The Mineral County Sheriff's Department was located in a large county; however, the County Sheriff's Department was small with five officers including the sheriff. The Charleston Police Department was the largest local police department in the state with ninety-five officers.

Research Procedures

Each of the participating agencies was given two hours of training prior to using the new form (See Appendix F). The West Virginia University research team trained the participating officers from the Bridgeport Detachment of the West Virginia State Police and the Mineral County Sheriff's Department. Due to the large number of officers 
participating in the field test, the Charleston Police Department requested that the project team train only the department's in-house trainers who in turn would train each of the officers participating in the field test. A field test-training manual was developed at WVU and given to each of the participating agencies for their use during the period of field-testing (See Appendix F). Although the participants were retrained on how to fill out the entire form, the emphasis was on the new or modified elements, changes in layout and design, and the like (See Appendix G). A period of question and answer followed each training session. After completion of the sixty-day pilot test, officers from the three participating agencies completed a 16-question survey instrument to evaluate the form (See Appendix H).

\section{Quality Control Methodology}

After the Uniform Traffic Crash Report had been used by law enforcement for approximately one year, the research team initiated a quality control phase as the final step of the research. This quality control phase many times is lost in the research process. The research team began executing a quality control plan to ensure that (1) residual training deficiencies were identified and met; (2) any lingering problems with the crash form itself were identified and addressed; (3) the changes in the data collection process in the future, particularly technology improvements, were still closely linked to the officers who continue to be the originators of the data and recorded for transmittal to DoH for future form change consideration.

\section{Subject Selection}

In scheduling the quality control meetings, the research team decided that a 
representative sample of regional agencies would be invited to attend a short quality control session. The sampling scheme involved (1) dividing the state into five general regions (See Table 3), (2) selecting three representative agencies within those regions based on population, (3) and selecting agencies based on information obtained from yearly crash reports supplied by the DoH and the WV DPS. Agencies in areas with poorer crash records were afforded higher likelihood of selection.

Research Procedures

The research team briefed the officers on the events and activities that lead to this meeting. After the opening remarks were concluded, the participating officers completed a written survey instrument of 25 questions (See Appendix I).

The literature reviewed showed that since the early 1960's there have been many federal and state initiatives to improve the collection and the evaluation of crash data. The Intermodal Surface Transportation Efficiency Act of 1991 mandated that states develop a safety management system. TEA-21 of 1998 reinforced this effort by providing grants to the states for the improvement of the collection of traffic crash data. However, many states failed in their efforts because of poor planning. One effort that was successful was the West Virginia Form Revision Project. The literature revealed that the West Virginia project team developed a needs assessment model that served as a foundation for their successful revision of their uniform crash report. 
Table 3. Quality Control Group Regional Session: Date and Attendance

\begin{tabular}{|c|c|c|c|c|}
\hline NORTHERN & CENTRAL & WESTERN & SOUTHERN & EASTERN \\
\hline $11 / 6 / 97$ & $11 / 7 / 97$ & $10 / 17 / 97$ & $10 / 16 / 97$ & $10 / 30 / 97$ \\
\hline \multicolumn{5}{|l|}{ Population $2200-5 \mathrm{~K}$} \\
\hline Follansbee & Weston & Ripley & Madison & Charleston \\
\hline Westover & Philippi & Pt. Pleasant & Lewisburg & Petersburg \\
\hline Wellsburg & Shinnston & Spencer & & \\
\hline \multicolumn{5}{|l|}{$\underline{\text { Population 5-10K }}$} \\
\hline Grafton & Bridgeport & Dunbar & Princeton & Keyser \\
\hline New Martinsville & Buchannon & Nitro & Oak Hill & \\
\hline \multicolumn{5}{|l|}{ Population $10-25 \mathrm{~K}$} \\
\hline Fairmont & Clarksburg & Vienna & Beckley & Martinsburg \\
\hline Weirton & & & So. Charleston & \\
\hline \multicolumn{5}{|l|}{ Population $25-50 \mathrm{~K}$} \\
\hline Morgantown & & Parkersburg & & \\
\hline \multicolumn{5}{|l|}{ Wheeling } \\
\hline \multicolumn{5}{|l|}{$\underline{\text { WVDPS }} \underline{50 \mathrm{~K}+}$} \\
\hline Monongalia/Marion & Bridgeport & Charleston & Logan & Martinsburg \\
\hline Ohio & Lewis & Huntington & Monroe & Elkins \\
\hline Marshall & Gilmer & $\underline{\text { DPS }}$ & Raleigh & Jefferson Co. \\
\hline Brooke & Richie & Kanawha & Mercer & Pochohontas Co. \\
\hline & & Wood & & (Bridgeport DPS) \\
\hline \multicolumn{5}{|l|}{$\underline{\text { Counties }}$} \\
\hline Monongalia & Harrison & Wayne/Lincoln & Raleigh & Mineral \\
\hline Ohio & Lewis & Kanawha & Mercer & Berkeley \\
\hline \multirow[t]{3}{*}{ Marion (Alt.) } & Doddridge & Counties & Fayette & Jefferson \\
\hline & & Cabell & Logan & Randolph \\
\hline & & Wood & & \\
\hline
\end{tabular}




\section{CHAPTER FOUR}

\section{Focus Group Results}

In most cases, enforcement officers do not have much choice about data elements because these are generally established by the State or Federal government. However, the focus groups revealed that the officers pointed out how to make logical flow and legibility improvements, which type faces to use, which local agency options to have, and even how to make the finished documents easier to file and proof-read at local departments.

Each focus group discussed the current form and its real in-the-field weaknesses or strengths, and then brainstormed ideas on how to improve it. I found the focus groups yielded the following results to the research team: (1) Thirteen area groups met between August 1995 and February 1996. (2) A total of 143 of the 272 officers invited attended the focus group meetings for a response rate of 52\%. (3) Eighty-eight percent of the focus group officers thought the "team approach" would yield a better reporting form than one developed without officers' input. (4) Over 400 identifiable responses and 100 unique alterations were generated during the 13 sessions that were reduced to 25 , nonoverlapping, unique changes that were incorporated into the new draft form (See

Appendix J). (5) The appropriate duration of the 13 focus group meetings was two hours.

Some of the most reoccurring responses of the focus group meetings were: (1) Adding name of insurance agent, phone number and insurance policy number; (2) Adding driver and witness phone numbers and zip codes; (3) Adjust passive restraint 
systems (air bag and seat belt information); (4) Delete cost of damage.

Among general results of the focus group meetings, I observed that the focus groups were adamant about making the revised form as "self-coding" as possible so that training requirements would be minimal and bulky codebooks would not be necessary to fill out the form. The draft form became "intuitive". The focus groups were cautious about going immediately to full automation (laptop computers) and approved a more intermediate move to machine scoring (optical scanning) instead (See Appendix K).

\section{Telephone Survey Results}

The SRC staff contacted more than $50 \%$ of the state's 272 law enforcement agencies and interviewed officers who regularly filled out the UTCR form. The operators made 150 calls and conducted 122 interviews for an $81.3 \%$ response rate. Some researchers believe a telephone response rate of $70-75 \%$ is adequate (Frey, 1989) while others consider $80-85 \%$ to be optimal (Dillman, 1978). The response rates for this survey were considered very good by the Survey Research Center at West Virginia University.

Sixty-seven (56\%) of the responses were municipal (town or city) agencies, twenty-seven (22\%) were County Sheriffs' offices, and twenty-eight (23\%) were State Police detachments. Fifty-eight (48\%) of the agencies, considered small agencies, had fewer than six officers; forty-six (38\%) of the agencies, considered mid size agencies, had between six and fifteen officers, and sixteen (13\%) of the agencies considered large agencies, had sixteen or more officers. Table 4 presents the relationship between the type of agency and the number of officers serving the departments. 
Table 4. Telephone Survey Agency /Officer Demographic

\begin{tabular}{lcccc}
\hline $\begin{array}{l}\text { Number of } \\
\text { Officers }\end{array}$ & Municipal & Sheriffs' & State Police & \\
$1-5$ & $35(52 \%)$ & $7(27 \%)$ & $16(59 \%)$ & $58(48 \%)$ \\
$6-15$ & $24(36 \%)$ & $12(46 \%)$ & $10(37 \%)$ & $46(38 \%)$ \\
16 or more & $8(12 \%)$ & $7(27 \%)$ & $1(4 \%)$ & $16(14 \%)$ \\
$\mathrm{n}=$ & $67(56 \%)$ & $26(22 \%)$ & $27(22 \%)$ & $120(100 \%)$ \\
Note: & read down for percent within enforcement agency type \\
\hline
\end{tabular}

I found that the telephone survey yielded the following results to the research team: (1) Nearly one-third of these agencies reported that completion of the crash report form typically required about 20 minutes, and half of the agencies reported that they routinely completed the forms in about half-an-hour. (2) Almost one-third reported that filling out crash forms originally required an hour or more time to finish the task. (3) The mean reported time used to fill out the UTCR form was 51 minutes. (4) The average number of crashes an agency reported monthly was about 20-25, amounting to almost one report a day. Smaller agencies, particularly small municipal departments, reported fewer crashes than state police detachments. (5) The sixteen largest departments (approximately $20 \%$ of all agencies) produced $62 \%$ of the estimated crash reports over a three-month period of time.

Additionally, $89 \%$ of the agencies surveyed reported sending some proportion of UTCR forms to the Department of Motor Vehicles. Over one third also reported sending completed UTCR forms to the DoH; almost all stated that this was done when there was 
damage to DoH property, and as crashes occurred. Local agencies were most likely to report sending completed UTCR forms to the DoH.

About one third of agencies surveyed reported the use of computers. Use did not vary greatly by type of agency. It did, however, seem to be directly related to size of agency. Eighty-one percent of large agencies reported the use of computers, one third of the mid-size agencies reported the use of computers, and sixteen percent of the smaller agencies reported the use of computers. While about $60 \%$ of the respondents estimated that it took seven days or fewer to send a completed data form to the $\mathrm{DoH}$, some agencies reported that it took as much as 90 days.

Forty-two responding agencies reported that they share traffic information with other agencies. County Sheriffs' offices were most likely to report sharing information, followed by local, then State Police agencies. Mid-sized agencies were most likely to report sharing information, followed by large agencies, then small agencies. Only four agencies, (all with over fifty officers) reported that they entered the old form information via keyboard and had computers that were networked with other agencies.

Results of the survey show that a prevailing concern deals with the amount of effort given to reporting crash investigation information. This particularly focused on the ease of producing or assigning correct and useful information as well as conveniences of consistent formatting to provide officers with routine efficiency in the disposition of the report itself. Concerns about the transfer and storage of information involved administrative decisions that reflected consistent and complete reporting during the investigation of a crash. 
About three-fourths of the officers' surveyed expressed surprise that they were contacted about pending changes regarding the old form. The results of the telephone survey bolstered and extended the Phase I focus group meetings, added to the research team's understanding of problems and possible solutions with the new draft form.

\section{Mock Crash Results}

In the third phase of the research, 35 of the 95 officers invited attended a one-day mock crash session at the West Virginia University Coliseum in Morgantown, WV. This was a response rate of $37 \%$ for the mock crash participants. The 35 participating officers represented 17 departments and state police detachments throughout West Virginia.

I found the officers surveyed at the mock crash meeting said that the new form would take less time to fill out after they achieved a certain level of proficiency and experience. The results of Question 11 revealed there were no significant differences on the forms efforts between the "no training" and "minimal training" groups. I concluded that the new crash form was, indeed, "self-coding" (See Appendix L). The officers concluded in Question 6 of the Mock Crash Survey, that the new form was clearly superior to the old form in collecting adequate data for reconstruction of crashes (See Appendix L). The officers indicated that the new form took less time to complete. The officers were also pleased with the graphic redesign of the form and said that it would be easier for them to read in poor light or inclement weather.

Because the "no training" and "minimal training" groups had similar overall results, I concluded that the new crash form could be trained in one or two short training sessions. All of the officers, in both the morning and afternoon sessions, declared in 
Question 5 of the Mock Crash Survey, that the new form showed more "user friendliness" than the old form and that the legibility of the new form was improved over the old form (See Appendix L). Over 85 percent of all mock crash participants gave a strong overall endorsement of the new crash form, with average completion times about 42 minutes with little or no practice.

\section{Pilot Test Results}

Following the 60-day field test period the research team debriefed and surveyed each of the participating agencies. The research team held a question and answer session about their experiences with the new crash form. One hundred ten officers participated in the field-testing, however, 52 surveys were returned for a response rate of $47 \%$. All the participants from Bridgeport (10) and Mineral County (5) responded to the survey, which was administered by the project team. Thirty-seven of the 95 officers from the Charleston Police Department, who actively participated in the field test, responded in to the survey.

Upon reviewing the 60-day field test survey, I noted these findings: (1) Eightyone percent of the officers stated, in Question 8 of the Pilot Test Survey, that the new crash form "flowed" in a more logical order than the old crash form (See Appendix M). (2) As with the mock crash tests, the logical order responses were encouraging because the "order of flow" was purposely implemented based on focus group input. (3) The officers felt several blocks on the old form that had been expanded after Phase I and II input made the form easier to use on the new form (Vehicle Identification Number and Social Security Number, for example). (4) Forty of the 52 officers responding to the 
pilot test survey stated that the new form now provided enough space for the officers to write in "local option" information when necessary. (5) The municipal police department gave the highest approval in this area. This was information, such as the location where a car might be towed, was used locally but was of no interest to state agencies. (6) Overall, almost 75\% of the officers, answered in Question 15 of the Pilot Test Survey, were satisfied with the legibility of the new form (See Appendix M).

This percentage was very encouraging considering that the team integrated one other complete supplemental form, and had also added seven new (federal government mandated) data elements by this time. The font was selected for ease of legibility and most of the form is in 5-point type, which is actually larger than many current forms used by WV enforcement. The survey concluded in Question 16, of the Pilot Test Survey, $73 \%$ of the officers' thought the new crash form was improved and the integrity of the old form had been retained (See Appendix M). While field test officers felt the new crash form was harder to use for the first two or three weeks, they universally agreed that the new crash form was easier to use with time.

\section{Quality Control Results}

In the final phase of the research a quality control plan was executed to ensure that 1) residual training deficiencies were identified and met and 2) any lingering problems with the crash form itself were identified and recorded for transmittal to $\mathrm{DoH}$ for future form-change consideration. A total of 110 officers were invited by letter to attend, of those, 40 officers participated in five quality control meetings scheduled and held in the following locations (See Table 5). 
Table 5. Quality Control Meetings Dates and Locations

\begin{tabular}{llc}
\hline Date & Location & Region \\
November 6 & Morgantown & I \\
October 17 & Charleston & II \\
October 16 & Beckley & III \\
November 7 & Weston & IV \\
October 30 & Elkins & V \\
\hline
\end{tabular}

Participants were surveyed at each session and then debriefed (See Appendix I).

In the first area of the quality control phase (finding training needs not yet met by the research team), the quality control sessions found that the Raleigh County Sheriff's Office had not been trained but attended the meeting, so the research team coordinated a training session for that agency. The minor training and logistic needs of some agencies were identified and met by other agencies attending. Agencies planned to offer local training service to the agency in need.

During my review of the results, I noted that some form-change problems were identified during the quality control sessions. First, participants at all five sessions requested that under "had a collision with" DoH might consider adding a new element to read "other vehicle stopped in traffic" to account for the ambiguity of the striking vehicle rear-ending another stopped motor vehicle. The closest element that officers can currently choose is "parked motor vehicle", which is inaccurate because the stopped vehicle is in a traffic lane, and "stopped in traffic lane" falls under "non-collision" events. At the suggestion of the officers, forms would be completed in the interim for 
such a crash, "other non-fixed object", plus they filled in the oval for "rear-end" (under "manner of collision") as was specified in training, and further clarified the potentially ambiguous event in the narrative. Coders, therefore, would be notified to look at "manner of collision" if the sequence of events is unclear and might suggest a rear-end crash.

Second, three sessions' participating officers were happy that a scale of reference for the drawing was provided by the research team, however, all of them were not happy with the fact that the drawing seemed to require a scale of 1:20. Most preferred "not drawn to scale" as an option because a scaled drawing took twice as much time to prepare for many of the officers. The research team suggested putting the following text in the same position as the current "scale: 1 inch $=20$ feet":

Scale: 1 inch $=20$ feet (with oval)

Scale: 1 inch $=16$ feet $($ with oval)

Not drawn to scale (with oval)

Third, two sessions' participants requested that in the right upper corner of page two the research team switched the placement of "on pavement or ___ feet" with " $\mathrm{N}-\mathrm{E}$ $-\mathrm{S}-\mathrm{W}$ " in order to give more space to write the number of feet.

A significant comment that had first surfaced during the training months before resurfaced at the quality control sessions. Officers across the state expressed continual interest in being kept informed on a regular basis of how they could obtain updated expert information about their own computer and software systems. 


\section{CHAPTER FIVE}

\section{Conclusions and Recommendations}

Most federal, state, and local agencies use information derived from traffic crash reports for decision- making purposes. The accuracy and timeliness of this data is vital to safety program managers and traffic engineers. The purpose of this study was to assess improvements in the crash data process and examine the impact of the research assessment model developed by the West Virginia University Project Research Team on the West Virginia Uniform Traffic Crash Report.

A telephone survey was developed by the West Virginia University Department of Safety and Environmental Management (SEM) and administered by the WVU Survey Research Center to assess problem areas with the current crash form and suggest areas for improvement. Data was also collected 60 days after full implementation of the crash form in three sites around the state.

Based on careful planning and the data collected from the focus groups, telephone surveys, mock crash meeting, 60-day pilot test, and quality control meetings, the research team felt justified in calling the new form a success. Collectively, the survey data suggested that the new form was user friendly, that the officers felt they were involved in the decision making process, and that, with time and experience, the new crash form will take less time to fill out than the old form.

Using continuous improvement, the stepwise progression of activities necessary to update the crash form was carefully planned and executed in order to build upon the findings of each previous phase. In Phases I and II, format and flow for the new crash form were determined by a representative group of actual users. These activities helped 
establish a level of trust that carried the rest of the revision process. In Phase I, the focus groups were important on two levels. First the focus groups established a "buy-in" with the West Virginia law enforcement community, by including them in the form revision process, meeting them in their own towns and cities and on their own terms was something other states did not do. This inclusion had a rippling affect. Officers at all levels were enthusiastic about being a part of the form revision process. Second, it was important to elicit the opinions of law enforcement, the initial generators of crash information, about their likes and dislikes of the existing form. The protocol for each session allowed law enforcement to develop a consensus about the new information that should be added and how the new form's elements should be sequenced and created the solid foundation for the remaining phases of the project. The costs and time associated with conducting the focus groups were greatly offset by the years of better data accuracy and completeness.

The second phase of the model was the telephone survey. The purpose of the telephone survey was to contact agencies that did not have the opportunity to attend the focus groups; many of these agencies had 10 or fewer officers. Phase II continued to seek a consensus about the make up of the new form as well as developing good will with law enforcement. Additionally, the telephone survey queried law enforcement about issues such as computer capabilities, training needs, form completion times, form completion rates, and agencies ability to share information with other agencies. None of the findings from Phase I and II were being considered prior to the beginning of the 
project, however due to the systematic nature of the model, many of the suggestions helped lay the foundation for the draft form developed and tested in Phase III.

Phase III was a key part of the model. Before putting the new form in use under actual conditions, controlled tests were held on mock wrecks, which helped further refine the form. Testing the form under controlled conditions allowed law enforcement to provide immediate feedback about problem areas on the new draft form. Because the data collection process was dynamic and not static, continuous improvement of the new form resulted in approximately forty iterations. Deficiencies were corrected and subtle changes were made before field-testing the form under actual conditions. Than and only then in Phase IV, was the form released to officers who used the form to record important data on actual crashes. I observed that by testing the form under controlled conditions validated the flow, sequencing, and new elements added to the form. The requirement for minimal training was also validated in Phase III. If a huge training effort was necessary, the probability increased that the new form would have not have been used by law enforcement.

In Phase IV, the form was tested under actual conditions. This phase, in many ways, was a continuation of Phase III. Law enforcement provided information about minor deficiencies on the form, which was encountered in the controlled tests. Through the continuous improvement approach of the model, most of these deficiencies were identified in earlier phases making corrections and improvements a simple process.

Phase V was dedicated to quality control. This phase was another important part of the model. While often overlooked by other states, the quality control initiative in 
West Virginia revisited the form after being in use for one year. The quality control initiative was executed to ensure that any lingering training deficiencies were identified and met; any residual problems with the form itself were identified and corrected; and that any future changes in the collection process were transmitted to law enforcement. The quality phase of the model served as the capstone of the project. This phase allowed the project team a final query of law enforcement ensuring them that all deficiencies had been resolved and that they were delivering a quality product.

In summary, I would make the following recommendations to other state agencies that wish to improve their crash data. I concluded that the West Virginia research team was successful because of the model. The research team recognized how important the step-wide progression and the continuous improvement features of the model were for developing a reliable crash data collection form. I concluded that the model was a very systematic and repeatable tool. States that wish to improve their crash data could use all or any portion of the model. The model was designed to meet the needs of the user. My research suggested that people were important to the model, when considering how to improve crash data forms. The process that was used to design and implement the model was focused on the needs of the data generator, law enforcement, who is originator of crash data information used by data customers. By focusing on the needs of the data generator, crash collection forms would be given a better chance to succeed. A crash form produced by a programmer or traffic safety engineer, would not identify with an officer who was sitting in a cruiser with an injured baby or standing in snowstorm while trying to fill out tiny boxes on a data form. A crash form that was 
designed for the ease of the data generator will also provide the coders and data customers with clear and more conclusive data than a form that does not address the data generator's needs.

I would recommend the model as a valuable tool not only to law enforcement who supply timely data to their state, but to agencies who are interested in researching how to link their crash data reports to workers' compensation, personnel files, state and federal agencies, EMS stations, hospitals, insurance agencies.

In conclusion, the West Virginia Research Team conducted this project as an "action research study". Further research could be more statistically based, testing the reliability of the survey instrument using an ANOVA, comparing the treatments, within groups or between groups, for correlations between measures. 
Bibliography List

Bitner, L. (2000). [Unpublished Survey Regarding Commercial Carrier Information] West Virginia Public Services Commission. Charleston, WV. Unpublished raw data.

Blair, Bruce R. (1997). GIS and GPS: Emerging Technologies in Law Enforcement. Montgomery County Department of Police, Rockville, Maryland.

CDC/National Highway Traffic Safety Administration (1992). Position papers from the Third National Injury Control Conference, setting the national agenda for injury control in the 1990s. Washington, DC, US Department of Health and Human Services, Public Health Service, CDC.

Center for Disease Control and Prevention (1999). Achievements in Public Health, 19001999 Motor-Vehicle Safety: A $20^{\text {th }}$ Century Public Health Achievement. Morbidity and Mortality Weekly Report, 369-374.

Cherry, Andrew L. Jr., A Research Primer for the Helping Professions, Methods, Statistics, and Writing. Wadsworth/Thomson Learning, 2000.

Committee on Injury Prevention and Control, Institute of Medicine (1999). Reducing the Burden of Injury: Advancing Prevention and Treatment. Washington, DC, National Academy Press.

Council, F.M. (1988). Selection of Participating States for the Highway Safety Information System, Task C Technical Memo. Highway Safety Research Center, University of North Carolina. 
Davises, P., et. al.(1991). Assessment of Advance Technologies for Relieving Urban Traffic Congestion, NCHRP Report 340, Transportation Research Board, Washington, DC.

Dillman, Don A. Mail and Telephone Surveys, the Total Design Method, Wiley and Sons, Inc., New York, NY.

Federal Highway Administration, Washington, D.C. (1990). Guidebook for the Michigan State Data Files. Highway Safety Research Center, University of North Carolina.

Federal Register: July 28, 1999 Uniform Procedures for State Highway Safety Programs. Volume 64, Number 144, 40757-40764.

Frey, James. 1989, Survey, Research by Telephone, $2^{\text {nd }}$ Edition, Sage Publishing, Newberry Park, CA.

Glasmer, Deeann (1996). Police Speed on Data Highway, Traffic Safety, National Safety Council, Itasca, EL. (September/October).

Graham, JD (1993). Injuries from Traffic Crashes: Meeting the Challenge. Ann Rev Public Health 14:515-43.

Heath, W.M. (1991). California Tank Truck Crash Survey, February 1, 1980 to January 31,1981. California Highway Patrol, Enforcement Services Division (December).

Highway Safety Act of 1966 (1998). 23 USC Chapter 4 Revision (June). 
Highway TechNet (1996/1997). Advanced law Enforcement Response Technology (ALERT) Vehicle, Improving Law Enforcement with Advanced Technology. (On line) Available: http://www.ota.fhwa.gov//featproj/fp te037.html.

Hughes, Warren, et. al. (1992). New and Emerging Technologies for Crash Collection, Federal Highway Administration, FHWA-RD 92-097, Washington, DC.

Intermodal Surface Transportation Efficiency Act of 1991.

Iowa Department of Transportation (1994). National Model Prospectus.

Johnson, S.W., VanSciver, E. (1991). Sensitivity Index Demonstration Project, National Association of Governors Highway Safety Representatives, supported by a grant from NHTSA.

Kentucky State Police (2001). CRASH (Collision Report Analysis for Safer Highways), International Association of Chiefs of Police Technology Clearinghouse (April). (Online). Available: http://www.state.ky.us/agencies/ksp/ksphome.htm

Ludwick, J.S., Jr. (1980). Comparison of Three Loran Position Determination Techniques in the Los Angeles Area. Transportation Research Record 770, Transportation Research Board, National Academy of Sciences, Washington, DC. 29-34.

Michigan State Police, Division of Traffic Records (2001). Automated Incident Capture System, International Association of Chiefs of Police Technology Clearinghouse. (July) (On-line). Available: http://www.iacptechnology.org/Programs/AutomateMSP.htm

National Association of Governor's Highway Safety Representatives (1995). Final Report: Strategic Planning Meeting on CODES and Data Linkage (August). 
National Association of Governor's Highway Safety Representatives (1998). Model

Minimum Uniform Crash Criteria, Improving Crash Data for Safer Roadways (August).

National Association of Governor's Highway Safety Representatives (2001). Taking the

Temperature of TEA-21 An Evaluation and Prescription for Safety Executive Summary (July).

National Center for Injury Prevention and Control, CDC (1997). Prevention of Motor Vehicle Related Injuries: A Compendium of Articles from the Morbidity and Morality Weekly Report, 1985-1996. Atlanta, Georgia: US Department of Health and Human Services, CDC.

National Automotive Sampling System (NASS) (1999). History of the National Automotive Sampling System. (July) (On-line). Available: http://wwwnass.nhtsa.dot.gov/NASS/99NASSHistory.html

National Highway Traffic Safety Administration, Home Page (2001). (February). (Online). Available: http://www.nhtsa.dot.gov

National Highway Traffic Safety Administration, (1996). CODES, What is CODES?

(July) (On-line). Available: http://www.nhtsa.dot.gov/people/ncsa/codes/codes2.htm

National Highway Traffic Safety Administration (2001). Fatality Analysis Reporting System (FARS), (On-line). Available: http://www.nhtsa.dot.gov/people/ncsa/fars.html

National Safety Council (1998). Accident Facts, 1998 Editions. Itasca, Illinois: National Safety Council.

National Transportation Library (1991). Intermodal Surface Transportation Efficiency Act Summary. 
National Traffic and Motor Vehicle Safety Act (1966)

O'Day, James, (1991). Data Quality, Transportation Research Board, NCHRP Synthesis 192, Washington, DC.

Rice, D.P., MacKenzie, E.J., Jones, A.S., et al (1989). The Cost of Injury in the United States: A Report to Congress. San Francisco, California: University of California, Institute of Health and Aging; Johns Hopkins University, Injury Prevention Center.

Sleet, D.A., Bonze, S., Branche, C. (1998) An overview of the National Center for Injury Prevention and Control at the Centers for Disease Control and Prevention. Injury Prevention. 4:308-12.

The Urban Transportation Monitor (1991) Dallas Transit Agency to Use GPS Vehicle Tracking System.

Thornton, C. (1999) [Unpublished Survey Regarding the West Virginia Crash Reporting System]. Federal Motor Carrier Safety Administration, Charleston, WV. Unpublished raw data.

Transportation Equity Act, TEA-21, Moving Americans into the $21^{\text {st }}$ Century. (2001) (July) (On-line). Available: http://www.fhwa.dot.gov/tea21/

Transportation Research Board (1990). Safety Research for a Changing Highway Environment. Washington, DC: National Research Council, Transportation Research Board. Special Report No. 229.

U.S. Department of Transportation, Home Page (2001). (On-line). Available: http://www.dot.gov 
U. S. Department of Transportation, Federal Highway Administration Home Page (2001). (July) (On-line). Available: http://www.fhwa.dot.gov

U.S. Department of Transportation, Federal Motor Carrier Safety Administration (2001) (May) (On-line). Available: http://www.fmcsa.dot.gov

U.S. Department of Transportation, Motor Carrier Safety Assistance Program, 2001 (OnLine), Available: http://www.usdot.fmcsa.gov/safetyprogs/mcsap.html

U.S. Department of Transportation, National Highway Traffic Safety Administration 1991). Assessing State Crash Data Using SAS. National Center for Statistics and Analysis.

Winn, G., Carr, M., and Bucy, D. (1997) Accident/Injury Database Linking Assessment

Report. Department of Safety and Environmental Management, West Virginia University.

Winn, G., Bucy, D., and Klishis, M. (1997) Forms and Functions. American Society for Industrial Security.

Wisconsin Department of Transportation (2001) Accident Record Keeping Program:

Division of Motor Vehicles. WISDOT (May) (On-line). Available:

http://danenet.wicip.org/wisms/orgs/arkpdomv.htm 
APPENDICES 
APPENDIX A: West Virginia Uniform Traffic Crash Report

Days and Locations of Focus Group User Input Meetings 
West Virginia Uniform Traffic Crash Report

Days and Locations of User Input Meetings
Date

August 8, 1994

August 27, 1994

August 28, 1994

September 13, 1994

September 20, 1994

October 7, 1994

October 21, 1994

October 27, 1994

November 4, 1994

November 15, 1994

November 15, 1994

December 14, 1994

February 15, 1995
Location

Morgantown

Beckley

Huntington

Morgantown

Clarksburg

Parkersburg

Keyser

Martinsburg

Logan

Weirton

Wheeling

Pt. Pleasant

Charleston 
APPENDIX B: West Virginia Uniform Traffic Crash Report Focus Group Protocol 


\section{West Virginia Uniform Traffic Crash Report \\ Focus Group Meetings Protocol and Methods}

Today's Topic: "What do you like and dislike about current UTCR?

Rules for Brainstorming

1. Everyone suggests something

2. No ideas will be rejected

3. No deep discussion; keep comments form specific (3 minutes)

4. No prioritization given to any idea

5. Each idea will be numbered for simplicity, not for priority

Introduction (.5 Hour)

All participants introduced and put at ease

WVU project staff relates history of form and project

Outline of day's complete activities presented

Brainstorming (1 Hour)

All ideas acceptable

All participants suggest something

Ideas unranked 


\section{West Virginia Uniform Traffic Crash Report \\ Focus Group Meetings Protocol and Methods (Continued)}

Local officer selected as moderator

Moderator lists ideas on easel

WVU Project Staff plays "background" role

Evaluation (1 Hour)

All ideas numbered accordingly

Similar ideas clustered

Impractical ideas eliminated

Each officer has 5 votes

Each can vote for 1 major interest or use 5 votes for 5 lesser interests

Moderator tabulates responses

Moderator rank-orders and lists all clusters in order

WVU project staff records responses

Final de-brief

Adjourn 
APPENDIX C: West Virginia Uniform Traffic Crash Report Telephone Survey 


\section{West Virginia Uniform Traffic Crash Report Telephone Survey}

\section{PART 1}

My name is and I'm calling from the Survey Research Center at West Virginia University. We are conducting a survey of West Virginia law enforcement agencies to gather their recommendations for modifications to the Uniform Traffic Accident Report. Information we collect from your organization and others will be summarized and presented to the Division of Highways and the Department of Transportation Division of Motor Vehicles to assist them in creating a new, more streamlined form. We are interested in talking to someone in your organization who investigates traffic accidents...would that be you, or do we need to speak to another person?

If The person answe-ed lile phores: Would you be willing to take a few minutes to give me some suggestions concerning the Uniform Traffic Accident Report?

Jf no one s avadilatelet: I'd like to call back at a better time. What do you think would be a good time for me to try again?

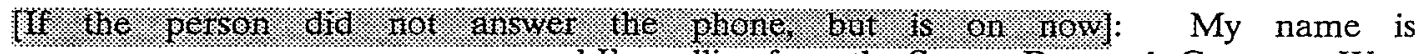
and I'm calling from the Survey Research Center at West "ginia University. We are conducting a survey of West Virginia law enforcement agencies lv gather their recommendations for modifications to the Uniform Traffic Accident Report. Information we collect from your organization and others will be summarized and presented to the Division of Highways and the Department of Transportation Division of Motor Vehicles to assist them in creating a new, more streamlined form. Would you be willing to take a few minutes to give me some suggestions concerning the Uniform Traffic Accident Report?

Before we begin, let me tell you that your participation in this survey is voluntary and your responses are confidential. If there are any questions you do not want to answer, let me know and we will move on to the next one. Do you have any questions? 


\section{West Virginia Uniform Traffic Crash Report Telephone Survey}

(Continued)

B. "re we begin, let me tell you that your participation in this survey is voluntary and your responses are confidential. If there are any questions you do not want to answer, let me know and we will move on to the next one. Do you have any questions?

7) How many total Uniform Traffic Accident Reports are completed by all those in your organization in a 90 day period?

8) What percent or proportion of that number would you say are sent to the Division of Motor Vehicles?

9) How often does your organization send completed Uniform Traffic Accident Reports to the Div. of Motor Vehicles? Are they sent.... MWER. RFAD OPTIONS:

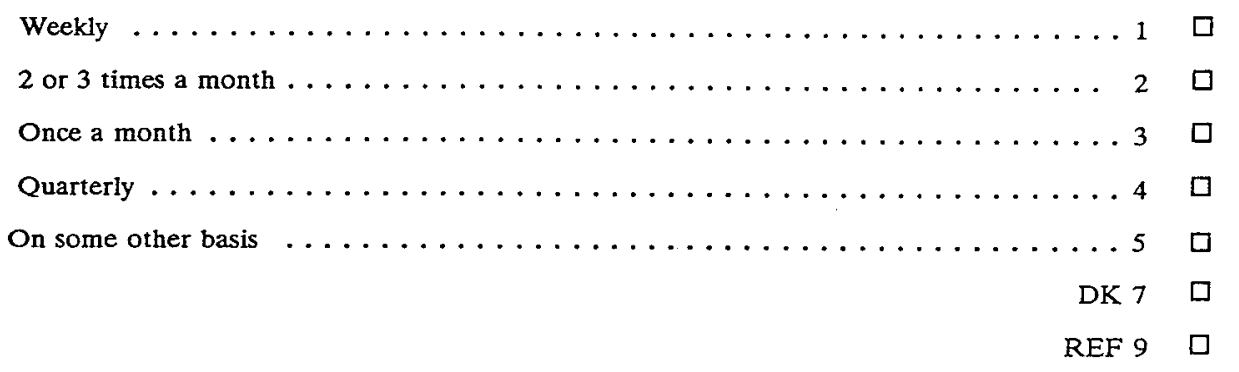

10) In what form, or by what means are Uniform Traffic Accident Reports sent to the

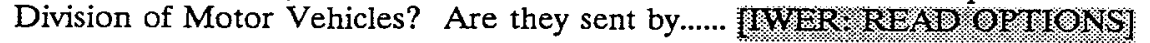

Mail $\ldots \ldots \ldots \ldots \ldots \ldots \ldots \ldots \ldots \ldots \ldots \ldots \ldots \ldots \ldots \ldots \ldots \ldots \ldots \ldots \ldots$

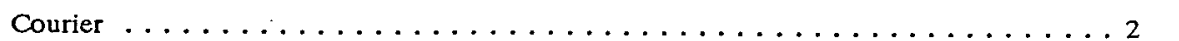

Electronic Transfer . . . . . . . . . . . . . . . . . . . . 3

Other $\ldots \ldots \ldots \ldots \ldots \ldots \ldots \ldots \ldots \ldots \ldots \ldots \ldots$

DK 7 口

REF $9 \square$

11) How long would you say it takes, on average, from the time an accident is investigated, for the completed Uniform Traffic Accident Report to reach the Division of Motor Vehicles? 


\section{West Virginia Uniform Traffic Crash Report Telephone Survey}

(Continued)

First, I would like to ask a couple of questions about your organization in general.

1) How many officers are there in your office or department?

2) How many of those officers regularly fill out the Uniform Traffic Accident Report?

3) How long would you say it takes, on average, to complete the Uniform Traffic Accident Report?

4) Now I am going to mention several items that have already been identified as possible data element additions to the Uniform Traffic Accident Report. As I read each one, please tell me whether you agree or disagree that the item should be added. The first item is.............

Agree Disagree $\begin{gathered}\text { No } \\ \text { Opinion/ } \\ \text { DK }\end{gathered}$ Refused

a) Vehicle Color

b) SS \#'s of operators

c) Space for information about photos or videos

$\begin{array}{llll}1 & 2 & 7 & 9 \\ 1 & 2 & 7 & 9 \\ 1 & 2 & 7 & 9 \\ & & & \\ 1 & 2 & 7 & 9 \\ 1 & 2 & 7 & 9\end{array}$
of accident scene

d) Insurance policy numbers

e) Telephone \#s of operators

5) Now, I am going to mention several possible physical changes to the Uniform Traffic Accident Report. As I read each statement, please tell me whether agree or disagree with the proposed changes.

a) The first page of the form should have a carbon copy to

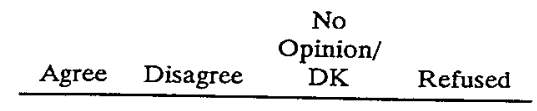
ease driver exchange of information.

b) The space provided for a diagram should be larger.

c) The Vehicle Information Number Block should be larger

$\begin{array}{llll}1 & 2 & 7 & 9 \\ 1 & 2 & 7 & 9 \\ 1 & 2 & 7 & 9\end{array}$




\section{West Virginia Uniform Traffic Crash Report Telephone Survey \\ (Continued)}

\section{$\underline{\text { PART } 3}$}

We would like to ask just a few questions concerning the computers at your organization. Are you familiar with the computer equipment your agency uses, or would we need to speak with another person?

If a aex persen is now on the plane........My name is and I'm calling from the Survey Research Center at West Virginia University. We are conducting a survey of West Virginia law enforcement agencies to gather their recommendations for modifications to the Uniform Traffic Accident Report. Information we collect from your organization and others will be summarized and presented to the Division of Highways and the Department of Transportation Division of Motor Vehicles to assist them in creating a new, more streamlined form. We would like to ask a few questions regarding record keeping by computer in your organization. Would you be able to answer a few questions for us?

Before we begin, let me tell you that your participation in this survey is voluntary and your responses are confidential. If there are any questions you do not want to answer, let me know and we will move on to the next one. Do you have any questions? 


\section{West Virginia Uniform Traffic Crash Report Telephone Survey}

(Continued)

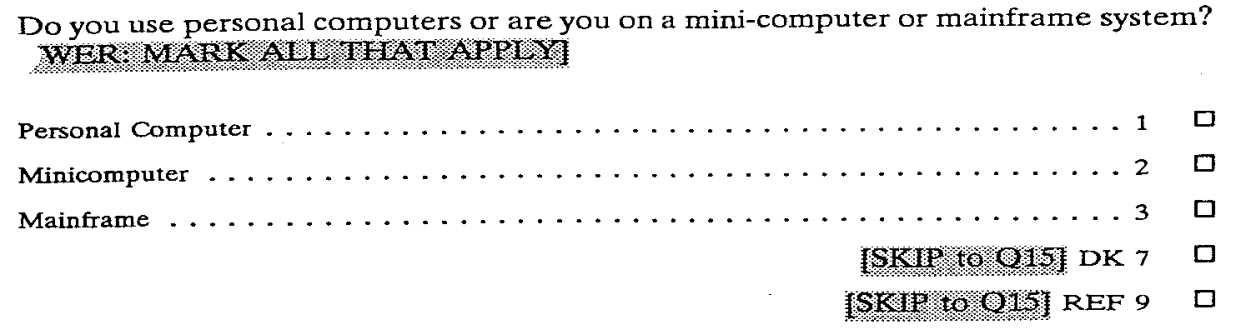

(Is/Are) your computer(s) DOS-based, UNIX-based, do you use a MAC, or is there some other operating system?

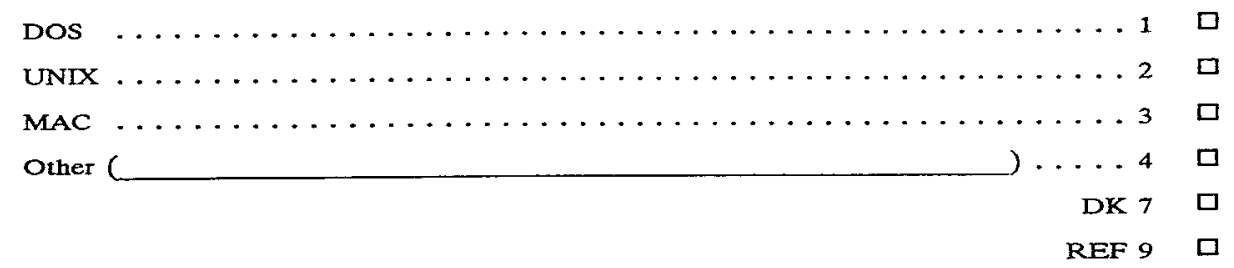

What software packages do you use for record management, tracking violations or case management?

Do you enter information from the Uniform Traffic Accident Report onto a computer system?

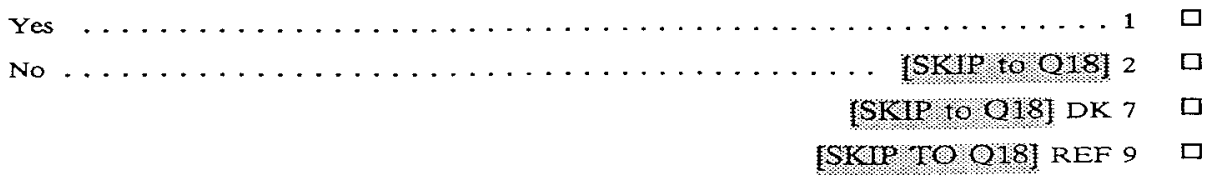




\section{West Virginia Uniform Traffic Crash Report Telephone Survey}

(Continued)

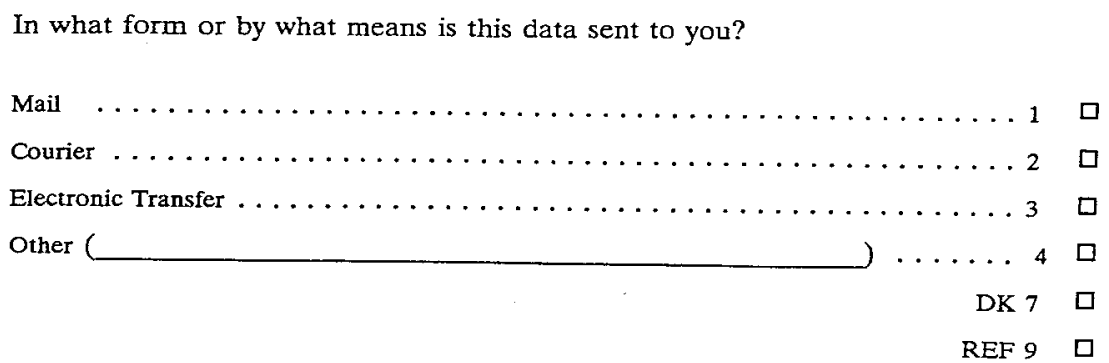

Those are all the questions I have for you. Thank you very much for your time. 
APPENDIX D: Morning Mock Crash Session Crash Scenario and Survey 


\section{Morning Mock Crash Session Crash Scenario and Survey Morning Traffic Crash Session Crash Scenario}

On Friday, October 20, 1995, at approximately 4:30 p.m., Jan T. was driving her blue 1988 Chevrolet Blazer, her 5-year-old daughter, Daisee T. (who lives with her mother), being the only passenger. They were traveling south on WV Route 16 approximately 3 miles south of Oak Hill, WV, in Fayette County, 1 mile north of the intersection with WV Route 61. At this time, Mrs. T. attempted to adjust the harness on her daughter's safety seat, which was located in the adjacent front outside passenger seat. While looking away and driving straight ahead, she ran off the right shoulder of the roadway and subsequently struck a utility pole with the right front fender.

At approximately 4:45 p.m., law enforcement authorities were notified, with the first officer arriving at the scene at approximately 4:50 p.m. The officer found that Mrs. T. and her daughter was uninjured although an EMS unit arrived at the scene. The officer determined that Mrs. T. was not under the influence of drugs or alcohol and she was wearing her seatbelt. There were not airbags equipped in the vehicle, no one was trapped or ejected, and there was no evidence of fire or hazardous cargo.

Upon the officer's inspection of the car, it was found that the car's right front fender was creased. The vehicle's frame was not damaged and the car was drivable. The utility pole, which was owned by American Electric Power at Route 16 Beckley, WV, had to be replaced. The pole was located ten feet from the right west shoulder of the roadway. 


\section{Morning Mock Crash Session Crash Scenario and Survey Morning Traffic Crash Session Crash Scenario \\ (Continued)}

WV Route 16 is a clearly marked, two-lane black top road with a posted $55 \mathrm{mph}$ speed limit. The portion of the roadway where Mrs. T. lost control of her vehicle was a sharp, level left-hand turn. The pavement was dry and the weather conditions were clear and cool. There was not type of traffic control in this area. There were no witnesses to the accident and no videos were taken, but the investigating officer did take photos of the accident scene.

Driver One's Statement

My daughter and I were traveling south on Route 16 at a speed of about 45-mph. I looked over and noticed that the harness on my daughter's safety seat was loose. As I reached over to try and adjust it, I took my eyes off the road for a second and before I knew it, my car ran off the right side of the road and hit the utility pole.

Jan T.'s Home Phone Number: (304) 555-5555

Jan T.'s Work Phone Number: (304) 555-5555 
Morning Mock Crash Session Crash Scenario and Survey

Morning Traffic Crash Session Crash Scenario

(Continued)
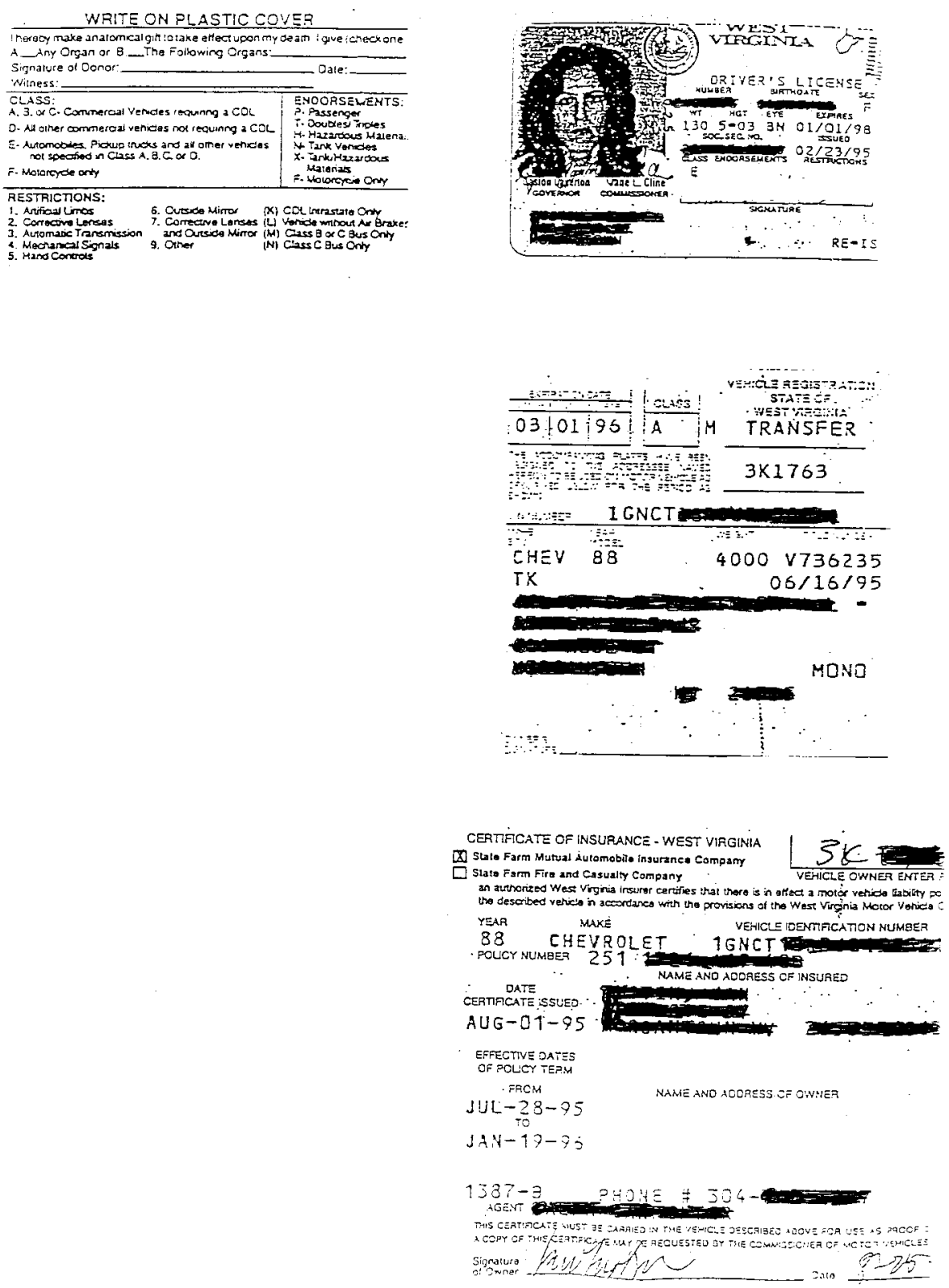


\section{Morning Mock Crash Session Crash Scenario and Survey Morning Mock Crash Session Crash Survey}

1. How do you compare your test form today with the one you are used to filling out?

___ Simpler to fill out Harder to fill out Same to fill out Other (please comment)

2. How much time do you think it took to fill out the form compared with the form you usually use?

Less time to fill out

More time to fill out

Same amount of time to fill out

Other (please comment)

3. The following three data elements seem easier to use than on the form I usually use:

a.

b.

c.

4. The following three data items seem harder to use than on the form I usually use:
a.
b.
c. 


\section{Morning Mock Crash Session Crash Scenario and Survey Morning Mock Crash Session Crash Survey \\ (Continued)}

5. Do you feel the form you filled out today is "user friendly"? What makes it that way, or not that way?

- Yes

No

Other (please comment)

6. Do you feel the form you filled out today collects enough information to adequately investigate and/or reconstruct an accident?

Yes
$\ldots \_$No
__ Other (please comment)

7. Does the form you filled out today flow in a logical order?

-_ Yes

__ No

___ Other (please comment)

8. Was there enough space allocated when information was required to be handwritten in boxes or on lines?

Yes

No

Other (please comment) 


\section{Morning Mock Crash Session Crash Scenario and Survey Morning Mock Crash Session Crash Survey \\ (Continued)}

9. How did you rate the legibility of the form you filled out today?

Easy to read

Hard to read

Did not notice

Other (please comment)

10. Is the meaning of each element on the form you just filled out clear and concise or did the information require you to think about what data is being sought? Yes; clear meaning

No; some elements not clear Other (please comment)

11. How do you compare your test form today with the one you normally fill out? Circle one

$\begin{array}{ccccccc}1 & 2 & 3 & 4 & 5 & 6 & 7 \\ \text { Much } & \text { Worse } & \text { Slightly } & \text { No } & \text { Slightly } & \text { Improved } & \text { Greatly } \\ \text { Worse } & & \text { Worse } & \text { Difference } & \text { Improved } & & \text { Improved }\end{array}$

12. Do you feel the form you filled out today is "user friendly"? Circle one

$\begin{array}{ccccccc}1 & 2 & 3 & 4 & 5 & 6 & 7 \\ \text { Much } & \text { Worse } & \text { Slightly } & \text { No } & \text { Slightly } & \text { Improved } & \text { Greatly } \\ \text { Worse } & & \text { Worse } & \text { Difference } & \text { Improved } & & \text { Improved }\end{array}$




\section{Morning Mock Crash Session Crash Scenario and Survey Morning Mock Crash Session Crash Survey \\ (Continued)}

13. How did you rate the legibility of the form you just filled out today? Circle one

$\begin{array}{ccccccc}1 & 2 & 3 & 4 & 5 & 6 & 7 \\ \text { Much } & \text { Worse } & \text { Slightly } & \text { No } & \text { Slightly } & \text { Improved } & \text { Greatly } \\ \text { Worse } & & \text { Worse } & \text { Difference } & \text { Improved } & & \text { Improved }\end{array}$

14. Compared to the old form how do you rate the new form? Circle one

$\begin{array}{ccccccc}1 & 2 & 3 & 4 & 5 & 6 & 7 \\ \text { Much } & \text { Worse } & \text { Slightly } & \text { No } & \text { Slightly } & \text { Improved } & \text { Greatly } \\ \text { Worse } & & \text { Worse } & \text { Difference } & \text { Improved } & & \text { Improved }\end{array}$

Survey Summary Key

Morning Session: $\quad$ Red Group = Control Group (Old Form)

White Group = New Form with No Training

Blue Group = New Form with 15 Minute Training Period

Afternoon Session: $\quad$ Red Group $=$ New Form with No Training

White Group $=$ New Form with 15 Minute Training Period

Blue Group = Control Group (Old Form) 
APPENDIX E: Afternoon Mock Crash Session Crash Scenario and Survey 


\section{Afternoon Mock Crash Session Crash Scenario and Survey Afternoon Traffic Crash Session Crash Scenario}

\section{Driver \#1}

The following are facts about your alleged actions as the driver of vehicle \#1 involved in this crash simulation. The subjects (police officers) will question you on these facts and maybe other facts that are not listed clearly here. Please develop your statements to the subjects from the given facts, however, if the absence of certain information forces you to improvise, please be consistent with your statements from subject to subject because the experimental data recorded on the form must also be consistent.

The facts as you perceive them are as follows:

- You were traveling north, straight ahead, at approximately $55 \mathrm{mph}$.

- Immediately before the crash, you turned to look at a road map.

- The next recollection you had is that you hit another car head on.

- Your neck is sore as a result of the crash.

- You were not sleepy, ill or drinking while you were driving.

- You have not been taking medication recently.

- You had no passengers with you.

- You exited your vehicle under your own power. 


\section{Afternoon Mock Crash Session Crash Scenario and Survey Afternoon Traffic Crash Session Crash Scenario \\ (Continued)}

- After getting out of your vehicle, you noticed that you had crossed the centerline, which must have happened while you were looking at the map, therefore, hitting vehicle \#2 traveling in the opposite direction.

\section{Driver \#2}

The following are facts about your alleged actions as the driver of vehicle \#2 involved in this crash simulation. The subjects (police officers) will question you on these facts and maybe other facts that are not listed clearly here. Please develop your statements to the subjects from the given facts, however, if the absence of certain information forces you to improvise, please be consistent with your statements from subject to subject because the experimental data recorded on the form must also be consistent.

The facts as you perceive them are as follows:

- You were traveling south, straight ahead, at approximately $45 \mathrm{mph}$.

- You entered a sharp left-hand torn.

- In the middle of the turn, a northbound vehicle crossed the centerline and, before you could take action, struck your vehicle heal-on.

- Your legs, especially your knees, are sore as a result from the crash 


\section{Afternoon Mock Crash Session Crash Scenario and Survey \\ Afternoon Mock Crash Session Crash Scenario \\ (Continued)}

- You were not sleepy, ill or drinking while you were driving.

- You have not been taking medication recently.

- You had no passengers with you.

- You exited your vehicle under your own power.

For the purpose of the following accident simulation, please play the role of an investigating officer. Listed below is important accident information which cannot easily be simulated but which is necessary to fill out the form. Please fill out the crash form as fully and completely as possible. Because no accident simulation is a perfect recreation, we must ask of you:

1. No discussion with each other outside of the given facts.

2 No questions for the research team after the investigation starts.

3. Use your current skills in any judgment call.

4. Work individually even if your partner is in your group.

The facts of the crash are as follows:

- The crash occurred at 12:30 p.m. today

- $\quad$ You were notified at 12:35 p.m. 


\section{Afternoon Mock Crash Session Crash Scenario and Survey \\ Afternoon Mock Crash Session Crash Scenario \\ (Continued)}

- Crash occurred on WV Route 73 in Monongalia County

- $\quad$ Posted Speed Limit: $55 \mathrm{mph}$

- $\quad$ Occurred 6 miles south of Morgantown

- Vehicle 1 - Northbound, crossed over the centerline in the middle of a right-

hand, level turn

- $\quad$ Vehicle 2 - Southbound, was struck head-on by Vehicle 1

- $\quad$ There were not witnesses

- No roadway damage or other property damage

- No files

- No hazardous cargo

- No alcohol or drug involvement 


\section{Afternoon Mock Crash Session Crash Scenario and Survey Afternoon Mock Crash Session Crash Survey}

1. How do you compare your test form today with the one you are used to filling out?

___ Simpler to fill out

Harder to fill out

Same to fill out

Other (please comment)

2. How much time do you think it took to fill out the form compared with the form you usually use?

Less time to fill out

More time to fill out

Same amount of time to fill out

Other (please comment)

3. The following three data elements seem easier to use than on the form I usually use:
a.
b.
c.

4. The following three data items seem harder to use than on the form I usually use:
a.
b.
c. 


\section{Afternoon Mock Crash Session Crash Scenario and Survey \\ Afternoon Mock Crash Session Crash Survey \\ (Continued)}

5. Do you feel the form you filled out today is "user friendly"? What makes it that way, or not that way?

___ Yes

No

Other (please comment)

6. Do you feel the form you filled out today collects enough information to adequately investigate and/or reconstruct an accident?

__ Yes

No

Other (please comment)

7. Does the form you filled out today flow in a logical order?

Yes

No

Other (please comment)

8. Was there enough space allocated when information was required to be handwritten in boxes or on lines?

Yes

No

Other (please comment) 


\section{Afternoon Mock Crash Session Crash Scenario and Survey \\ Afternoon Mock Crash Session Crash Survey \\ (Continued)}

9. How did you rate the legibility of the form you filled out today?

Easy to read

Hard to read

Did not notice

Other (please comment)

10. Is the meaning of each element on the form you just filled out clear and concise or did the information require you to think about what data is being sought? Yes; clear meaning

No; some elements not clear

Other (please comment)

11. How do you compare your test form today with the one you normally fill out?

Circle one

$\begin{array}{ccccccc}1 & 2 & 3 & 4 & 5 & 6 & 7 \\ \text { Much } & \text { Worse } & \text { Slightly } & \text { No } & \text { Slightly } & \text { Improved } & \text { Greatly } \\ \text { Worse } & & \text { Worse } & \text { Difference } & \text { Improved } & & \text { Improved }\end{array}$

12. Do you feel the form you filled out today is "user friendly"? Circle one

$\begin{array}{ccccccc}1 & 2 & 3 & 4 & 5 & 6 & 7 \\ \text { Much } & \text { Worse } & \text { Slightly } & \text { No } & \text { Slightly } & \text { Improved } & \text { Greatly } \\ \text { Worse } & & \text { Worse } & \text { Difference } & \text { Improved } & & \text { Improved }\end{array}$




\section{Afternoon Mock Crash Session Crash Scenario and Survey \\ Afternoon Mock Crash Session Crash Survey \\ (Continued)}

13. How did you rate the legibility of the form you just filled out today? Circle one

$\begin{array}{ccccccc}1 & 2 & 3 & 4 & 5 & 6 & 7 \\ \text { Much } & \text { Worse } & \text { Slightly } & \text { No } & \text { Slightly } & \text { Improved } & \text { Greatly } \\ \text { Worse } & & \text { Worse } & \text { Difference } & \text { Improved } & & \text { Improved }\end{array}$

14. Compared to the old form how do you rate the new form? Circle one

$\begin{array}{ccccccc}1 & 2 & 3 & 4 & 5 & 6 & 7 \\ \text { Much } & \text { Worse } & \text { Slightly } & \text { No } & \text { Slightly } & \text { Improved } & \text { Greatly } \\ \text { Worse } & & \text { Worse } & \text { Difference } & \text { Improved } & & \text { Improved }\end{array}$

Survey Summary Key

Morning Session: $\quad$ Red Group = Control Group (Old Form)

White Group = New Form with No Training

Blue Group $=$ New Form with 15 Minute Training Period

Afternoon Session: $\quad$ Red Group $=$ New Form with No Training

White Group $=$ New Form with 15 Minute Training Period

Blue Group $=$ Control Group (Old Form) 
APPENDIX F: West Virginia Uniform Traffic Crash Report Training Materials 
West Virginia Uniform Traffic Crash Report Training Materials

Department of Safety \& Environmental Management

Vest Virginia University

College of Engineering and Mineral Resources

ENFORCEMENT ORIENTATION AND TRAINING SESSION WEST VIRGINIA TRAFFIC CRASH FORM, 1997 REVISION

WVU, DEPARTMENT OF SAFETY AND ENVIRONMENTAL MANAGEMENT WV DOT, DIVISION OF HIGHWAYS, TRAFFIC ENGINEERING

MEETNG AGENDA

1. WELCOME AND INTRODUCTION OF ALL PARTICIPANTS

1.1 CIRCULATE PARTICIPANT ROSTER

2. BACKGROUND FOR NEW CRASH FORM TRAINING

2.1 WHY WE'RE DOING THIS IN THE FIRST PLACE (NGA; NHTSA)

2.2 TIME LINE: NOW UNTIL DECEMBER, 1997

2.3 3 PHASES: SUPER TRAINERS (AREA TRAINER-ORGANIZERS)

TRAINERS (LOCAL)

TRAINEES (MAY BE NEW RECRUTTS OR REFRESHER)

3. THINGS YOU NEED TO DO EACH TIME CRASH FORM TRAINING IS SCHEDULED

4. GETTING INSIDE THE TRAINER MANUAL

4.1 TRAINER NOTES, MATERIALS, LAYOUT OF THE MANUAL

4.2 THE VALUE OF THE APPENDICES

4.3 THE "GRA YED OUT" FORM; THE "BOX NUMBERED" FORM

4.4 THE COMMERCIAL CARRIER MATERIAL

5. GETTING INSIDE THE PARTICIPANT (TRAINEE) MANUAL

6. THE NEW FORM AND THE NEW MATERIAL

7. QUESTIONS AND ANSWER PERIOD

8. ADJOURN

304 293-2742 O FAX 304 293-5708 o 341 COMER 8uilding O PO BOX 6070 a MORGANTOWN WV 26506-6070

Equal Opportunity/ Affirmative Action Institution 


\section{West Virginia Uniform Traffic Crash Report Training Materials}

\section{(Continued)}

\section{Introduction}

The following information is presented as background for trainers in introducing the form revision process and the new form itself. Trainers should feel free to read this page or a summary of it to officers before training commences. This information will provide a foundation for the training of the new crash form and may answer many of the questions you will encounter later.

Highlights of the process of revising the crash form:

- The revision process began as a committed, joint effort among the West Virginia Division of Highways, local enforcement agencies, the West Virginia State Police, and West Virginia University, plus a number of computer experts, out-of-state enforcement agencies, and the federal government.

- This was a carefully planned, carefully executed, carefully controlled process.

- One full year was dedicated to taking input from local enforcement around the state. Every issue from those meetings was addressed by a panel. Both West Virginia University and the

Division of Highways tried very hard to meet the concerns of officers from all parts of the state.

- The new crash form was intensely tested on paper and by telephone surveys, then tested further in mock-crashes and pilot tested on real crashes at three locations around the state.

- All the commercial vehicle data elements have been included in the new crash form, eliminat ing the commercial vehicle supplement. And sixteen new, federally-required, elements have been integrated into the new form.

- While the form has many new elements, it was designed to be entirely self-coding, eliminating the need for a codebook or code reference sheet, and about 50 percent of the new crash form is scannable by computer.

- The FARS supplement was also modified during the course of this project to coordinate the collection of fatality data with the new form and the scannable format being developed.

- About 69 percent of the new crash form's data elements are either entirely new or have been changed in some way without changing the familiar look of the old form. For example, effort was made to maintain the logical flow of information in the new form, similar to the old form.

- While the strengths of the old form have been retained, our survey results showed that the new form is even more user-friendly, takes a bit less time to fill out, and prevents mistakes which lead to less supervisor time spent editing crash forms.

- Bottom line: the new form should make your work easier and improve the "time value" of crash data to all data customers.

The project sponsors and research team remain fully committed to more efficient enforcement, more efficient data collection, and making this ongoing process a continued success for all citizens in West Virginia. The training materials which follow will help you fulfill this commitment to a better, safer West Virginia by making basic data collection faster, less expensive, and more reliable than ever. 


\section{West Virginia Uniform Traffic Crash Report Training Materials}

\section{(Continued)}

\section{Notes to the Trainer}

What This Trainer Manual Contains:

Included in this manual are materials to facilitate training the new crash form. Each area is broken up into modules (small units) so trainers can choose to train the form all at one sitting, or in blocks of modules, or even one module at a time (at roll call, for example). For your convenience, we have designed a self-test and answer key which can be found in appendix B. For further clarifications regarding accident investigations please refer to the West Virginia Motor Vehicle Laws Section: Chapter 17C, Article 4, Section 4.1-4.16.

\section{Time Requirements:}

The time requirements to complete training of the new form will vary with the demands of each agency. It is suggested that a block of 3.5 hours be designated to successfully complete the training requirements for new recruits. Time commitments will be somewhat less for experienced officers.

Materials Required:

Suggested materials required to successfully complete the training of the new form are:

- the Trainer Manual

- Participant Manuals

- the Commercial Carrier Training Video

- the overhead transparencies

- photocopies of the new form

- photocopies of "box-numbered" new forms.

Audio/Visual Requirements:

The audio/visual equipment required to successfully complete training is:

- overhead projector

- viewing screen

- television and VCR (if video is used)

- chalk board and chalk

- flip chart and pens

(While all of the training mediation aids listed above may be used, the minimum requirement is an overhead projector and screen.)

\section{Suggested Room Layout:}

The project team understands that the room layout used for new form training will vary greatly. However, trainers should select a horseshoe or standard classroom layout if possible and should avoid any circular class layouts. Trainers should provide desks with writing surfaces available (desk or table) and absolute minimal distances from student to screen because the crash form boxes and spaces, when projected, are small to begin with. 


\section{West Virginia Uniform Traffic Crash Report Training Materials \\ (Continued)}

\section{Overhead Transparencies:}

Appendix A includes the transparencies recommended to complete this training. These can be used to create handouts for students as needed. Instructors should note that these materials are designed to completely and fully train the new traffic crash form, which replaces the Uniform Traffic Accident Form in 1997. Because much of this material is not new to experienced officers, a template for locating only the new or changed data elements is found as Appendix A, and is grayscreened to save time for experienced officers. New recruits or persons not current on the new form should choose to read the whole manual and ignore the gray-screen in Appendix A.

\section{The Format of This Manual}

The Trainer Manual is organized such that each data element is described by a working definition, and is followed by a "cut out" of the actual blank box where the information will be found, and also the same box filled in with sample, fictitious data. For example, refer to the following box in which the officer lists the number of occupants in the second vehicle involved in the crash.

BOX \#53: Total Occupants of This Vehicle

The total number of persons, including the driver occupying the vehicle at the time of the crash.

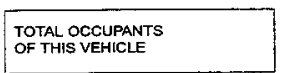

\begin{tabular}{|l|l}
\hline TOTAL OCCUPANTS \\
OF THIS VEHICLE
\end{tabular}

At times, a given box can be filled in more than one way, and in that case more than one example is provided. See the following.

Box \#11: Crash Occurred on: Route 1

If the crash occurred on a numbered route; write in the full route number, which may include such designations as Alternate (Alt.), Alternate Southbound (Alt. S.) or Spur. If the crash occurred at an intersection, the number of the major route would be written in here.

\begin{tabular}{|c|c|}
\hline $\begin{array}{c}\text { CRASH } \\
\text { OCCURRED } \\
\text { ON }\end{array}$ & ROUTE 1 \\
\hline
\end{tabular}

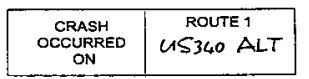

Or,

If the numbered route also has a name, enter both

\begin{tabular}{|c|c|}
\hline $\begin{array}{c}\text { CRAASH } \\
\text { OCCURRED } \\
\text { ON }\end{array}$ & ROUTE 1 \\
CAS Go \\
\hline
\end{tabular}

Or WASHINGTON STR.

Or,

If the crash occurred on a road with no route number, enter the name of the road or street, as follows:

\begin{tabular}{|c|c|}
\hline $\begin{array}{c}\text { CRASH } \\
\text { OCCURRED } \\
\text { ON }\end{array}$ & ROUTE 9 \\
\hline
\end{tabular}

or JACKSON STR.


West Virginia Uniform Traffic Crash Report Training Materials

\section{(Continued)}

\section{Sequencing This Course}

When you begin training, and for ease and clarity, trainers should start training participants in the following sequence:

- SIDE 1 of the New Form (page 1) (beginning with "Location"), top to bottom, then

- SIDE 2 of the New Form (page 1) (beginning with "Property Damage Other Than Other Vehicles"), top to bottom, then

- SIDE 3 of the New Form (page 2) (beginning with "Narrative"), top to bottom (not addressed in this manual: local agency discretion), then

- SIDE 4 of the New Form (page 2) (beginning with "Diagram")(not addressed in this manual: local agency discretion).

Trainers should proceed through this course from SIDE 1 to SIDE 2 to SIDE 3 to SIDE 4 in sequence. Officers experienced with filling out SIDES 3 and 4 (narrative and diagram) will find that the only change is the addition of a legend: $1 "=20 \mathrm{ft}$., as this was a very popular request by officers during the focus group meetings.

\section{Notes About "Filling in" vs "Writing in"}

Please note the following general instructions to participants:

- Write in means to print numbers and/or letters in the space provided. Do not use check marks or " $\mathrm{x}$ " marks.

- Fill in means to shade or darken the oval corresponding to the desired information. Do not use check marks or " $x$ " marks in this case.

\section{A Word About Size of the Examples in This Manual}

Trainers will note that some examples which follow in the manual will seem larger than the type size of the form itself. The authors felt that the examples would be easier to read if the type was enlarged slightly but if there are questions, the authors suggest the use of overhead masters of the new crash form in the background for constant reference. The WVU research team apologizes in advance for any difficulties this may cause trainers or participants. 
West Virginia Uniform Traffic Crash Report Training Materials

\section{(Continued)}

\section{One Thing To Anticipate When Training and Using the New Crash Form...}

Based on 150 surveys of individual enforcement officers who have used the new crash form in mock crashes ( 30 officers) and in two months of real-life crashes (120 officers) we are well aware that the new crash form takes longer to fill out at least in the beginning. In debriefing these officers carefully, the reasons seem clear that there seems to be a steep learning curve taking more time to complete the new crash form, more time to refer to new definitions, and more time to correct mistakes.

- First, there are more items to fill out. Sixty-nine percent of the elements on the new crash form are either modified or are totally new items.

- Second, the number of blocks on the form has increased 21 percent (from 99 blocks to 126 blocks).

- Third, in eliminating one supplemental form entirely (the Commercial Carrier form), the elements from the old supplement were merged with the new crash form.

Experienced trainers, however, tell us that time improves performance with the new crash form and that once an officer has used the new form and is past the leaming curve efficiency improves. Not only that, we found out in talking to shift supervisors that there is even less time expended correcting errors. Experienced veterans have expressed to us both in their surveys and also orally that the new crash form is not really harder to fill out or more time consuming than was the old crash form after they learned it for the first time. Our surveys also suggest that, with increasing experience, time requirements decrease to fill out the new crash form and the numbering errors drops. Like any other skill, such as even a sports skill which can be developed to a high degree, good performance:

- takes time to develop

- needs frequent feedback by supervisors

- requires many opportunities to perform the new skill. 
West Virginia Uniform Traffic Crash Report Training Materials

(Continued)

\section{A Note on Commercial Carriers}

In 1992 the National Governor's Association released a set of data elements which would soon be required by law to be collected by state traffic enforcement officers. These data were collected on a supplementary data form between 1993 and 1997, but are now included, verbatim on the new revised crash form. If a trainer wishes to train on only these data elements, this Trainer Manual has been arranged to accommodate this. In this case, trainers should select for use:

- Commercial Carrier section of the Trainer Manual, with definitions

- Commercial Carrier overheads

- Commercial Carrier Trainer Videos

- APPENDIX B: Commercial Carrier Data Elements, even though these data elements are technically not new.

- APPENDIX D: Commercial Carrier Self-Test and Answer Key 
APPENDIX G: West Virginia Uniform Traffic Crash Report Pilot Instrument 
West Virginia Uniform Traffic Crash Report Pilot Instrument

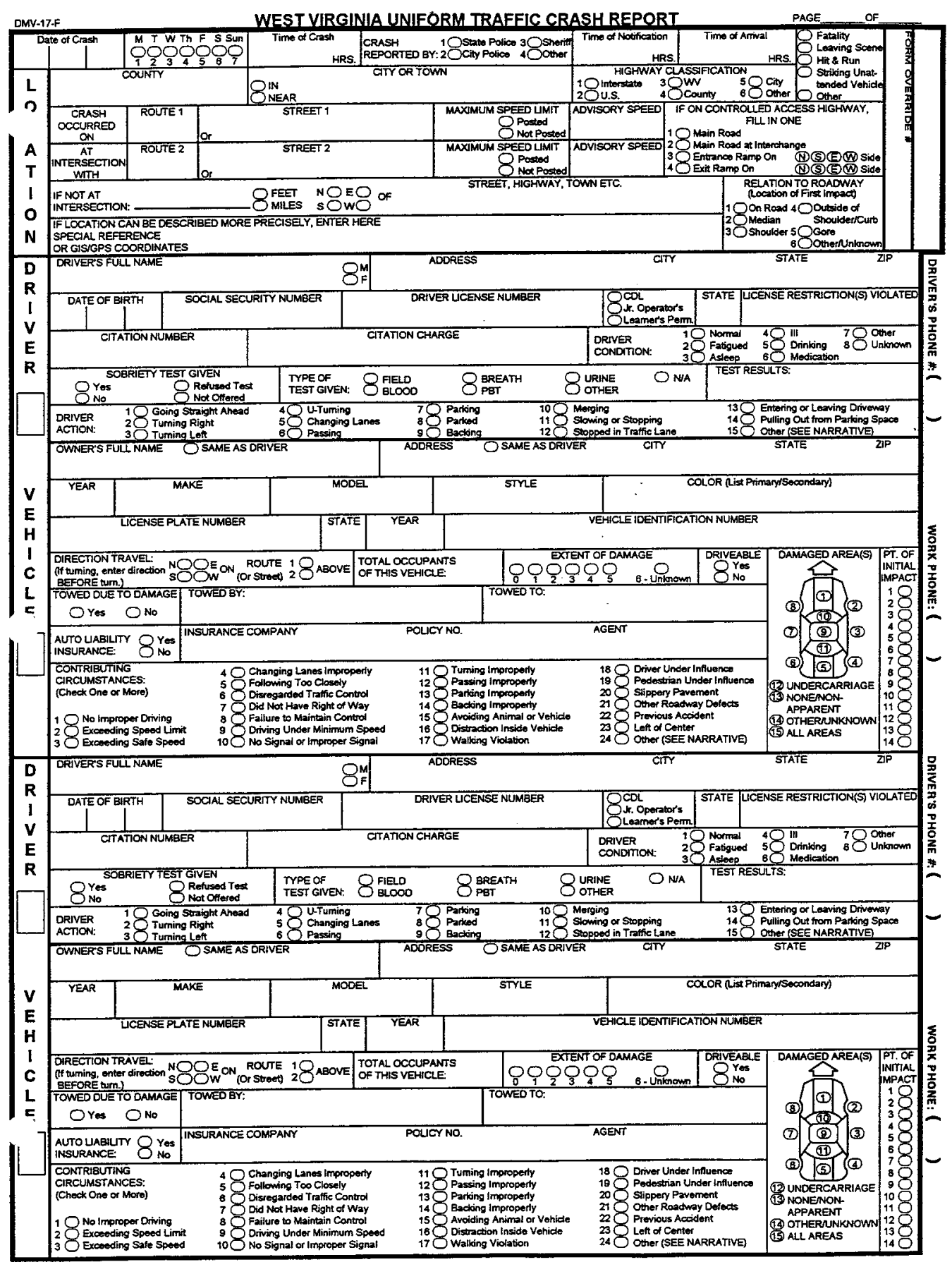


West Virginia Uniform Traffic Crash Report Pilot Instrument

(Continued)

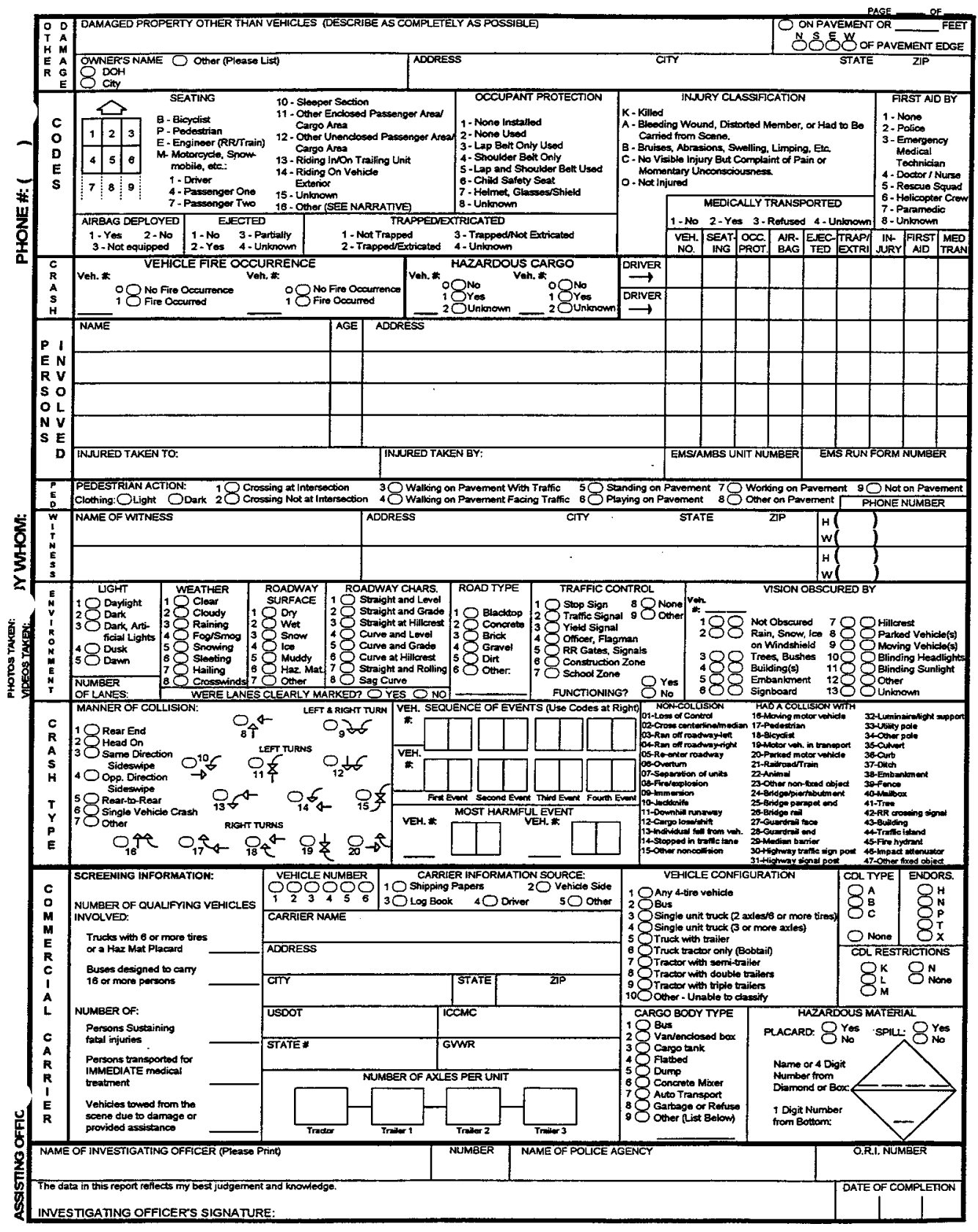


West Virginia Uniform Traffic Crash Report Pilot Instrument (Continued)

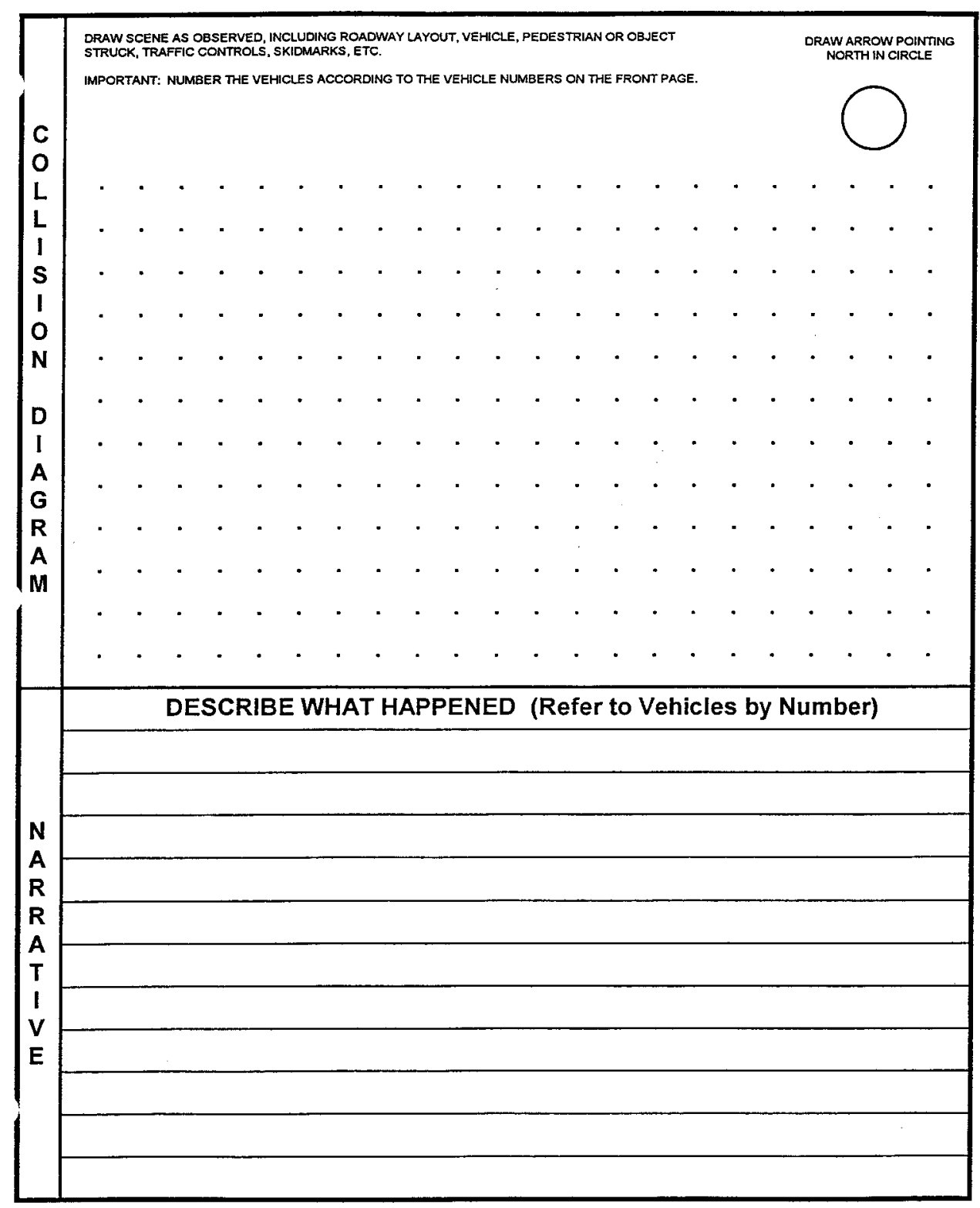


West Virginia Uniform Traffic Crash Report Pilot Instrument

(Continued)

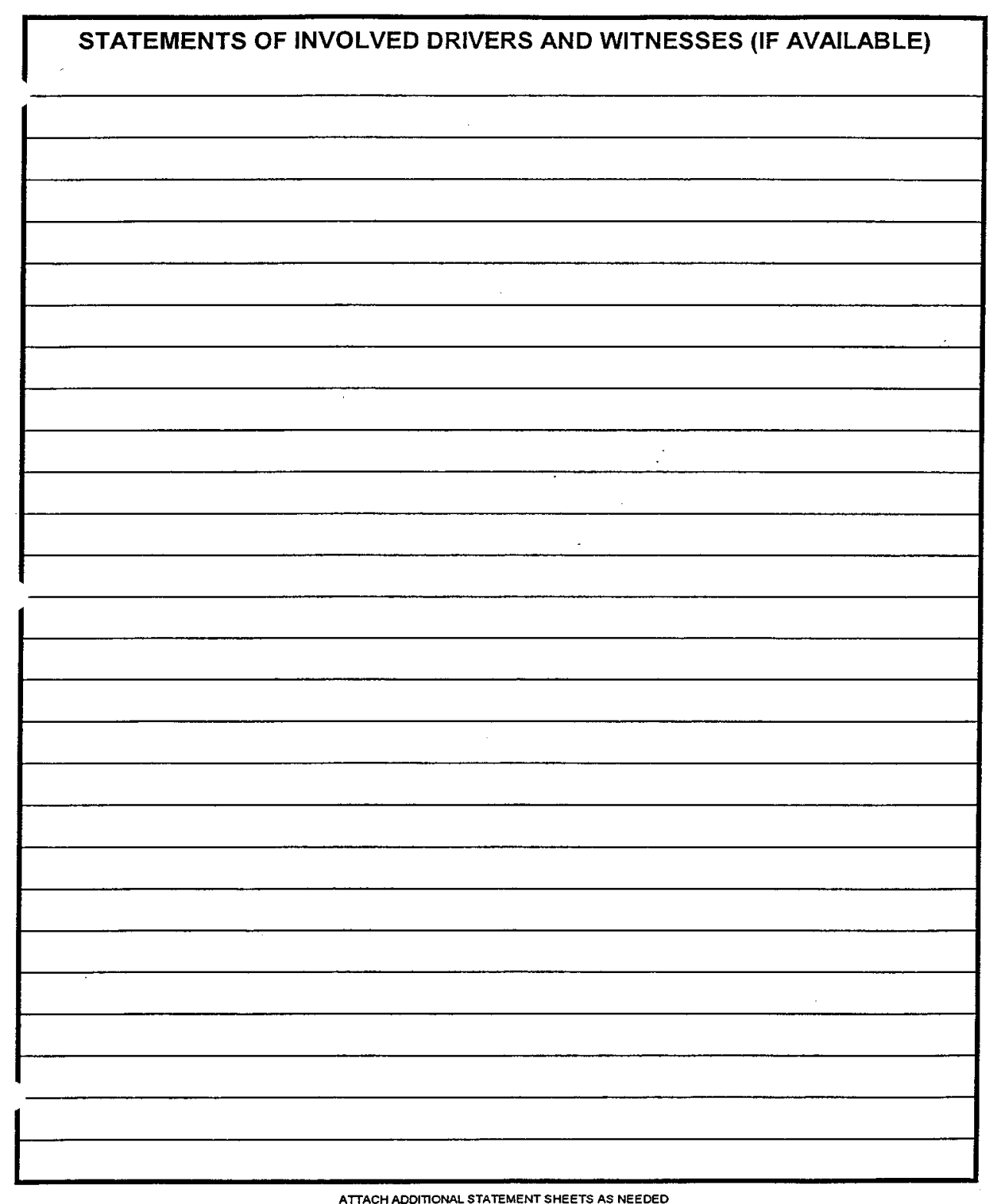

ATTACH ADOITONAL STATEMENT SHEETS AS NEEDED 
APPENDIX H: West Virginia Uniform Traffic Crash Report Pilot Test Post Survey 
West Virginia Uniform Traffic Crash Report Pilot Test Post Survey

Name:

Detachment Location:

Field Test Post Survey

1. Since the field test, how do you compare the new form you are filling out with the old form?

___ simpler to fill out

__ harder to fill out

__ same to fill out

___ other (please comment)

2. Since the field-test, how much time do you think it took to fill out the new form? less time to fill out more time to fill out same amount of time to fill out other (please comment)

3. Since the field test, do you feel the new form is more "user friendly" than the old form? What makes it that way, or not that way?

_- Yes

_- No Other (please comment) 


\section{West Virginia Uniform Traffic Crash Report Pilot Test Post Survey (Continued)}

4. Since the field test, do you feel the new form collects enough information to adequately investigate an accident?

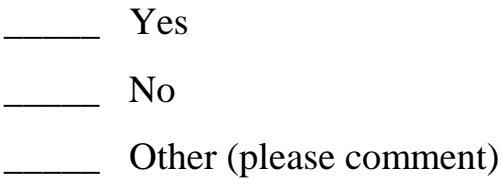

5. Since the field test, do you feel the new form collects enough information to adequately reconstruct an accident?

Yes

- No

__ Other (please comment)

6. Since the field test, is the meaning of each element on the new form clear and concise or does the information still require you to think about what data is being sought?
_ Yes; clear meaning
__ No; some elements not clear
__ Other (please comment)

7. Since the field testing how many new forms have you completed?

$\begin{array}{ll}- & 0-5 \\ - & 6-10 \\ - & 1-15\end{array}$

$16-20$

21-25 (if more than 25 please approximate number) 


\section{West Virginia Uniform Traffic Crash Report Pilot Test Post Survey (Continued)}

8. Since the field test, how do you compare the new form with the old form? Circle one.

$\begin{array}{ccccccc}1 & 2 & 3 & 4 & 5 & 6 & 7 \\ \text { Much } & \text { Worse } & \text { Slightly } & \text { No } & \text { Slightly } & \text { Improved } & \text { Greatly } \\ \text { Worse } & & \text { Worse } & \text { Difference } & \text { Improved } & & \text { Improved }\end{array}$

9. Since the field test, do you feel the new form is "user friendly"? Circle one.

$\begin{array}{ccccccc}1 & 2 & 3 & 4 & 5 & 6 & 7 \\ \text { Much } & \text { Worse } & \text { Slightly } & \text { No } & \text { Slightly } & \text { Improved } & \text { Greatly } \\ \text { Worse } & & \text { Worse } & \text { Difference } & \text { Improved } & & \text { Improved }\end{array}$

10. Since the field test, how did you rate the legibility of the new form? Circle one.

$\begin{array}{ccccccc}1 & 2 & 3 & 4 & 5 & 6 & 7 \\ \text { Much } & \text { Worse } & \text { Slightly } & \text { No } & \text { Slightly } & \text { Improved } & \text { Greatly } \\ \text { Worse } & & \text { Worse } & \text { Difference } & \text { Improved } & & \text { Improved }\end{array}$

11. Is the meaning of each element on the form you just filled out clear and concise or did the information require you to think about what data is being sought?

12. During the period of the field testing how many new forms did you complete? $0-25$ $26-50$ 50 or more 


\section{West Virginia Uniform Traffic Crash Report Pilot Test Post Survey}

(Continued)

13. How do you compare your field test form during the field test with the form you used to fill out (the old form)?

$\begin{array}{ccccccc}1 & 2 & 3 & 4 & 5 & 6 & 7 \\ \text { Much } & \text { Worse } & \text { Slightly } & \text { No } & \text { Slightly } & \text { Improved } & \text { Greatly } \\ \text { Worse } & & \text { Worse } & \text { Difference } & \text { Improved } & & \text { Improved }\end{array}$

14. Do you feel the form you filled out during the field test is "user friendly"?

$\begin{array}{ccccccc}1 & 2 & 3 & 4 & 5 & 6 & 7 \\ \text { Much } & \text { Worse } & \text { Slightly } & \text { No } & \text { Slightly } & \text { Improved } & \text { Greatly } \\ \text { Worse } & & \text { Worse } & \text { Difference } & \text { Improved } & & \text { Improved }\end{array}$

15. How do you rate the legibility of the form you filled out during the field test?

$\begin{array}{ccccccc}1 & 2 & 3 & 4 & 5 & 6 & 7 \\ \text { Much } & \text { Worse } & \text { Slightly } & \text { No } & \text { Slightly } & \text { Improved } & \text { Greatly } \\ \text { Worse } & & \text { Worse } & \text { Difference } & \text { Improved } & & \text { Improved }\end{array}$

16. Compared to the form you usually use, how do you rate the form you used during the field test?

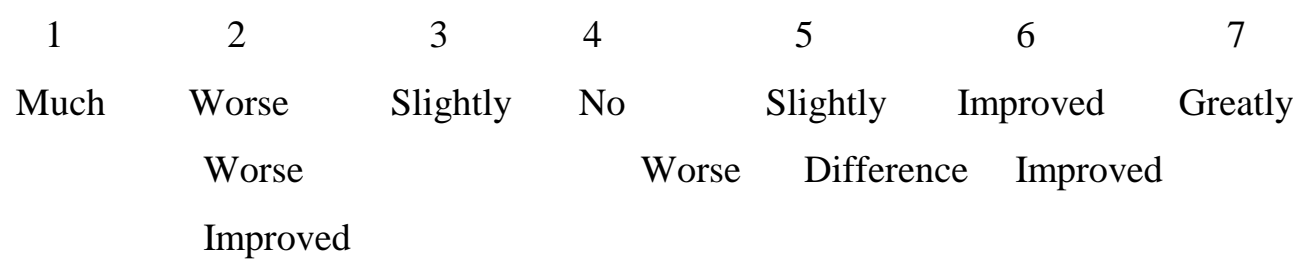


APPENDIX I: West Virginia Uniform Traffic Crash Report Quality Control Survey 


\section{West Virginia Uniform Traffic Crash Report \\ Quality Control Survey}

1. How important is it to you, personally, that West Virginia law enforcement has been involved in the crash form revision process?

It was absolutely imperative that law enforcement was involved

_ It was somewhat important

_ It was not more or less important than other things

_ It was somewhat unimportant

_ It was imperative that law enforcement not be involved

2. Did you expect that West Virginia law enforcement would be involved in the crash form revision process?

I was very surprised that enforcement was involved

_ I was somewhat surprised to be involved

_ I really did not care one way or the other whether law enforcement was involved

I was somewhat disappointed that law enforcement was involved I was very disappointed that law enforcement was involved

3. How long in months have you been using the new crash form?

_ 1 month or less

_ 1-3 months

3-6 months

6-12 months

over 12 months 


\section{West Virginia Uniform Traffic Crash Report \\ Quality Control Survey}

(Continued)

4. I was trained in the new form (as either a trainer or participant) by:

W _ WVU (Bucy or Winn)

___ My agency trainer

___ I trained myself using one of the WVU manuals

I was not formally trained (OJT)

Other (explain if you wish)

5. If you were trained by WVU above only:

I found the training suited to my needs

___ I found the training unsuited to my needs

___ Other (explain if you wish)

n

6. If you were trained by agency personnel or by OJT:

I found the training suited to my needs

I found the training unsuited to my needs

Other (explain if you wish)

$\mathrm{n} / \mathrm{al}$

7. I found the quality of the training materials that I used to be

___ Much better than expected

___ Somewhat better than expected

Adequate

Poorer than expected

Much poorer than expected 


\section{West Virginia Uniform Traffic Crash Report \\ Quality Control Survey}

(Continued)

8. If similar crash form training (or law enforcement data collection in general)) is ever offered again by WVU, what would you suggest to improve the quality of that training?

9. Regarding the commercial carrier data elements and commercial carrier training, I found:
T__ The training was much better th
Somewhat better than expected
-_ Adequate
__ Somewhat poorer than expected
__ Much poorer than expected

10. Now, with experience on the new crash form, how do you compare the new form to the old form in terms of ease to fill out:

The new form is much easier to fill out

__ The new form is somewhat easier to fill out

__ The new form is the same as the old form to fill out

__ The new form is somewhat harder than the old form

__ The new form is much harder to fill out 


\section{West Virginia Uniform Traffic Crash Report \\ Quality Control Survey}

(Continued)

11. After I used the new form for at least a couple of weeks, I found that:

___ The new form takes much less time to fill out

___ The new form takes somewhat less time to fill out

__ The new form takes the same amount of time to fill out

___ The new form takes somewhat more time to fill out

__ The new form takes much more time to fill out

$-1 \mathrm{n} / \mathrm{a}$

13. Do you think the new form gives you enough information on file locally to investigate an accident and record the details for later use, compared to the old form?

-

- No

$\mathrm{n} / \mathrm{a}$

Feel free to comment:

14. Do you think the new form gives you enough information to reconstruct an accident and record the details for future use, compared to the old form?

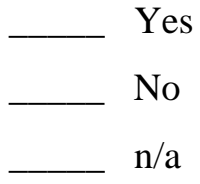

Feel free to comment: 


\section{West Virginia Uniform Traffic Crash Report \\ Quality Control Survey}

(Continued)

15. To what degree do you think the data elements on the new form, compared to the old form, are "self-coding" or "intuitive"? By this we mean, are the data elements on the new form easier to grasp and remember meaning compared to the old form?

New form is much easier to remember meaning

New form somewhat easier to remember meaning

New form same as old form

__ New form somewhat harder to remember meanings

__ New form much harder to remember meanings

16. For supervisors: How much has the new crash form changed the error rate (reject rate) at your agency:

The reject rate is much less now

The reject rate is somewhat less now

- The reject rate is the same as before

The reject rate is somewhat higher than before

- The reject rate is much higher than before

I'm not a crash form reviewer or supervisor of them

$\mathrm{n} / \mathrm{a}$ 


\section{West Virginia Uniform Traffic Crash Report \\ Quality Control Survey}

(Continued)

17. For supervisors: How has your workload changed with regard to the new form only:

My workload on crash forms is much less now

___ My workload is somewhat less now

__ My workload is somewhat increased with the new form

___ My workload is much greater with the new crash form

___ I'm not a crash form reviewer or supervisor of them

$-1 \mathrm{n} / \mathrm{a}$

18. For supervisors: How has the new crash form impacted your ability to do your job overall? What changes, if any, are we not picking up on this survey, for example?

19. For all form users: How much more complete are you able to fill out the new form than the old form?

I think my new forms are 75-90\% more complete than before I think my new forms are 10-75\% more complete than before

___ I think my new forms are complete to the same degree as before

___ I think my new forms are 10-75\% less complete than before

___ I think my new forms are $75-90 \%$ less complete than before 


\section{West Virginia Uniform Traffic Crash Report \\ Quality Control Survey}

(Continued)

20. I think that in terms of data accuracy, compared to the fold form,

___ The new form allows me to enter much more accurate data than before The new form allows me to enter somewhat more accurate data The new form is the same as the old form in terms of accuracy

The new form allows somewhat less accurate data entry

The new form allows much less accurate data entry than before

21. If you could pick a single thing to change about the form or the process with which data is collected, in the most general terms, what would you choose? Put " 1 " in the blank.

__ I would like to have the new form available on our computers for data entry

___ I would like to be able to transmit the data by modem (electronically) (Assuming you are not doing so now)

__ I would like to link to other agencies (DoH, DPS, etc.) and exchange files

I would like to have GPS data available (global positioning data)

I would like to have more "local information" spaces available on the form 


\section{West Virginia Uniform Traffic Crash Report \\ Quality Control Survey \\ (Continued)}

22. If you could pick a second choice from the above question to change after you already had the first change made, what would it be? Put a " 2 " in that blank above in the previous question.

I would like to have the new form available on our computers for data entry

I would like to be able to transmit the data by modem (electronically) (Assuming you are not doing so now)

___ I would like to link to other agencies (DoH, DPS, etc.) and exchange files

___ I would like to have GPS data available (global positioning data)

___ I would like to have more "local information" spaces available on the form

23. If you could select one and only one new technology to implement to assist with crash investigation and data collection, which of the following would you select?
Lap top computers (cruiser or office)
Personal computers (office)
Hand held computers (personal data assistant, as they are commonly called)
___ Pen-based computers (PC or lap top)
___ Global positioning system(s)
__ Cellular telephones
__ Digital cameras
___ Video tape recorders
__ Scanners 


\section{West Virginia Uniform Traffic Crash Report \\ Quality Control Survey}

(Continued)

24. If you could pick a second choice from question 23 above to select after you already had the first selection made, what would it be? Put a "2" in that blank above in the previous question.

___ Lap top computers (cruiser or office)

___ Personal computers (office)

___ Hand

__ Pen based computers (PC or laptop)

___ Global positioning system(s)

__ Cellular telephones

___ Digital cameras

__ Video tape recorders

__ Scanners

$\mathrm{n} / \mathrm{a}$

25. The last portion is reserved for anything of any kind that you would like to say about the form, the process, the training, the people, the idea of data collection, or anything else. Your thoughts and your space: 
APPENDIX J: West Virginia Uniform Traffic Crash Report Focus Group Summary Data 
West Virginia Uniform Traffic Crash Report WVU/DoH Crash Form Revision Project

User Input Sessions: Summary Data

\begin{tabular}{|c|c|c|c|c|c|c|c|c|c|c|c|c|c|c|}
\hline & Mtn & Hunt & Beck & Mtn II & Clksbg & Pksbg & Keyser & Mtsbg & Logan & Wier & Wheel & Pt. Pt & Chlstn & Totals \\
\hline Add agent name, phone \#, policy \# & $\mathrm{X}$ & $\mathrm{X}$ & $\mathrm{X}$ & $\mathrm{x}$ & $\mathrm{X}$ & $\mathrm{X}$ & $\mathrm{X}$ & $\mathrm{X}$ & $\mathrm{X}$ & $\mathrm{X}$ & $\mathrm{X}$ & $\bar{X}$ & $\bar{X}$ & 13 \\
\hline Add phone \#, zips, witness and driver & & $\bar{X}$ & & $\mathrm{X}$ & $\mathrm{X}$ & $\mathrm{X}$ & $\mathrm{X}$ & $\mathrm{X}$ & $\mathrm{X}$ & $\mathrm{X}$ & $\mathrm{X}$ & $\bar{x}$ & $\overline{\mathrm{X}}$ & 11 \\
\hline Adjust passive restraint (add air bag \& seat belt info) & $\mathrm{X}$ & & $\mathrm{X}$ & $\mathrm{X}$ & $\mathrm{X}$ & & $\mathrm{X}$ & $\bar{X}$ & $\bar{X}$ & $\bar{X}$ & $\mathrm{X}$ & $\mathrm{X}$ & $\mathrm{X}$ & 11 \\
\hline Delete cost of damage & & $\mathrm{X}$ & $\mathrm{X}$ & & $\mathrm{X}$ & & $\bar{X}$ & $\bar{X}$ & $\mathrm{X}$ & $\mathrm{X}$ & $\mathrm{X}$ & $\mathrm{X}$ & $\mathrm{X}$ & 10 \\
\hline Larger VIN block & $\mathrm{X}$ & & & $\mathrm{X}$ & $\mathrm{X}$ & & & $\mathrm{X}$ & $\mathrm{X}$ & $\mathrm{X}$ & & $\mathrm{X}$ & $\mathrm{X}$ & 8 \\
\hline Eliminate EMS information & & $\mathrm{X}$ & $\mathrm{X}$ & & $\mathrm{X}$ & & & $\mathrm{X}$ & $\mathrm{X}$ & $\mathrm{X}$ & & $\mathrm{X}$ & $\mathrm{X}$ & 8 \\
\hline Add vehicle color & $\mathrm{X}$ & $\mathrm{X}$ & $\bar{X}$ & & $\mathrm{X}$ & & & & & & $\mathrm{X}$ & $\mathrm{X}$ & $\mathrm{X}$ & 7 \\
\hline 3 Part NCR Form for driver exchange & $\mathrm{X}$ & $\mathrm{X}$ & & $\mathrm{X}$ & $\mathrm{X}$ & & & $\mathrm{X}$ & & & $\mathrm{X}$ & $\mathrm{X}$ & & 7 \\
\hline Eliminate or reduce odometer information & $\mathrm{X}$ & & $\mathrm{X}$ & & $\mathrm{X}$ & & $\bar{X}$ & & $\mathrm{X}$ & $\mathrm{X}$ & & & $\bar{X}$ & 7 \\
\hline Delete other damage & & & & & $\mathrm{X}$ & $x$ & $X$ & & & & $\mathrm{X}$ & $\mathrm{X}$ & $\mathrm{X}$ & 6 \\
\hline Eliminate code/tolerance & & & & & $\mathrm{X}$ & & $\mathrm{X}$ & $\mathrm{X}$ & & & $\mathrm{X}$ & $\mathrm{X}$ & $\mathrm{X}$ & 6 \\
\hline Increase threshold from $\$ 250$ & $\mathrm{X}$ & $\bar{X}$ & $\bar{X}$ & & & & $\mathrm{X}$ & & $\bar{X}$ & & & & $\mathrm{X}$ & 6 \\
\hline Change towed to towed by (poss) towed to & & $\mathrm{X}$ & $\mathrm{X}$ & & & & & $\mathrm{X}$ & $\mathrm{X}$ & & & & $\mathrm{X}$ & 5 \\
\hline Eliminate or revise photo box (VCR) & & $\mathrm{X}$ & $\mathrm{X}$ & & & & & $\mathrm{X}$ & $\mathrm{X}$ & & & & $\mathrm{X}$ & 5 \\
\hline Add see narrative & & & & & $\mathrm{X}$ & $\mathrm{X}$ & & & & $\mathrm{X}$ & & $\bar{x}$ & $\bar{x}$ & 5 \\
\hline Delete unit $\#$ & & & & & $\mathrm{X}$ & $\mathrm{X}$ & & & $\mathrm{X}$ & & $\mathrm{X}$ & $\mathrm{X}$ & & 5 \\
\hline Eliminate contribu. Cir \#23 to sp. Study notes & & & & & $\mathrm{X}$ & & $\mathrm{X}$ & $\mathrm{X}$ & & & & & $\mathbf{X}$ & 4 \\
\hline Eliminate green form & & & $\mathrm{X}$ & & & & $\bar{X}$ & $\mathrm{X}$ & & & & & $\mathrm{X}$ & 4 \\
\hline Fold at top & & $\mathrm{X}$ & $\mathrm{X}$ & & & & & & & & & & $\mathrm{X}$ & 3 \\
\hline Delete age/sex witness block & & & & & & & & & & & & $\mathrm{X}$ & $\frac{x}{X}$ & $\frac{5}{2}$ \\
\hline Controlled access highway & & & & & & & $\mathrm{x}$ & & & & & & $\mathrm{X}$ & $\frac{2}{2}$ \\
\hline Eliminate single vehicle accident report & & $\mathrm{X}$ & $\mathrm{X}$ & & & & & & & & & & & 2 \\
\hline Place for File \# & & & & $\bar{X}$ & $\mathrm{X}$ & & & & & & & & & 2 \\
\hline Clarify and improve flow of accident report & & $\mathrm{X}$ & & & $\mathrm{X}$ & & & & & & & & & $\frac{2}{2}$ \\
\hline Put timers and dates together & & & & & & & $\mathrm{X}$ & & & & & & $\bar{X}$ & 2 \\
\hline TOTALS & 7 & 12 & 12 & 6 & 16 & 5 & 12 & 12 & 11 & 8 & 9 & 13 & 20 & 143 \\
\hline
\end{tabular}

West Virginia Uniform Traffic Crash Report Focus Group Summary Data 
APPENDIX K West Virginia Uniform Traffic Crash Report Focus Group Results 


\section{West Virginia Uniform Traffic Crash Report \\ Focus Group Results}

\section{Morgantown, WV \#1}

1. Add telephone number of operator

2. Add vehicle colors

3. Larger VIN block

4. Bigger diagram area (graph likewise)

5. Air bags; function or not (restraint information section)

6. Duplicating half page for drive exchange

7. Separate page for vehicle 2 and 3

8. Incident number spot

9. Add terrain and grade information

10. Operator license number block larger

11. Reduce odometer block

12. Insurance policy number and company name

13. Eliminate accident report for accidents less than $\$ 250$ in damage

14. Improve direction of travel 


\section{West Virginia Uniform Traffic Crash Report \\ Focus Group Results \\ (Continued)}

Huntington, WV

1. Dislike cost of repairs

2. Day and date of accident

3. Date of accident

4. Abbreviated: (3) project form; (4) NCR form; no line drawing; narrative short; for fender benders

5. Don't need statement and diagram on fender benders

Property drawing only, no bodily injury insurance or arrest reports; under

$\$ 5,000$. Move current form. (Simplifies records) Not to exclude single vehicle accident.

6. Exclude law information (out)

7. Separate sheet for drawings (in)

8. Video CAM and recording (in)

9. Raise the reportable limit (property damage) ( $\$ 1000$ cut in). If damage above certain dollar amount only fill out the top.

10. EMS times/Department. Already collecting these. Data through EMS (out)

11. Single accident left vehicle area (out)

12. Social Security number in place of name (in)

13. Social Security number as owners license number (in)

14. Eliminate statement by drivers (out)

15. Phone number add number 1 driver

16. Add colors of vehicle

17. Add vehicle towed by (wrecker's name) (not towed where)

18. Eliminate HAZ MAT (out) 


\section{West Virginia Uniform Traffic Crash Report \\ Focus Group Results \\ (Continued)}

19. Scannability (pen) (in) (pencil) (out)

20. Tearing forms in half to copy and tape back together (no folds) 


\section{West Virginia Uniform Traffic Crash Report \\ Focus Group Results \\ (Continued)}

\section{Beckley, WV}

1. Too long (4 pages) length

2. Form folded at top

3. Contributing circumstances (term ambiguous)

4. Working for attorneys and insurance companies

5. Narrative could be eliminated

6. Code violations, statistics information

7. Photos, videos (input)

8. Eliminate towed by

9. $\quad$ Add phone number (in)

10. Add social security number

11. Add policy number

12. Eliminate approximate cost of repair

13. Eliminate green form if police fill out accident report

14. Increase dollar amount if reportable accident to $\$ 750.00$

15. Eliminate odometer information

16. More than two vehicles

17. Eliminate EMS information

18. Eliminate contribution circumstances

19. Add restraint area
a. seat shoulder belt
b. seat lap belt
c. child restraints
d. helmets
e. air bags 


\section{West Virginia Uniform Traffic Crash Report}

Focus Group Results

(Continued)

20. Colors of vehicle not needed

21. Add race

22. City or incorporation town information - determine need

23. Measurements 


\section{West Virginia Uniform Traffic Crash Report \\ Focus Group Results \\ (Continued)}

Morgantown, WV \#2

1. Booklet form with additional pages if necessary

2. Carbon first page for driver exchange

3. More uniform training

4. (Uniform Hardware and software) share worthy

5. Tractor trailer information (how much)

6. VIN block expanded

7. Add incident number block

8. Add telephone number block

9. Injury data more detail

10. Injury in driver condition block

11. Add insurance policy number, agent

12. Improve Vehicle Impact Point

13. Eliminate duplicate information

14. Add tractor, trailer, bus diagram

15. Combine driver and passenger damaged information

16. Accident location more defined

17. Witness phone number

18. Add drivers action "in curve"

19. Add passenger restraint information

20. Add left of center to contributing circumstances

21. Direction traveled (compass direction)

22. Add towed to/towed by

23. Doing work for insurance company 


\section{West Virginia Uniform Traffic Crash Report}

Focus Group Results

(Continued)

24. Eliminate route of street block

25. Change name of report from accident and crash 


\section{West Virginia Uniform Traffic Crash Report \\ Focus Group Results \\ (Continued)}

\section{Parkersburg, WV}

1. Driver information; social security number and phone number

2. Use social security number only

3. Vehicle towed to/by (both)

4. Contributing circumstances; many instances where none of the give apply

5. Driver's name; policy number

6. Doing insurance company work

7. Duplicate in area of damage; not space for if tractor-trailer must use narrative (vehicle in tow)

8. Statement and information on one page

9. Injury and restraint information on same page

10. Keep drawing and narrative

11. Better witness information; work and home phone numbers

12. Place for $4^{\text {th }}$ witness information. Now only three

13. Injured taken to or by; expand or modify box

14. Eliminate other damage area

15. Rear end - doesn't take backing up into consideration

16. Bicycle; information (see narrative block)

17. Accident type; see narrative block

18. Information on vehicle on road improperly

19. Do away with unit marker

20. Number of lanes, environment, and or controlled, access highway. Nothing shows it is a divided highway

21. Number of lanes misleading if you have turning lane 


\section{West Virginia Uniform Traffic Crash Report \\ Focus Group Results \\ (Continued)}

22. Consolidate fatal accident supplement form into uniform traffic accident report

23. Bigger narrative

24. Upset for data collection and respond for investigation

25. Shorten form in length

26. Increase threshold to $\$ 1000 / \$ 1500$

27. Form too long to (hrs) to fill out

28. Section for supervisor's approval 


\section{West Virginia Uniform Traffic Crash Report \\ Focus Group Results \\ (Continued)}

Martinsburg, WV

1. Add section for videotape (in photo section)

2. Add page number drivers (3-4)

3. Delete cost of repair

4. Add space for violation(s) citation number

5. Enlarge box for co-owners

6. Enlarge VIN block

7. Tear away - NCR for driver exchange

8. No More Green Form

9. Delete block 23 make it write in

10. Increase number of points of impact

11. Delete tolerance (what is it)

12. Add insurance company name and policy number

13. Add space for drivers phone number

14. Add space for witness phone number

15. Add space for case number by sheet number

16. Make OLN social security number

17. Add more space in other damage area

18. First aid; make more specific (example at the scene)

19. Delete approximately damage box

20. Persons involved (add) additional spaces or supplemental

21. Add ATV in motorcycle area

22. Improve seat belt section

23. Add driver $3 \& 4$ to match Driver $1 \& 2$ (witness) 


\section{West Virginia Uniform Traffic Crash Report \\ Focus Group Results \\ (Continued)}

24. Delete vision impaired section make it a write in

25. Delete EMS information. Add block if EMS there $\mathrm{Y} / \mathrm{N}$

26. Anywhere - "other" is listed make block larger

27. Simplify pedestrian action box

28. Pedestrian clothing, leave space to describe clothing

29. Space to ID hazardous information (write in)

30. One form

31. Diagram one page

32. Raise reportable limit

33. If agree form goes with front sheet

34. Working for insurance company 


\section{West Virginia Uniform Traffic Crash Report \\ Focus Group Results \\ (Continued)}

\section{Clarksburg, WV}

1. Place for a file number(s)

2. Delete highway classification box

3. Delete code

4. Delete state

5. Delete tolerance (not used)

6. Direction - compass or route markings

7. Delete license restrictions violations (never used)

8. Delete driver condition block

9. Delete sobriety and test results (on D \& I sheet)

10. Larger VIN number

11. Larger space for phone

12. Eliminate green form

13. NCR perforation area for driver (x-change)

14. Date of birth and age side by side

15. Make form $8 \frac{1}{2} 2 \times 14$

16. Eliminate odometer reading space

17. Modify blocks in driver 1 block. Some bigger some smaller

18. More room owners name

19. Add block for color

20. Delete approximate cost of repair

21. Delete total number of occupants

22. Delete other damage

23. Add block for other (fill in blank) 


\section{West Virginia Uniform Traffic Crash Report \\ Focus Group Results \\ (Continued)}

24. Delete special study notes (23)

25. Add left of center

26. Clarify routes of impact section

27. Change to; towed by

28. Insurance company phone and policy numbers

29. Improve seat belt areas; add air bag

30. Codes, "A" not reflective. Always immobile when transported.

Add “T”, transported for evaluation

31. Accident selection (delete) All in supplementary forms

32. EMS (delete) its on their run sheet

33. Single vehicle accident (add) (Bicycle)

34. Witness (delete) age and sex (add) phone

35. Delete (unit number)

36. Larger drawing sheet

37. Narrative on back sheet

(Share ware (software) available) 


\section{West Virginia Uniform Traffic Crash Report \\ Focus Group Results \\ (Continued)}

\section{Keyser, WV}

1. Delete tolerance

2. Data Controlled Access Highway

3. Consolidate times on first line

4. Need coded format

5. Not typewriter friendly

6. Delete sobriety test; test results BAC make $\mathrm{Y} / \mathrm{N}$

7. Delete driver condition line

8. Make citation information in sobriety section yes or change yes or no

9. Entire front of form could be codes

10. Add zips everywhere

11. OLN and social security numbers the same

12. Use bar codes

13. Eliminate approximate cost of repair

14. Odometer reading (delete)

15. Driver license more consistent licenses, information (in sequencing)

16. Add place for phone number owner or operator

17. Add towed by rather than towed to

18. Control (23) no one knows what there is. Also study note

19. Delete milepost and tolerance (doesn't apply to Mineral County)

20. Make form more uniform (in layout)

21. Eliminate green sheet

22. Eliminate other damage block; put in narrative

23. Codes section and accident type can be coded 


\section{West Virginia Uniform Traffic Crash Report \\ Focus Group Results \\ (Continued)}

24. Seat belt section add air bag and reclassify

25. First aid; in scrabbled order

26. Injured taken by/injured taken to

27. Eliminate five; Eliminate or make more complete

28. Special team for major accidents

29. Witnesses phone block

30. Smaller; diagram; death or sever injury (special unit) (less detailed)

31. Delete 31

32. Make separate sheet; not sent to Charleston. Kept in file

33. Clean up 12, 3, 40, 11, 4, 17, 18, 21, 23, 25 


\section{West Virginia Uniform Traffic Crash Report \\ Focus Group Results \\ (Continued)}

\section{Logan, WV}

1. Enlarge space for VIN

2. Eliminate approximate cost of repairs

3. Eliminate accident type; goes into narrative

4. Eliminate odometer reading

5. Number of accident in vehicle; on back page

6. Eliminate EMS block

7. Add car towed to/towed by

8. Eliminate photos taken

9. License restrictions violation

10. Eliminate the driver condition on a separate report

11. Change " $\mathrm{G}$ " in codes

12. Add another code for just transported

13. Make seat belt block $\mathrm{Y} / \mathrm{N}$

14. Eliminate that block in citation

15. Eliminate accident section

16. Eliminate ejected (person involved) Add air bag

17. Redundancy in persons involved front/back page

18. Eliminate injured taken to section

19. Delete single vehicle accident section

20. Add witness information phone number
a. Eliminate age and sex
b. Statements taken $\mathrm{Y} / \mathrm{N}$

21. Add policy number and insurance company name, not agency 


\section{West Virginia Uniform Traffic Crash Report \\ Focus Group Results \\ (Continued)}

22. Eliminate green form

23. Vision obscured (add foggy)

24. Consolidate roadway type and surface

25. Eliminate light see (environment)

26. Eliminate weather

27. Eliminate name, unit number and agency and eliminate date

28. Eliminate circle direction

29. Narrative shorten or make it a supplement

30. Officer take statement (replace, make just statement)

31. Add section, date, time, and location 


\section{West Virginia Uniform Traffic Crash Report \\ Focus Group Results \\ (Continued)}

Wheeling, WV

1. Controlled access highway (direction redundant)

2. Delete tolerance

3. Add two pages

4. Age; driver one; take off page 3

5. Yes or no BAC sobriety test block

6. Eliminate cost of damage

7. Block cost of damage; light, medium, heavy, etc.

8. Eliminate cost of damage of repair; eliminate code

9. Add agents' name

10. Modify impact area

11. Towed to/towed by

12. Get rid green form

13. Other damage add phone number; eliminate $\$$ of damage

14. Add section code transport not serious

15. Seat belts; passive restraints; air bags

16. Eliminate EMS area

17. Switching code section with accident section

18. Delete run in person involved

19. Persons involved; eliminate age and sex

20. Vehicle number one printed vehicle number two

21. Add witness phone number

22. Pedestrian section, rarely used, normally a fatal

23. Delete RR gates flagmen, write in box 


\section{West Virginia Uniform Traffic Crash Report \\ Focus Group Results \\ (Continued)}

24. Delete (unit number)

25. Diagram OK

26. Make narrative smaller

27. Witness statement; separate sheets

28. Drawing references; post not place to draw boxes; (fatal, serious)

29. Change OLN to social security number

30. Accident restriction box smaller

31. Model if not registered add block for color

32. Direction of travel box smaller

33. Number of occupants smaller box

34. Controls defects; write in (21) pot holes, debris on road 


\section{West Virginia Uniform Traffic Crash Report \\ Focus Group Results \\ (Continued)}

Weirton, WV

1. Traffic control (include speed information) Block addition

2. Driver one and driver two vehicle section expand to include tractor and trailer information

3. Eliminate approximate cost of repair

4. Contributing circumstances sobriety; use information to rearrange impaired (Y/N). Special section 18 driver and under influence

5. VIN block number bigger

6. Odometer reading is it necessary?

7. Impact area; updated to tractor-trailer; add to supplement commercial carrier information.

8. Insurance agent name and insurance block policy number

9. Accident type; block left of center

10. Accident type; backing accident; block

11. Eliminate; vision obscured; which driver one or two

12. Expanding property damage area; move detail other damage

13. Decrease accident blocks; page 2

14. Make EMS smaller

15. Seat belts; add air bags; deployed; Y/N

16. Rearrange codes adjacent to persons involved

17. Phone number for witnesses

18. Contributing conditions

19. Pedestrian accident; (improve flow) 


\section{West Virginia Uniform Traffic Crash Report \\ Focus Group Results \\ (Continued)}

20. Put signature on back of form below diagram; set sign, date of accident; diagram done by

21. Front page tip assigning report

22. Add height of shoulder (page 1); contributing circumstances

23. Car towed to/towed by

24. Sheet; number each ___ of ___ of ___

25. Move room; drawing; DOT equally spaced

26. Drawing bigger; wording and compass pt above line and 2 lines lower (as is but bigger) DOT should scale (1 to 120 or 1 to 240 make DOTS equal)

Statements; supplemental pages

Phone number and address, driver's phone number add 


\section{West Virginia Uniform Traffic Crash Report \\ Focus Group Results \\ (Continued)}

\section{Pt. Pleasant, WV}

1. Eliminate code and tolerance block

2. Add blocks for phone numbers and social security numbers

3. Re-order drivers section; make flow better

4. Eliminate "BAC" block in sobriety section

5. Make serial number block larger

6. Eliminate costs of repairs

7. Change vehicle towed, to vehicle towed to

8. Contributing circumstances

a. Eliminate number 23 and special study notes

b. Add left of center

9. Add insurance policy number, phone number to driver section

10. Add phone number to witness area

11. Eliminate green form

12. Eliminate other damage section

13. Add owners name address and phone numbers

14. Rework passive restraint area
a. Add air bags
b. Deployed $\mathrm{Y} / \mathrm{N}$

15. Add block for transported no visible injuries

16. Put first aid and EMS information together

17. Eliminate EMS information

18. Witness block delete age/sex

19. Single accident block add space to list other 


\section{West Virginia Uniform Traffic Crash Report \\ Focus Group Results \\ (Continued)}

20. Add block for backing

21. Add other to pedestrian section

22. Eliminate unit member

23. Move pedestrian information to front page with vehicle information 


\section{West Virginia Uniform Traffic Crash Report \\ Focus Group Results \\ (Continued)}

\section{Charleston, WV}

1. Photo block move and integrate

2. Vehicle towed to; switch with location, driver one, driver two

3. Evidence collected (yes/no box)

4. Add hit and run

5. Change name of report to Crash Report

6. Supplemental page (narrative continued)

7. Witness; Driver statement (separate supplemental)

8. Drawing - a supplemental

9. Additional vehicles - a supplemental

10. Fatal add a supplemental to form

11. Label accident number box

12. Standardize date entry

13. Add field or walk-in report

14. Delete code to tolerance

15. Mile post box? Do we need it

16. Change to refine scales

17. Integrate routes and streets

18. Controlled access highway (size)

19. Location of fold in form. Keep the same

20. Write in box for environmental section. Delete all others

21. Eliminate contributing circumstances number 23 and special study notes

22. Add in; attentiveness/outside distraction

23. Add left of center 


\section{West Virginia Uniform Traffic Crash Report \\ Focus Group Results \\ (Continued)}

24. Add narrative box to contributing circumstances

25. Add wrong way to contributing circumstances

26. Add posted speed

27. Add vehicle towed by

28. Initial impact - write in

Additional impact - diagram

Delete Area(s) damage block

29. Make VIN box larger

30. Add color box for auto, model and style box

31. Reduce odometer and direction of travel block

32. Reduce total occupants box

33. Add insurance policy number

Agents name

Expiration date

34. Delete approximate cost of repair

35. Do away with green form

36. Add driver phone number (home, work, other)

37. Add social security number

38. Reduce citation, license, state boxes

39. Driver condition (hurt/injured)

40 Sobriety test given (yes/no)

Check box:

$\begin{array}{ll}\text { Field } & \text { Breather } \\ \text { PBT } & \text { Blood }\end{array}$

41. Add interlock block 


\section{West Virginia Uniform Traffic Crash Report \\ Focus Group Results \\ (Continued)}

42. Add zip code to all pertinent areas

43. Reduce license restrictions

44. Add hit by train

45. Traffic control (add construction zone)

46. Witness box (delete age/sex, add phone number)

47. Print name of officer

48. Use agency name not URI

49. Vision; observed driver one and driver two

50. EMS blocks; eliminate hours; make Y/N block; add unit number block

51. Reduce persons involved block and add phone number

52. Delete age/sex of drivers one and two in persons involved. 
APPENDIX L: West Virginia Uniform Traffic Crash Report Mock Crash Summary

Data 


\section{West Virginia Uniform Traffic Crash Report \\ Mock Crash Summary Data}

1. How do you compare your test form today with the one you are used to filling out?

No

Simpler Harder Same Other Response Comments

$\begin{array}{lllllll}\text { Red AM } & 0.00 \% & 0.00 \% & 92.00 \% & 8.00 \% & 0.00 \% & \text { Control Group } \\ \text { White AM } & 8.00 \% & 25.00 \% & 58.00 \% & 8.00 \% & 0.00 \% & \text { Taking steps toward } \\ & & & & & & \text { simplicity, but could } \\ & & & & & & \text { be more so. }\end{array}$

$\begin{array}{llllll}\text { Blue AM } \quad 27.00 \% & 9.00 \% & 64.00 \% & 0.00 \% & 0.00 \%\end{array}$

$\begin{array}{llllll}\text { Red PM } & 73.00 \% & 9.00 \% & 9.00 \% & 9.00 \% & 0.00 \%\end{array}$

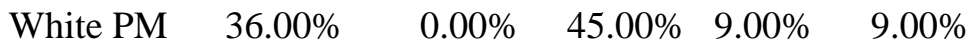

$\begin{array}{llllll}\text { Blue PM } \quad 36.00 \% & 18.00 \% & 45.00 \% & 0.00 \% & 0.00 \% & \text { Control Group }\end{array}$

2. How much time do you think it took to fill out the form compared with the form you usually use?

$$
\text { Simpler Harder Same Other Response Comments }
$$

$\begin{array}{llllll}\text { Red AM } & 0.00 \% & 0.00 \% & 100.00 \% & 0.00 \% & 0.00 \%\end{array}$

$\begin{array}{llllll}\text { White AM } \quad 42.00 \% \quad 33.00 \% & 25.00 \% & 0.00 \% & 0.00 \% & \text { More time to fill out }\end{array}$

Because of being unfamiliar w/changes.

Blue AM $\quad 27.00 \% \quad 18.00 \% \quad 45.00 \% \quad 9.00 \% \quad 0.00 \% \quad$ Slightly longer, but captures more information 


\section{West Virginia Uniform Traffic Crash Report \\ Mock Crash Summary Data \\ (Continued)}

$\begin{array}{lllllll}\text { Red PM } & 18.00 \% & 18.00 \% & 55.00 \% & 9.00 \% & 0.00 \% & \\ \text { White PM } & 27.00 \% & 18.00 \% & 54.00 \% & 0.00 \% & 0.00 \% & \text { Okay once you get } \\ & & & & & & \text { familiar with it. }\end{array}$

Blue PM $\quad 27.00 \% \quad 27.00 \% \quad 45.00 \% \quad 0.00 \% \quad 0.00 \% \quad$ Control Group

3. The following three data elements seem easier to use than on the form I usually use:

Red AM a. Same form

White AM a. Vehicle damage section

b. Events/Vehicle section/Crash section

c. Less time to complete; easier to shade boxes; diagram better detailed

d. CDL info; Cost of damage estimate removed.

e. Injury info; driver areas

f. Phone numbers; Large Vin space

g. Omitted odometer section; insurance information

h. Initial point of impact; Vehicle/Driver numbers

Blue AM a. Field sobriety test; extent of damage; damaged area(s)

b. Towing information; added social security number; odometer omission

c. Large VIN space; phone numbers; insurance info 
West Virginia Uniform Traffic Crash Report

Mock Crash Summary Data

(Continued)

d. Location of property damage

e. Flowed better.

Red PM a. CDL form

b. Vehicle/driver info

c. Contributing circumstances; overall format

d. Fill blocks easier

White PM a. Damaged areas; point of initial impact

b. Towing information; vehicle numbering; accident type condensed

c. Crash/vehicle damage info; sequence of events

d. VIN space

e. Accident breakdown; passenger/driver section

f. Insurance information; phone numbers

g. Extent of damage; occupant protection

h. CDL section

Blue PM a. General information more organized

b. Used old form

4. The following three data items seem harder to use than on the form I usually use:

Red AM a. Used old form 


\title{
West Virginia Uniform Traffic Crash Report \\ Mock Crash Summary Data \\ (Continued)
}

\begin{abstract}
White AM a. CDL section
b. Sequence of events; extent of damage

c. DUI section

d. Accident type

e. MDY - harder to see date

Blue AM a. CDL section

b. Persons involved; accident type

c. Contributing circumstances harder to locate for Vehicle 2

d. Statistic boxes - seating, seat belts, etc.
\end{abstract}

Red PM a. Elements that were not on the old form

b. Extent of damage too wordy

White PM a. Finding appropriate block; damage codes

b. Air bags

Blue PM a. Used old form

5. Do you feel the form you filled out today is "user friendly"? What makes it that way, or NOT that way?

Yes No Other Response Comments

$\begin{array}{lllll}\text { Red AM } & 58.00 \% & 17.00 \% & 17.00 \% & 0.00 \%\end{array}$ Control Group 


\section{West Virginia Uniform Traffic Crash Report \\ Mock Crash Summary Data \\ (Continued)}

$\begin{array}{cccccc}\text { White AM } \quad 91.00 \% \quad 9.00 \% & 0.00 \% & 0.00 \% & \text { Good flow. Easier to } \\ & & & \text { fill in blanks. More detailed } \\ & & \text { Resembles old form. }\end{array}$

Yes No Other Response Comments

Blue AM $\quad 100.00 \% \quad 0.00 \% \quad 0.00 \% \quad 0.00 \% \quad$ Good, logical flow.

Well thought out.

Captures better data.

$\begin{array}{llllll}\text { Red PM } & 91.00 \% & 9.00 \% & 0.00 \% & 0.00 \% & \text { Wasn't sure about some } \\ & & & & \text { parts (unfamiliar). }\end{array}$

White PM $\quad 91.00 \% \quad 9.00 \% \quad 0.00 \% \quad 0.00 \% \quad$ Better flow. Resembles

old form. Some print too

small.

Blue PM $\quad 91.00 \% \quad 0.00 \% \quad 9.00 \% \quad 0.00 \% \quad$ Control Group 


\section{West Virginia Uniform Traffic Crash Report \\ Mock Crash Summary Data \\ (Continued)}

6. Do you feel the form you filled out today collects enough information to adequately investigate and/or reconstruct an accident?

\begin{tabular}{|c|c|c|c|c|c|}
\hline & Yes & No & Other & $\begin{array}{c}\text { No } \\
\text { Response }\end{array}$ & Comments \\
\hline Red AM & $55.00 \%$ & $36.00 \%$ & $9.00 \%$ & $0.00 \%$ & $\begin{array}{l}\text { Control Group. Need colors } \\
\text { for hit and runs. Need policy } \\
\text { and phone numbers. }\end{array}$ \\
\hline White AM & $75.00 \%$ & $0.00 \%$ & $17.00 \%$ & $8.00 \%$ & \\
\hline Blue AM & $72.00 \%$ & $0.00 \%$ & $9.00 \%$ & $0.00 \%$ & $\begin{array}{l}\text { Good for investigation, } \\
\text { not for reconstruction. }\end{array}$ \\
\hline Red PM & $100.00 \%$ & $0.00 \%$ & $0.00 \%$ & $0.00 \%$ & \\
\hline White PM & $91.00 \%$ & $9.00 \%$ & $0.00 \%$ & $0.00 \%$ & \\
\hline Blue PM & $91.00 \%$ & $0.00 \%$ & $9.00 \%$ & $0.00 \%$ & $\begin{array}{l}\text { Control Group. Good for } \\
\text { investigation, not for } \\
\text { reconstruction. }\end{array}$ \\
\hline
\end{tabular}

7. Does the form you filled out today flow in a logical order?

$\begin{array}{cccccl} & \text { Yes } & \text { No } & \text { Other } & \begin{array}{c}\text { No } \\ \text { Response }\end{array} & \text { Comments } \\ \text { Red AM } & 82.00 \% & 18.00 \% & 0.00 \% & 0.00 \% & \begin{array}{l}\text { Control Group. Data on } \\ \text { occupants hard to use. }\end{array}\end{array}$




\section{West Virginia Uniform Traffic Crash Report \\ Mock Crash Summary Data \\ (Continued)}

$\begin{array}{lrrrrr}\text { White AM } & 100.00 \% & 0.00 \% & 0.00 \% & 0.00 \% & \text { Good, logical flow } \\ \text { Blue AM } & 100.00 \% & 0.00 \% & 0.00 \% & 0.00 \% & \\ & & & & & \\ \text { Red PM } & 100.00 \% & 0.00 \% & 0.00 \% & 0.00 \% & \\ \text { White PM } & 100.00 \% & 0.00 \% & 0.00 \% & 0.00 \% & \\ & & & & & \\ \text { Blue PM } & 91.00 \% & 0.00 \% & 9.00 \% & 0.00 \% & \text { Control Group. }\end{array}$

8. Was there enough space allocated when information was required to be hand written in boxes or on lines?

$\begin{array}{lccccl} & \text { Yes } & \text { No } & \text { Other } & \begin{array}{c}\text { No } \\ \text { Response }\end{array} & \text { Comments } \\ \text { Red AM } & 9.00 \% & 91.00 \% & 0.00 \% & 0.00 \% & \text { VIN block to small. } \\ \text { White AM } & 67.00 \% & 17.00 \% & 17.00 \% & 0.00 \% & \text { Passenger \& owner's name are } \\ & & & & & \text { too small. Not enough room } \\ & & & & & \\ & & & & & \\ & & & & & \end{array}$

$\begin{array}{lllll}\text { Blue AM } & 100.00 \% & 0.00 \% & 0.00 \% & 0.00 \%\end{array}$

$\begin{array}{lllll}\text { Red PM } & 100.00 \% & 0.00 \% & 0.00 \% & 0.00 \%\end{array}$ 


\section{West Virginia Uniform Traffic Crash Report \\ Mock Crash Summary Data \\ (Continued)}

$\begin{array}{llllll}\text { White PM } \quad 91.00 \% \quad 9.00 \% & 0.00 \% & 0.00 \% & \begin{array}{l}\text { Insurance company } \\ \text { information too small. }\end{array}\end{array}$

Blue PM $\quad 91.00 \% \quad 0.00 \% \quad 9.00 \% \quad 0.00 \% \quad$ Address boxes too small.

9. How do you rate the legibility of the form you filled out today?

\begin{tabular}{|c|c|c|c|c|c|c|}
\hline & $\begin{array}{c}\text { Easy To } \\
\text { Read }\end{array}$ & $\begin{array}{c}\text { Hard To } \\
\text { Read }\end{array}$ & $\begin{array}{c}\text { Did Not } \\
\text { Notice }\end{array}$ & Other & $\begin{array}{c}\text { No } \\
\text { Response }\end{array}$ & Comments \\
\hline Red AM & $92.00 \%$ & $0.00 \%$ & $8.00 \%$ & $0.00 \%$ & $0.00 \%$ & \\
\hline White AM & $83.00 \%$ & $8.00 \%$ & $8.00 \%$ & $0.00 \%$ & $0.00 \%$ & $\begin{array}{l}\text { Took a couple of } \\
\text { minutes to adjust to } \\
\text { changes. }\end{array}$ \\
\hline Blue AM & $91.00 \%$ & $0.00 \%$ & $0.00 \%$ & $0.00 \%$ & $9.00 \%$ & \\
\hline Red PM & $72.00 \%$ & $18.00 \%$ & $0.00 \%$ & $9.00 \%$ & $0.00 \%$ & $\begin{array}{l}\text { Extent of Damage } \\
\text { block, collision block } \\
\text { writing too small. }\end{array}$ \\
\hline
\end{tabular}

$\begin{array}{llllll}\text { White PM } & 91.00 \% & 9.00 \% & 0.00 \% & 0.00 \% & 0.00 \%\end{array}$

Blue PM $\quad 91.00 \% \quad 0.00 \% \quad 9.00 \% \quad 0.00 \% \quad 0.00 \%$ 


\section{West Virginia Uniform Traffic Crash Report \\ Mock Crash Summary Data \\ (Continued)}

10. Is the meaning of each element on the form you just filled out clear and concise or did the information require you to think about what data is being sought?

\begin{tabular}{|c|c|c|c|c|c|}
\hline & $\begin{array}{l}\text { Yes-Clear } \\
\text { Meaning }\end{array}$ & $\begin{array}{l}\text { No-Not } \\
\text { Clear }\end{array}$ & Other & $\begin{array}{c}\text { No } \\
\text { Response }\end{array}$ & Comments \\
\hline Red AM & $73.00 \%$ & $27.00 \%$ & $0.00 \%$ & $0.00 \%$ & $\begin{array}{l}\text { Occupant data difficult to } \\
\text { use. }\end{array}$ \\
\hline White AM & $50.00 \%$ & $50.00 \%$ & $0.00 \%$ & $0.00 \%$ & $\begin{array}{l}\text { Extent of damage-had to } \\
\text { look for codes. Sequence of } \\
\text { events. }\end{array}$ \\
\hline Blue AM & $91.00 \%$ & $0.00 \%$ & $0.00 \%$ & $9.00 \%$ & HBD unclear. \\
\hline Red PM & $5.00 \%$ & $45.00 \%$ & $0.00 \%$ & $0.00 \%$ & $\begin{array}{l}\text { Needs collision with another } \\
\text { vehicle in Sequence of } \\
\text { events codes. }\end{array}$ \\
\hline White PM & $54.00 \%$ & $36.00 \%$ & $0.00 \%$ & $9.00 \%$ & $\begin{array}{l}\text { Extent of damage. Clear with } \\
\text { training. Roadway type at } \\
\text { intersection. }\end{array}$ \\
\hline
\end{tabular}

$\begin{array}{lllll}\text { Blue PM } \quad 91.00 \% & 0.00 \% & 9.00 \% & 0.00 \%\end{array}$ 


\author{
West Virginia Uniform Traffic Crash Report \\ Mock Crash Evaluation Results - Raw Data \\ (Continued)
}

1. How do you compare your test form today with the one you are used to filling out?
Much
Slightly No
Slightly
Greatly
Worse Worse Worse Difference Improved Improved Improved N/A

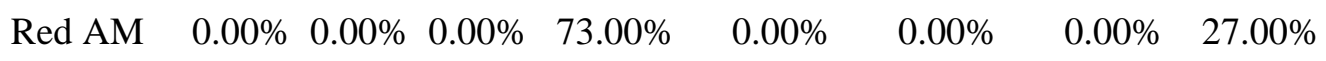

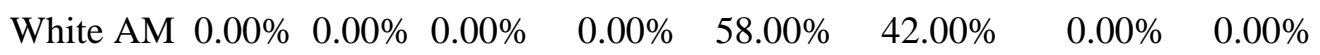

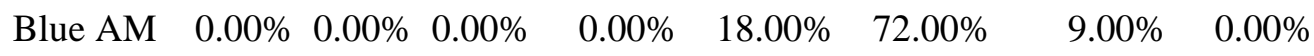

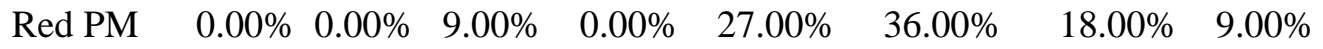

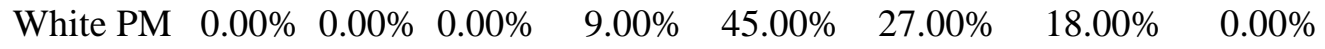

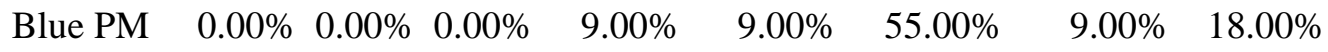

12. Do you feel the form you filled out today is "user friendly"?

Much Slightly No Slightly Greatly

Worse Worse Worse Difference Improved Improved Improved N/A

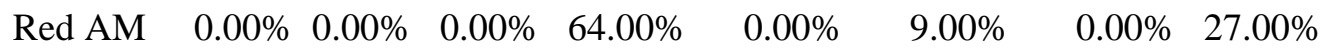

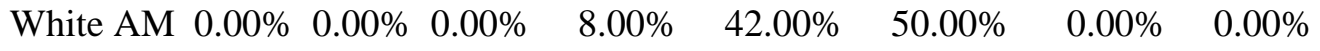

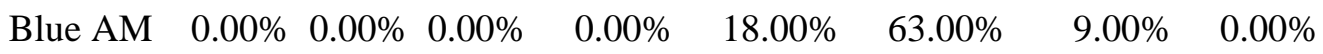

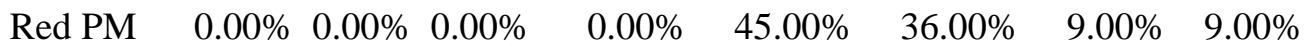

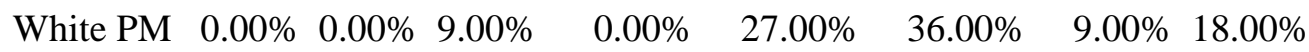

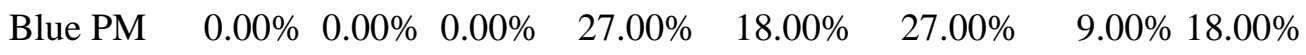




\section{West Virginia Uniform Traffic Crash Report \\ Mock Crash Evaluation Results - Raw Data \\ (Continued)}

13. How did you rate the legibility of the form you just filled out today?

\begin{tabular}{lrllllllll}
\multicolumn{2}{c}{$\begin{array}{l}\text { Much } \\
\text { Worse }\end{array}$} & \multicolumn{2}{c}{$\begin{array}{c}\text { Slightly } \\
\text { Worse Worse Difference }\end{array}$} & $\begin{array}{l}\text { Slightly } \\
\text { Improved }\end{array}$ & \multicolumn{2}{c}{$\begin{array}{c}\text { Greatly } \\
\text { Improved } \\
\text { Improved }\end{array}$} & N/A \\
Red AM & $0.00 \%$ & $0.00 \%$ & $0.00 \%$ & $73.00 \%$ & $0.00 \%$ & $9.00 \%$ & $0.00 \%$ & $18.00 \%$ \\
White AM & $0.00 \%$ & $0.00 \%$ & $8.00 \%$ & $0.00 \%$ & $25.00 \%$ & $67.00 \%$ & $0.00 \%$ & $0.00 \%$ \\
Blue AM & $0.00 \%$ & $0.00 \%$ & $9.00 \%$ & $9.00 \%$ & $27.00 \%$ & $45.00 \%$ & $9.00 \%$ & $0.00 \%$ \\
& & & & & & & & \\
Red PM & $0.00 \%$ & $0.00 \%$ & $9.00 \%$ & $18.00 \%$ & $18.00 \%$ & $27.00 \%$ & $18.00 \%$ & $9.00 \%$ \\
White PM & $0.00 \%$ & $9.00 \%$ & $0.00 \%$ & $0.00 \%$ & $45.00 \%$ & $18.00 \%$ & $9.00 \%$ & $18.00 \%$ \\
Blue PM & $0.00 \%$ & $0.00 \%$ & $0.00 \%$ & $36.00 \%$ & $9.00 \%$ & $27.00 \%$ & $9.00 \%$ & $18.00 \%$
\end{tabular}

14. Compared to the old form how do you rate the new form?

Much Slightly No Slightly Greatly

Worse Worse Worse Difference Improved Improved Improved N/A

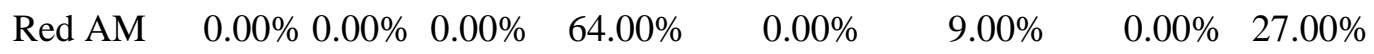

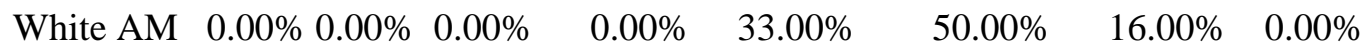

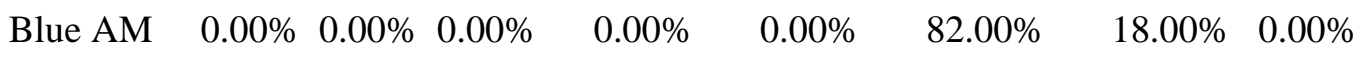

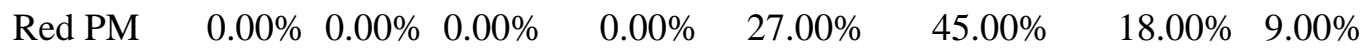

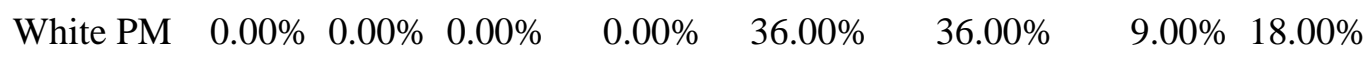

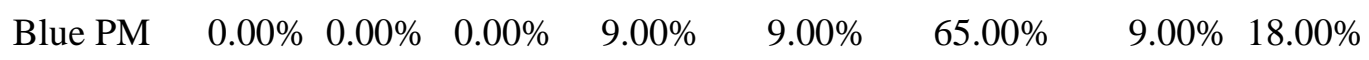


APPENDIX M: West Virginia Uniform Traffic Crash Report Pilot Test Summary Data 


\section{West Virginia Uniform Traffic Crash Report \\ Pilot Test Summary Data}

1. How do you compare your test form today with the one you are used to filling out?

\begin{tabular}{|c|c|c|c|c|c|c|}
\hline & Simpler & Harder & Same & Other & No Response & Comments \\
\hline \multirow[t]{4}{*}{ Mineral Co. } & 0 & 2 & 2 & 1 & & Some info is \\
\hline & & & & & & simpler and there $\mathrm{i}$ \\
\hline & & & & & & extremeduplicatior \\
\hline & & & & & & i.e., narrative \\
\hline \multirow[t]{6}{*}{ Bridgeport } & 3 & 1 & 2 & 4 & & Requires more \\
\hline & & & & & & thought and effort \\
\hline & & & & & & which is to be \\
\hline & & & & & & expected because \\
\hline & & & & & & more data is \\
\hline & & & & & & collected. \\
\hline
\end{tabular}

$\begin{array}{lllllll}\text { Charleston } & 6 & 15 & 13 & 1 & 2 & \text { Easy to overlook }\end{array}$
some newer blocks.

$\begin{array}{llllll}\text { Total } & 9 & 18 & 17 & 6 & 2\end{array}$

2. How much time do you think it took to fill out the form compared with the form you usually use? 
West Virginia Uniform Traffic Crash Report

Pilot Test Summary Data

(Continued)

Less Time More Time Same Other No Response Comments

\begin{tabular}{|c|c|c|c|c|c|}
\hline Mineral Co. & 0 & 4 & 1 & & \\
\hline Bridgeport & 0 & 6 & 3 & 1 & $\begin{array}{l}\text { Slightly more } \\
\text { time, but more } \\
\text { info obtained. } \\
\text { Only a little } \\
\text { more time. }\end{array}$ \\
\hline Charleston & 2 & 26 & 7 & 1 & $\begin{array}{l}2 \text { Simpler once } \\
\text { you get used to } \\
\text { it. Once you } \\
\text { get a report } \\
\text { back for not } \\
\text { doting every "i”" } \\
\text { and crossing } \\
\text { every " } \mathrm{t} \text { " it's } \\
\text { harder. }\end{array}$ \\
\hline Total & 2 & 36 & 11 & 2 & 2 \\
\hline
\end{tabular}




\section{West Virginia Uniform Traffic Crash Report \\ Pilot Test Summary Data \\ (Continued)}

3. The following three data elements seem easier to use than on the form I usually use:

$\begin{array}{ll}\text { Mineral Co. } & \text { 1. Damaged Area(s) } \\ \text { 2. Opens like a book } \\ \text { 3. Perforations } \\ \text { 4. Insurance block } \\ \text { 5. Personal info on driver } \\ \text { 6. Form is easier to use }\end{array}$

$\begin{array}{ll}\text { Bridgeport } & \text { 1. Damaged Area(s). (6) } \\ \text { 2. Sobriety portion (2) } \\ \text { 3. Crash Type (2) } \\ \text { 4. Occupant information } \\ \text { 5. Commercial Carrier section } \\ \text { 6. Vehicle Information } \\ \text { 7. Contributing Circumstances } \\ \text { 8. VIN box } \\ \text { 1. Extent of Damage (7) } \\ \text { 2. Driver numbering (6) } \\ \text { 3. Larger VIN (4) } \\ \text { 4. Do Not have to Estimate Damage (4) } \\ \text { 5. Point of Impact (4) } \\ \text { 6. Phone \# (2) } \\ \text { 7. Environmental Section (2) } \\ \text { 8. Person Involved (2) }\end{array}$




\section{West Virginia Uniform Traffic Crash Report \\ Pilot Test Summary Data \\ (Continued)}

4. The following three data items seem harder to use than on the form I usually use:

Mineral Co. 1. Date of crash (2)

2. EMS Information (2)

3. More time consuming

4. Damaged Area(s)

5. Injury classification

6. Date of birth

7. Towing Information

Bridgeport 1. Sequence of Events (3)

2. Extent of Damage (2)

3. Persons Involved

4. Driver Information

5. Towing

6. EMS

7. Citation Charge box

8. Date of Crash

9. Manner of Collision

10. Commercial Carrier/Most Harmful Event

Charleston 1. Sequence of Events (9)

2. Extent of Damage (3)

3. EMS Run Form \# (2)

4. Occupant Protection (2)

5. Not able to write $\mathrm{n} / \mathrm{a}$ in blocks that does not need filling in (2) 


\section{West Virginia Uniform Traffic Crash Report \\ Pilot Test Summary Data \\ (Continued)}

5. Do you feel the form you filled out today is "user friendly"?

\begin{tabular}{|c|c|c|c|c|c|}
\hline & Yes & No & Other & No Response & Comments \\
\hline Mineral Co. & 1 & 3 & 1 & & $\begin{array}{l}\text { Yes in some areas. No } \\
\text { in others. }\end{array}$ \\
\hline Bridgeport & 8 & 0 & 2 & & $\begin{array}{l}\text { With more experience, } \\
\text { may become more } \\
\text { user friendly }\end{array}$ \\
\hline Charleston & 24 & 9 & 3 & 1 & $\begin{array}{l}\text { Certain areas, such as } \\
\text { extent of damage } \\
\text { more information. }\end{array}$ \\
\hline Total & 33 & 12 & 6 & 1 & \\
\hline
\end{tabular}

6. Do you feel the form you filled out today collects enough information to adequately investigate a crash?

Mineral Co.

Yes No Other No Response Comments

5

Bridgeport $\quad 10$

Charleston

\begin{tabular}{llll}
32 & 1 & 3 & 1 \\
\hline
\end{tabular}

$\begin{array}{lllll}\text { Total } & 47 & 1 & 3 & 1\end{array}$ 


\section{West Virginia Uniform Traffic Crash Report \\ Pilot Test Summary Data \\ (Continued)}

7. Do you feel the form you filled out today collects enough information to adequately reconstruct a crash?

Yes No Other No Response Comments

$\begin{array}{llll}\text { Mineral Co. } & 5 & & \\ \text { Bridgeport } & 9 & 1 & \begin{array}{l}\text { Depends on detail of the } \\ \text { drawing }\end{array}\end{array}$

$\begin{array}{lllll}\text { Charleston } & 28 & 4 & 4 & 1\end{array}$

$\begin{array}{lllll}\text { Totals } & 42 & 5 & 4 & 1\end{array}$

8. Does the form you filled out today flow in a logical order?

\begin{tabular}{|c|c|c|c|c|c|}
\hline & Yes & No & Other & No Response & Comments \\
\hline Mineral Co. & 3 & 2 & & & \\
\hline Bridgeport & 9 & 0 & 1 & & $\begin{array}{l}2^{\text {nd }} \text { page info references } \\
\text { driver info on pg. } 1\end{array}$ \\
\hline
\end{tabular}

Charleston

30

4

2

1

Totals

42

3

1 


\section{West Virginia Uniform Traffic Crash Report \\ Pilot Test Summary Data \\ (Continued)}

9. Was there enough space allocated when information was required to be hand written in boxes or on lines?

Yes No Other No Response Comments

Mineral Co. 2

$\begin{array}{lllll}\text { Bridgeport } & 6 & 2 & 2 & \text { Citation block too small. }\end{array}$

Some boxes crowded but okay.

\begin{tabular}{lllll} 
Charleston & 32 & 2 & 2 & 1 \\
\hline
\end{tabular}

$\begin{array}{lllll}\text { Total } & 40 & 7 & 4 & 1\end{array}$

10. How do you rate the legibility of the form you filled out today?

$\begin{array}{cccccc}\text { Easy To } & \text { Hard to } & & \text { Did Not } & \text { No } & \\ \text { Read } & \text { Read } & \text { Other } & \text { Notice } & \text { Response } & \text { Comments }\end{array}$

$\begin{array}{llllll}\text { Mineral Co. } & 1 & 2 & 1 & 1 & \text { Small print in places. }\end{array}$

Could be better 


\section{West Virginia Uniform Traffic Crash Report \\ Pilot Test Summary Data \\ (Continued)}

$\begin{array}{ccccc}\text { Bridgeport } & 6 & 2 & 1 & \text { Too many boxes, easy } \\ & & \text { to miss. Some } \\ & \text { printing too small to } \\ & \text { read in dark. }\end{array}$

Charleston

$\underline{23}$

6

$2 \quad 5 \quad 1$

Total

$30 \quad 10$

4

7

1

11. Is the meaning of each element on the form you just filled out clear and concise or did the information require you to think about what data is being sought?

$\begin{array}{ccccc} & \text { Yes Clear } & \text { No Not } & \text { No } & \\ \text { Other } & \text { Meaning } & \text { Clear } & \text { Response } & \text { Comments }\end{array}$

$\begin{array}{lllll}\text { Mineral Co. } & 1 & 4 & 0 & \text { Yes and No } \\ \text { Bridgeport } & 1 & 8 & 1 & \begin{array}{l}\text { Much new info that } \\ \text { required some thought. } \\ \end{array} \\ & & & \begin{array}{l}\text { In crash \& sequence of } \\ \text { events. }\end{array}\end{array}$

Charleston

$\underline{2}$

15

19 1

Total

4

27

20

1 


\section{West Virginia Uniform Traffic Crash Report \\ Pilot Test Summary Data \\ (Continued)}

12. During the period of field testing how many new forms did you complete?

0-25 26-50 51-75 $\quad 76$ or more No Response

Mineral Co. 32

Bridgeport $\quad 7 \quad 3$

$\begin{array}{llll}\text { Charleston } & 28 & 8 & 1\end{array}$

$\begin{array}{llll}\text { Total } & 38 & 13 & 1\end{array}$

13. How do you compare your test form during the field test with the form you used to fill out (the old form)?

\begin{tabular}{|c|c|c|c|c|}
\hline Much & Slightly & No & Slightly & Greatly \\
\hline
\end{tabular}

$\begin{array}{lcccccccr}\text { Mineral Co. } & 0 & 2 & 0 & 0 & 1 & 2 & 0 & 0 \\ \text { Bridgeport } & 0 & 0 & 0 & 0 & 6 & 4 & 0 & 0 \\ \text { Charleston } & 2 & 3 & 9 & 4 & 8 & 10 & & 1 \\ \text { Total } & 2 & 5 & 9 & 4 & 15 & 16 & 0 & 1\end{array}$




\section{West Virginia Uniform Traffic Crash Report \\ Pilot Test Summary Data \\ (Continued)}

14. Do you feel the form you filled out during the field test is "user friendly"?

Much Slightly No Slightly Greatly No

Worse Worse Worse Difference Improved Improved Improved Response

\begin{tabular}{|c|c|c|c|c|c|c|c|}
\hline Mineral Co. & 0 & 0 & 0 & 2 & 1 & 1 & 1 \\
\hline Bridgeport & 0 & 0 & 1 & 1 & 4 & 4 & 0 \\
\hline Charleston & 3 & 4 & 6 & 8 & 5 & 9 & 0 \\
\hline Total & 3 & 4 & 7 & 11 & 10 & 14 & 1 \\
\hline
\end{tabular}

15. How did you rate the legibility of the form you filled out during the field test?

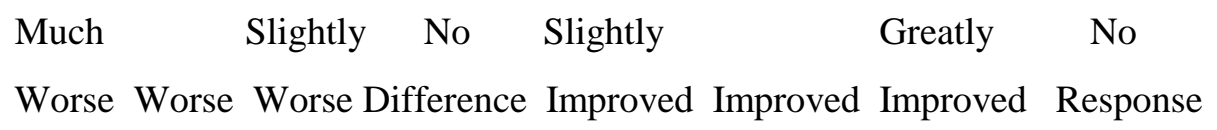

$\begin{array}{llccccccc}\text { Mineral Co. } & 0 & 0 & 2 & 1 & 2 & 0 & 0 & 0 \\ \text { Bridgeport } & 0 & 0 & 1 & 2 & 4 & 3 & 0 & 0 \\ \text { Charleston } & 2 & 3 & 7 & 12 & 8 & 4 & 0 & 1 \\ \text { Total } & 2 & 3 & 10 & 15 & 14 & 7 & 0 & 1\end{array}$




\section{West Virginia Uniform Traffic Crash Report \\ Pilot Test Summary Data \\ (Continued)}

16. Compared to the form you usually use, how do you rate the form you used during the field test?

\begin{tabular}{|c|c|c|c|c|}
\hline Much & Slightly & No & Slightly & Greatly \\
\hline
\end{tabular}

\begin{tabular}{lllllllll} 
Mineral Co. & 1 & 1 & 0 & 0 & 1 & 2 & 0 & 0 \\
Bridgeport & 0 & 0 & 0 & 0 & 4 & 5 & 1 & 0 \\
Charleston & 3 & 5 & 4 & 5 & 7 & 12 & 0 & 1 \\
\cline { 3 - 8 } & 4 & 6 & 4 & 5 & 12 & 19 & 1 & 1
\end{tabular}

